$1-1-2015$

\title{
Exploratory study of breast cancer survivors' lived experience : activity engagement during and after breast cancer treatment
}

\author{
Anne Fleischer \\ Nova Southeastern University
}

This document is a product of extensive research conducted at the Nova Southeastern University College of Health Care Sciences. For more information on research and degree programs at the NSU College of Health Care Sciences, please click here.

Follow this and additional works at: https://nsuworks.nova.edu/hpd_ot_student_dissertations

Part of the Occupational Therapy Commons

All rights reserved. This publication is intended for use solely by faculty, students, and staff of Nova Southeastern University. No part of this publication may be reproduced, distributed, or transmitted in any form or by any means, now known or later developed, including but not limited to photocopying, recording, or other electronic or mechanical methods, without the prior written permission of the author or the publisher.

\section{NSUWorks Citation}

Anne Fleischer. 2015. Exploratory study of breast cancer survivors' lived experience : activity engagement during and after breast cancer treatment. Doctoral dissertation. Nova Southeastern University. Retrieved from NSUWorks, College of Health Care Sciences Occupational Therapy Department. (34)

https://nsuworks.nova.edu/hpd_ot_student_dissertations/34.

This Dissertation is brought to you by the Department of Occupational Therapy at NSUWorks. It has been accepted for inclusion in Occupational Therapy Program Student Theses, Dissertations and Capstones by an authorized administrator of NSUWorks. For more information, please contact nsuworks@nova.edu. 


\title{
EXPLORATORY STUDY OF BREAST CANCER SURVIVORS' LIVED EXPERIENCE: ACTIVITY ENGAGEMENT DURING AND AFTER BREAST CANCER TREATMENT
}

\author{
by
}

Anne Fleischer
Submitted in partial fulfillment of the requirements for the degree of
Doctor of Philosophy in Occupational Therapy
Occupational Therapy Department
College of Allied Health and Nursing
Nova Southeastern University
Fort Lauderdale, Florida 33328

May 2015 


\section{NOVA SOUTHEASTERN UNIVERSITY HEALTH PROFESSIONS DIVISION COLLEGE OF ALLIED HEALTH AND NURSING OCCUPATIONAL THERAPY DEPARTMENT FORT LAUDERDALE, FL 33328}

This dissertation, written by Anne Fleischer under direction of her Dissertation Committee, and approved by all of its members, has been presented and accepted in partial fulfillment of requirements for the degree of

DOCTOR OF PHILOSOPHY

DISSERTATION COMMITTEE

Max A. Ito, Ph.D., OTR/L

Date

Chairperson of Dissertation Committee

Adrienne Lauer, Ed.D, OTR/L

Date

Dissertation Committee Member

Robin Cooper, Ph.D.

Date

Dissertation Committee Member 


\title{
NOVA SOUTHEASTERN UNIVERSITY \\ HEALTH PROFESSIONS DIVISION COLLEGE OF ALLIED HEALTH AND NURSING OCCUPATIONAL THERAPY DEPARTMENT FORT LAUDERDALE, FL 33328
}

\section{Dissertation Report Certification}

\begin{abstract}
We hereby certify that this dissertation report, submitted by Anne Fleischer, conforms to acceptable standards and is fully adequate in scope and quality to fulfill the dissertation requirement for the Doctor of Philosophy degree.
\end{abstract}

\section{Approved:}

Kristin Winston, Ph.D., OTR/L

Date

Ph.D. OT Program Director

Wendy Stav, PhD., OTR/L, SCDCM, FAOTA

Date

Chair, Occupational Therapy Department

Peter L. Taylor, Ph.D.

Date

Associate Professor, Associate Dean of Academic Affairs, College of Health Care Sciences

Stanley H. Wilson, PT, Ed.D., CEAS

Date

Dean, College of Health Care Sciences 


\begin{abstract}
The aim of this study is to describe breast cancer survivors' experiences and the associated meanings participating in their important activities during and after breast cancer treatment and the relationship among the survivor, environment, occupation, and performance, using a concurrent mixed method design. Ten survivors between the ages of 45 and 64 with Stage I, II, or III breast cancer who had been treated consecutively with surgery, chemotherapy, and radiation therapy were recruited for the study. Each survivor completed the Activity Card Sort-modified scoring system (ACSm) during the first and last week of radiation therapy and 3 and 6 months post radiation therapy. Additionally, each survivor participated in a semi-structured interview at the end of radiation therapy and 6 months afterwards. Qualitative data was analyzed using interpretative phenomenological analysis (IPA) to understand the survivors' experiences participating in their most important activities. The means and standard deviations of the proportion of activities resumed for the participants' global and category activities were calculated at each time point. A desire to resume participation in meaningful activities emerged from the data and demonstrated the interrelationship between environment, person, and occupation. Themes from the last week of radiation were (a) individual outlook influences how activities are approached, (b) social support reduces the stress of life, (c) side effects influence how activities are completed, and (d) personal and treatment stresses and struggles influenced their perspectives on life. At 6 months post radiation therapy, the themes were (a) emotional effect on activities, (b) life after cancer has changed due to cancer diagnosis and treatment, and (c) side effects continue to influence daily activities. Using the seven stages of analyzing mixed method data developed by
\end{abstract}


Onwuegbuzie and Teddlie (2003), the qualitative and quantitative data were integrated. The results illustrated that the participants resumed a greater proportion of instrumental activities, which were reported consistently as one of their five most important activities. Additionally, supportive extrinsic factors appeared to be more influential in resuming participation important activities than intrinsic factors. Findings from this study support using the Person-Environment-Occupational-Performance (PEOP) model to develop treatment plans for women undergoing or recovering from breast cancer treatment. 


\section{Acknowledgements}

Pursuing my doctorate has been a journey for my participants, my family, and me. When interviewing the 10 women for this study, I was not surprised by their struggles with their side effects. However, I was struck by the additional challenges these women were experiencing: deaths of children, terminal illnesses of siblings, teenage drug abuse, and teenage pregnancy. These stories of perseverance were inspiring and provided a clearer picture of the complexity of each person's life. I am thankful for their willingness to share their very personal stories.

Similar to the women in my study, I knew the process of pursuing my doctoral degree would include academic challenges and successes, but I did not anticipate family crises. During this journey, my son struggled with symptoms of bipolar disorder and a daughter sustained a mild head injury. Through these experiences and working on this dissertation, I have felt the power of love and support.

My interest in oncology rehabilitation and this dissertation topic developed from my personal experiences with having breast cancer and the encouragement of a number of mentors: Kaye Leonard, PT; Susan Redmond, MBA, OTR/L; Kelly Lambeth, MPH, OTR/L; Susan Reaves, DPT; Dr. Gretchen Kimmick; Dr. Doris Brown; and Dr. Julia Lawrence. I am particularly grateful to Dr. Brown who recruited the participants for this study and supported me throughout this process.

When I began this doctoral program, I entered with a quantitative background and was certain that my dissertation would be quantitative. After taking a number of classes with Dr. Robin Cooper, I became intrigued with qualitative methods, which led me to use a mixed method design for this study. I am very grateful for all the hours that she spent reviewing my analysis and providing the needed feedback. I would not have become as 
proficient of a qualitative researcher without her mentoring. Dr. Max Ito has been the quiet and steady force behind my dissertation. He has pushed me to improve my analytic and writing skills to a level that I did not think was possible. Dr. Adrienne Lauer's sharp eye for detail has improved the quality of this dissertation.

I would only have a bachelor's degree in occupational therapy if it were not for my best friend and husband, Alan. He encouraged me to pursue my MPH at UNCChapel Hill and supported me as I pursued my doctorate at Nova Southeastern University. His undying love and encouragement made this possible for me. Lastly, I could not write this acknowledgement without mentioning my children. Their intermittent curious questions about my dissertation and the look of pride in their eyes when I completed writing my first draft of my dissertation were a joy for me. I hope my journey inspires them to pursue their dreams. 
Table of Contents

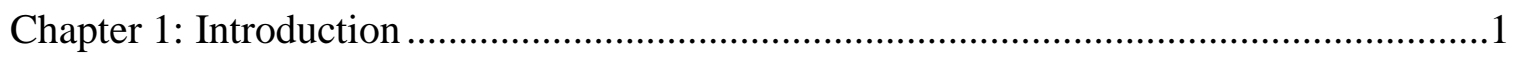

Background to the Problem .................................................................................

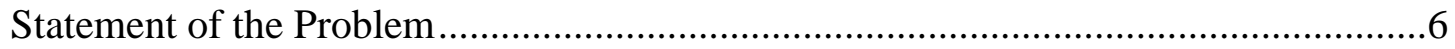

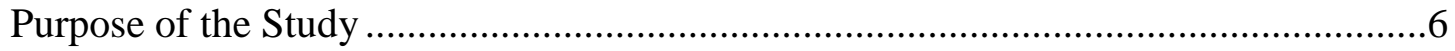

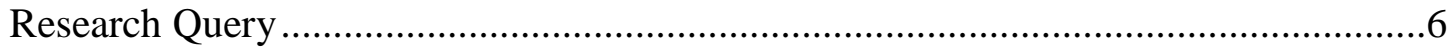

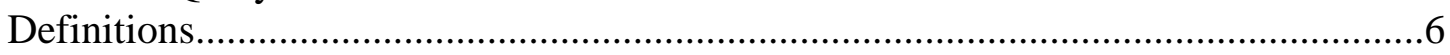

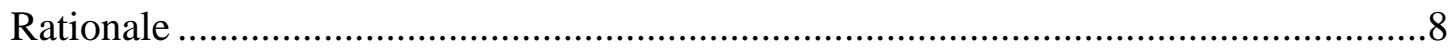

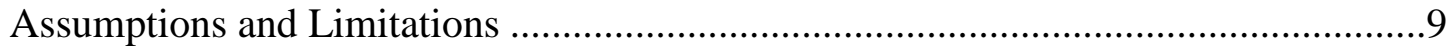

Chapter 2: Selected Review of the Literature ...........................................................13

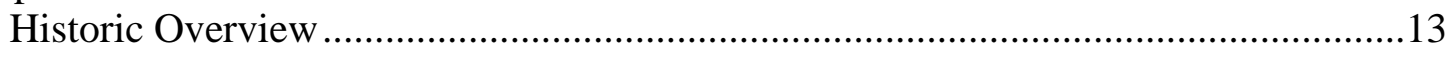

Overview of the People-Environment-Occupational-Performance Model...................14

Methodological Underpinnings …………………………......................................2

Interpretive Phenomenological Analysis .............................................................29

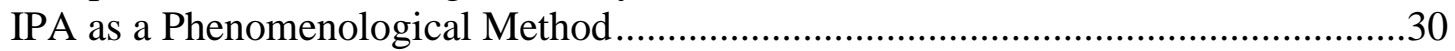

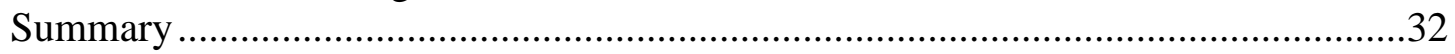

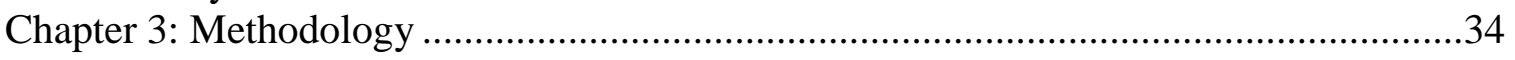

Research Design and Methodology ………………….........................................34

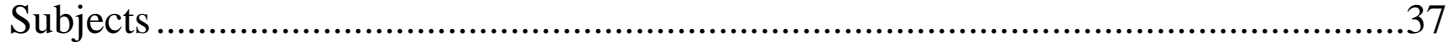

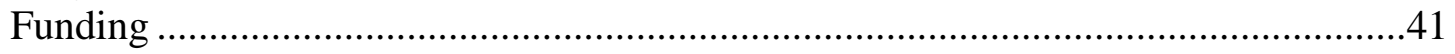

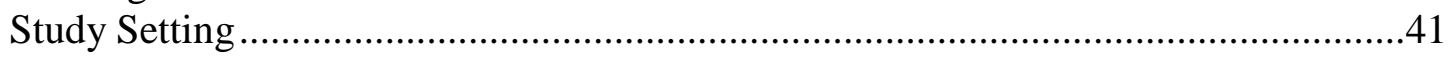

Measurement Tools .............................................................................................

Data Collection Procedures...................................................................................46

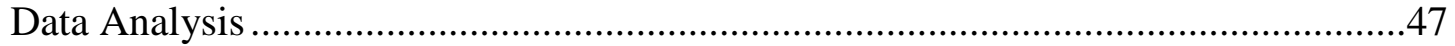

Assumptions, Limitations, and Delimitations of Methods ..........................................52

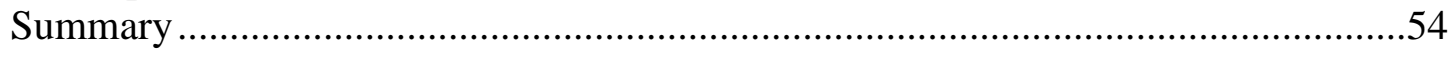

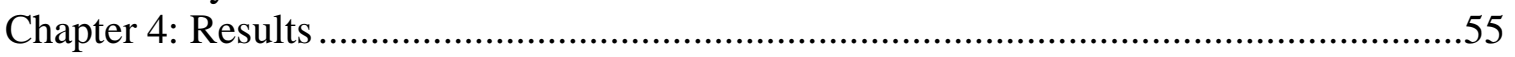

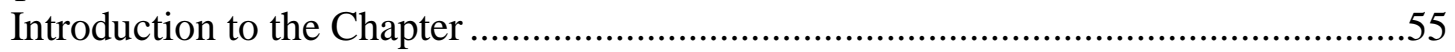

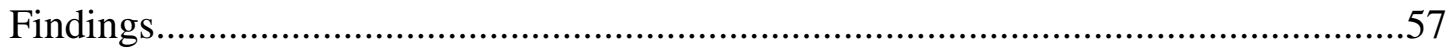

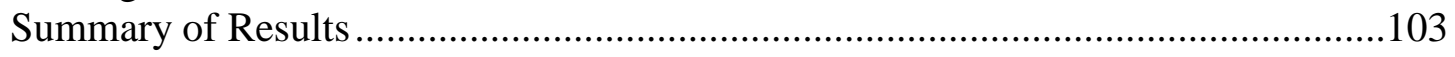

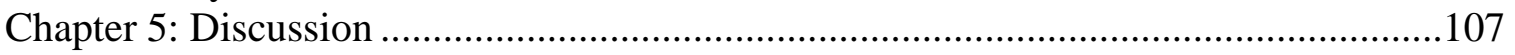

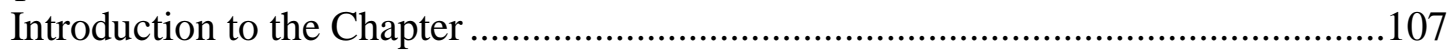

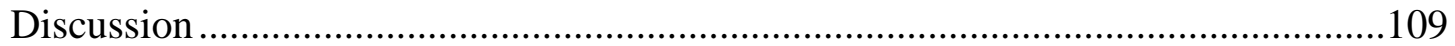

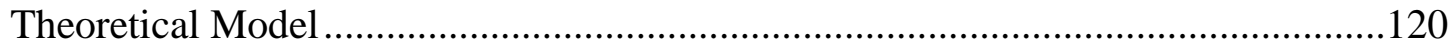

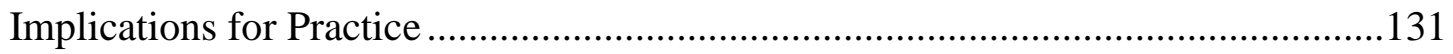

Implications for Future Research .......................................................................136

Limitations and Delimitations.........................................................................139

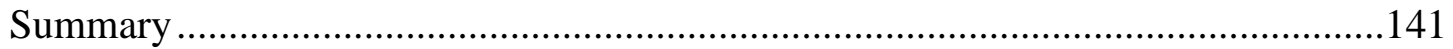

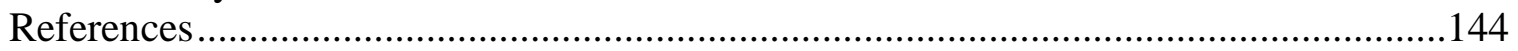

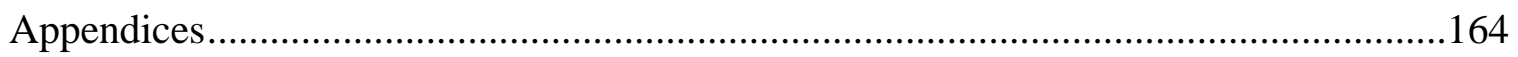

Appendix A. Activity Card Sort-Modified Scoring System (ACSm) ……………....164

Appendix B. Participant Profile ...........................................................................168

Appendix C. Study Flyer …………………………………………………....170

Appendix D. Nova Southeastern University IRB Approval Letter .............................171

Appendix E. Nova Southeastern University and Wake Forest Baptist Health 


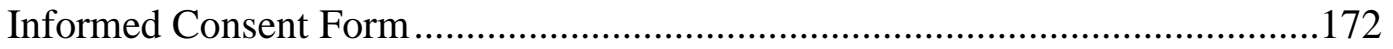
Appendix F. Wake Forest University IRB Approval E-mail.................................178 


\section{List of Tables}

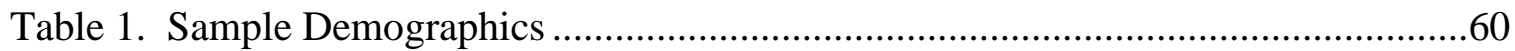

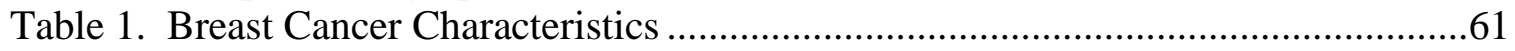

Table 3. Medical History Characteristics...................................................................62

Table 4. Employment Prior, During, and 6 Months Post Radiation Therapy ...................64

Table 5. List of Important Activities by Category and Time Period ...............................78

Table 6. Above and Below 71\% Retention of Instrumental Activities by Superordinate

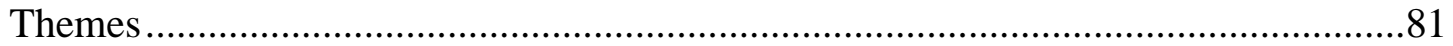

Table 7. Above and Below 70\% Retention of Low-Demand Leisure Activities by

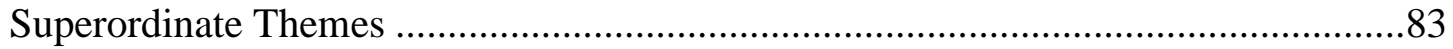

Table 8. Above and Below 43\% Retention of High-Demand Leisure Activities by Superordinate Themes ....

Table 9. Above and Below 59\% Retention of Social Activities by Superordinate Themes

Table 10. Above and Below 91\% Retention of Instrumental Activities by Superordinate Themes

Table 11. Above and Below 92\% Retention of Low-Demand Leisure Activities by Superordinate Themes

Table 12. Above and Below 71\% Retention of High-Demand Leisure Activities by Superordinate Themes

Table 13. Above and Below 82\% Retention of Social Activities by Superordinate Themes

Table 14. Last Week of Radiation: Low versus High Activity Retention Organized by Person in the PEOP Model

Table 15. Last Week of Radiation: Low versus High Activity Retention Organized by Environment in the PEOP Model

Table 16. Six Months Post Radiation: Low versus High Activity Retention Organized by Person in the PEOP Model

Table 17. Six Months Post Radiation: Low versus High Activity Retention Organized by Environment in the PEOP Model 


\section{List of Figures}

Figure 1. Superordinate and Emergent Themes Related to Activity Retention at the Last Week of Radiation Therapy

Figure 2. Superordinate and Emergent Themes Related to Activity Retention at 6

Months Post Radiation.

Figure 3. Instrumental Activity Card Sort-Modified Scoring System Score Summary

Figure 4. Low-Demand Leisure Activity Card Sort-Modified Scoring System Score

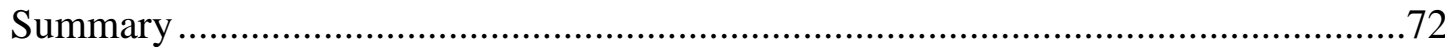

Figure 5. High-demand Leisure Activity Card Sort-Modified Scoring System Score

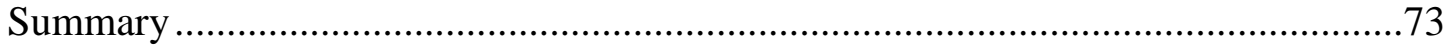

Figure 6. Social Activity Card Sort-Modified Scoring System Score Summary .............75

Figure 7. Mean Proportion of Activity Retention for Each Category by Time

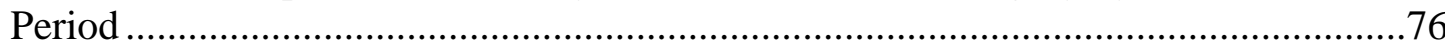

Figure 8. Proportion of Important Activities Within Each Activity Category at Each

Time Period. 


\section{Chapter 1: Introduction}

\section{Background to the Problem}

Breast cancer is the most widespread cancer among females in the United States. In 2015, an estimated 234,190 women will be diagnosed with breast cancer, accounting for $29 \%$ of all newly diagnosed female cancers with an average of $91 \%$ of women surviving breast cancer for 5 years (Siegel, Miller, \& Jemal, 2015). Many investigators, primarily oncology nurses and physicians, have studied and described cancer survivorship, including occupational scientists who have begun to study the experience of living with cancer from an occupational perspective (Lyons, 2006; Lyons et al., 2011; Player, MacKenzie, Willis, \& Loh, 2014; Unruh \& Elvin, 2004; Unruh, Scammell, \& Smith, 2000; Vrkljan \& Miller-Polgar, 2001).

Understanding breast cancer survivors' occupational viewpoint is relevant because engagement in occupations has been found to improve the quality of life of breast cancer survivors (McNeely et al., 2006; Palmadottir, 2010; Parry, 2008; Shannon \& Bourque, 2005; Unruh \& Elvin, 2004). Moreover, cancer survivors frequently gauge their health or quality of life from an occupational outlook. They report feeling healthy or satisfied with life when they can participate in the activities that are important to them. Persons with cancer frequently express their goals in occupation-based terms by describing the desire to regain the ability to do certain activities that allow them to fulfill meaningful roles (Hogan, 2014; la Cour, Johannessen, \& Josephsson, 2009; la Cour, Nordell, \& Josephsson, 2008; Lyons, 2006; Newman, 2013; van der Spek et al., 2013). For instance, Vrkljan and Miller-Polgar (2001) found breast cancer survivors felt alive, healthy, and capable as they regained their ability to perform cherished occupations, yet 
some women are limited in their ability to participate in these treasured occupations because of impairments and fatigue from the breast cancer treatments. Several studies have demonstrated an association among various treatment-induced impairments, breast cancer survivors' attributes, and their activity levels (Hayes, Battistutta, Parker, Hirst, \& Newman, 2005; Hayes, Rye, Battistutta, DiSipio, \& Newman, 2010; Hegel et al., 2011; Hidding, Beurskens, van der Wees, van Laarhaoven, \& Nijhuis-an der Sanden, 2014; Karki, Simonen, Malkia, \& Selfe, 2005; Kenyon, Mayer, \& Owens, 2014; Kopec et al., 2013; Lyons, Lambert, Stefan, Hegel, \& B., 2013; Player et al., 2014).

\section{Impairments Experienced by Breast Cancer Survivors}

The type of physical impairments encountered by breast cancer survivors is a result of various treatments (Cantarero-Villanueva et al., 2011; Edelstein \& Bernstein, 2014; Hidding et al., 2014; Karki et al., 2005; Kaya, Karatepe, Gunaydin, Yetis, \& Uslu, 2010; Kenyon et al., 2014; Kheir, Sniegowski, El-Sawy, Li, \& Esmaeli, 2014; Kopec et al., 2013; Levy et al., 2012; Player et al., 2014; Rietman et al., 2003; Smoot et al., 2010; Swisher, Davison, Aranda, Eye, \& Erickson, 2010; Verbelen, Gebruers, Eeckhout, Verlinden, \& Tjalma, 2014). Karki et al. (2005) found that women who had undergone mastectomy or breast conserving surgery for their breast cancer were more likely to experience axillary scar tightness, limb numbness, and neck-shoulder pain. In a similar way, Hidding et al. (2014); Kaya et al. (2010); and Lee, Kilbreath, Refshauge, Herbert, and Beith (2008) found reduced shoulder function, pain, and decreased hand strength were more common among women who had a mastectomy and axillary web syndrome. Verbelen et al. (2014) demonstrated that sensory disorders were present amid women who had axillary lymph node dissections. Similar findings were described by Levy et al. 
(2012), who demonstrated an association among early shoulder range-of-motion impairment and the removal of greater than 15 lymph nodes, mastectomy, and Stage II breast cancer. Additionally, 12 months post surgery, they found reduced shoulder range of motion was more common among older women and those who had positive lymph nodes and a body mass index greater than 25 . Along with surgical interventions, radiation and chemotherapy have also been associated with physical impairments. Reduced shoulder function and lymphedema are commonly experienced after radiation therapy (Crossley, 2001; Hamner \& Fleming, 2007; Hidding et al., 2014; Lasinski, 2013; T. Lee et al., 2008; Rietman et al., 2003). Women who received chemotherapy with neurotoxic agents were more likely to experience peripheral neuropathies (Kuroi et al., 2009; Mols, Beijers, Vreugdenhil, \& Poll-Franse, 2014; Wickham, 2007), and women receiving targeting chemotherapies can experience "dry eye syndrome" (Kheir et al., 2014).

Chemotherapy has also been connected to a reduction in cognitive skills needed for daily activities (Collins, Mackenzie, \& Kyeremanteng, 2013; Edelstein \& Bernstein, 2014; Kenyon et al., 2014; Player et al., 2014). Breast cancer survivors' cognitive abilities have been associated with individual characteristics, including, age, education, previous head injury, genetics, medical comorbidities, anxiety, depression, and fatigue (Downie, Mar Fan, Houede-tchen, Yi, \& Tannock, 2006; Kenyon et al., 2014; ReuterLorenz \& Cimprich, 2012; Wefel, Vardy, Ahles, \& Schlagen, 2011). Cancer-specific variables, such as stage of cancer, surgery, anesthesia, chemotherapy regimens, and targeted therapies (Herceptin), also influence cognitive functioning (Bender et al., 2007; Edelstein \& Bernstein, 2014; Paganini-Hill \& Clark, 2000; Schilder et al., 2010). These 
factors increased the between-subject variance, increasing the challenge of detecting cognitive changes. Despite these differences, longitudinal studies have demonstrated lower cognitive performance following chemotherapy compared with healthy or nochemotherapy cancer cohorts (Collins et al., 2013; Deprez et al., 2012).

Additionally, increasingly more women are experiencing reduced cognition from metastases to the central nervous system and its associated treatments. Fifty percent more breast cancer survivors are living with these metastases than at the beginning of the millennium. Neuropsychological studies have investigated this phenomenon (Ahles, Root, \& Ryan, 2012; Ahles et al., 2010; Breckenridge, Bruns, Todd, \& Feuerstein, 2010; Cherrier et al., 2013; Collins et al., 2013; de Ruiter et al., 2011; Deprez et al., 2012; Jansen, Cooper, Dodd, \& Miaskowski, 2011; Jenkins et al., 2006; McDuff et al., 2013; Schilder et al., 2010; Tallet et al., 2012).

\section{Associations with Activity}

Along with understanding the association between specific breast cancer treatments and particular impairments, investigators have also sought to understand the relationship among breast cancer survivors' characteristics, treatments, and activity (Hidding et al., 2014). In a study of women's activity participation prior to breast cancer surgery and 12 months after surgery, a connection was found between a reduction in the women's activity participation and having (a) a spouse, (b) two to three positive nodes, (c) 20 or more axillary nodes dissected, and (d) returned to paid employment (Devoogdt et al., 2010). Another study found that women receiving radiation therapy altered their daily activities, particularly toward the end of the day due to fatigue (Knobf \& Sun, 2005). Similarly, Ogce and Ozkan (2008) found that women undergoing chemotherapy 
had greater physical and psychological disruption in their daily activities. Interestingly, de Jong, Candel, Schouten, Abu-Saad, and Courtens (2006) did not find a difference in activity level among women who received different chemotherapy regimens but did find that the activity level in women who had received in total more chemotherapy treatments did not decrease as much as the women who had received fewer treatments. Hidding et al. (2014), Lee et al. (2009), Rietman et al. (2003), and Swisher et al. (2010) found that breast cancer survivors experienced more impairments if they received more extensive surgery, chemotherapy, and/or radiation treatments. They also found that survivors who received extensive treatment had more function if they used their arm normally. Further supporting this finding, Sagen, Karesen, Sandvik, and Risberg (2009) discovered in their prospective randomized controlled study that women who had axillary lymph node dissection and did not restrict their activities experienced significantly lower arm limb volume compared to women who restricted their activity level. Subsequently, other investigators have obtained similar findings (Ahmed, Thomas, Yee, \& Schmitz, 2006; Hidding et al., 2014; Sabiston \& Brunet, 2012; Schmitz et al., 2010; Schmitz et al., 2009; Silver, 2007). As a result, women are encouraged to use their affected arm normally and to incrementally increase the strength in their arms (Ahmed et al., 2006; Battaglinia et al., 2014; Cormie et al., 2013; Kim, Sim, Jeong, \& Kim, 2010; Sabiston \& Brunet, 2012; Schmitz et al., 2010; Schmitz et al., 2009; Silver, 2007). Previous advice to never participate in strenuous upper-body activities after breast cancer treatment is no longer advocated. Despite the fact that current research indicates that women can resume their daily activities (strenuous and non-strenuous), women continue to limit the use of their affected extremity during daily activities (T. Lee et al., 2009) and do not resume previous 
levels of physical activities (Pinto, Trunzo, Reiss, \& Shiu, 2002) or achieve public health physical activity level recommendations (Hong et al., 2007; Phillips \& McAuley, 2013).

\section{Statement of the Problem}

Currently, there is an assumption that impairments developed from the treatments are the reason survivors have not resumed previous activity levels (Cantarero-Villanueva et al., 2011; Karki et al., 2005; Kaya et al., 2010; Levy et al., 2012; Rietman et al., 2003; Swisher et al., 2010). Without knowledge of survivors' experiences of participating in meaningful activities, occupational therapists do not have sufficient information to develop interventions to restore the survivors' ability to participate in important activities.

\section{Purpose of Study}

There was one purpose for the study. The purpose of the study was to describe the experience of participating in important activities during and after breast cancer treatment from the perspective of the breast cancer survivor and the connection with occupational performance.

\section{Research Query}

What are the breast cancer survivors' experiences and associated meanings participating in important activities during and after breast cancer treatment? Are there connections among survivors, environment, and occupational performance?

\section{Definitions}

\section{Occupation}

Occupations are the ordinary, purposeful, and familiar activities that people do every day. Occupational participation is a basic human need because it enables humans to develop as individuals and members of society and demonstrate their value and worth 
to society and the world. Each individual participates in multiple occupations, which provide enjoyment, payment, personal identity, and competence (Christiansen, Clark, Kielhofner, Rogers, \& Nelson, 1995; Christiansen \& Townsend, 2010; Ludwig, 2004; Townsend, 1997).

\section{Occupational Performance}

Occupational performance is an open and complex system composed of the person, environment, and occupation. Due to its complexity, occupational performance is unique and unpredictable for each individual. Many intrinsic and extrinsic factors influence occupational performance. Intrinsic factors are those within the person, such as psychological, physiological, developmental, and neurobehavioral influences.

Motivation, experience, beliefs, abilities, and skills are intrinsic enablers of performance. Extrinsic factors include interpersonal, societal, cultural, and physical environmental factors. Occupational performance is a product of a dynamic interwoven relationship that exists among people, occupations, roles, and the environment where they live (Ikiugu, 2007; Law et al., 1996; Ludwig, 2004).

\section{Activity}

An activity is distinguished from an occupation by the fact that it is observable and has an identified beginning and end. In other words, activity is the "doing component" of occupational performance or the execution of the task. Engagement in activity is identified as a source of meaning and has been linked to health and well-being throughout life (Christiansen \& Townsend, 2010; la Cour et al., 2009; Ludwig, 2004). Within this study, activity or the doing component of occupational performance was measured using the Activity Card Sort-modified scoring system (ACSm) with permission 
from Carolyn Baum PhD, OTR/L, FAOTA (Baum \& Edwards, 2008; Everard, Lach,

Fisher, \& Baum, 2000; Katz, Karpin, Lak, Furman, \& Hartman-Maeir, 2003; Lyons et al., 2011; Lyons et al., 2013; Lyons, Li, Tosteson, Meehan, \& Ahles, 2010; Sachs \& Josman, 2003).

\section{Person-Environment-Occupational-Performance Model}

Person-Environment-Occupational-Performance model (PEOP) describes occupational performance as an interaction between person and the environment and assumes the individual is naturally motivated to explore and master the environment. This mastery is a measure of how successful an individual has adapted to or met the challenges of daily living by using personal, social, and material resources (Christiansen \& Baum, 1997; Ludwig, 2004).

\section{Rationale}

Humans have occupied their lives with goal-directed activities necessary for existence and well-being since the beginning of time. These activities have included acquiring food and water, finding shelter, and nurturing their offspring. However, as humans evolved, socio-culturally diverse occupations emerged, which included specialized work and leisure (Christiansen \& Townsend, 2010). These occupations have been influenced by personal factors, for example biological, neurological, and psychological, and environmental factors, such as temporal, socio-economic, cultural, political, physical, and social (AOTA, 2014; Christiansen \& Townsend, 2010; Law et al., 1996; Ludwig, 2004). Multiple disciplines beyond occupational therapy have studied the relationship between people and environment (Kahana, 1982; S. Kaplan, 1983; Knapper, Lerner, \& Bunting, 1986; Lawton, 1977; Moore, VanHaitsma, Curyto, \& Saperstein, 
2003; Moos, 1980; Shalinsky, 1986; Weisman, 1981) from which a number of occupational therapy theories and models have evolved: (a) Person-EnvironmentOccupational Performance model, (b) Ecology of Human Performance model (EHP), (c) Model of Human Occupation (MOHO), (d) Person-Environment-Occupation model (PEO), and (e) occupational adaptation (OA) (Ludwig, 2004). These models have been applied to a variety of populations to understand the influence of the person and environment on occupational performance (Abeydeera, Willis, \& Forsyth, 2006; Lyons et al., 2011; O'Brien, Bergeron, Duprey, Olver, \& St. Onge, 2009; Ward, Mitchell, \& Price, 2007), but only a couple have been applied to breast cancer survivors (Newman, 2013; Palmadottir, 2009, 2010) and none have specifically utilized the PEOP.

So far, investigators have shown an association between breast cancer survivors using their affected arm and experiencing less pain, symptoms of lymphedema, and shoulder restrictions (T. Lee et al., 2009; Sagen et al., 2009), but none has described the survivor's experience of participating in activities during and after breast cancer treatment and its impact on occupational performance. During the data analysis, the investigator has used her interpretations and theoretical understanding of PEOP concepts to illustrate how the experience of participating in important activities are influenced by personal and environmental factors during and after breast cancer treatment (Ludwig, 2004; Sagen et al., 2009).

\section{Assumptions and Limitations}

Unlike a multiple method research approach, which is a series of complete related qualitative and/or quantitative research projects guided by a theoretical frame, mixed method research uses qualitative and quantitative methods in tandem to answer a 
complex research question that cannot be answered by using one of these methods alone (Creswell, 2009; Morse \& Niehaus, 2009). Mixed method research applies a pragmatic method and system of philosophy, which seeks to discover patterns, test theories, and/or hypotheses to uncover the best explanation for understanding the results. Within this study, the investigator collected both quantitative and qualitative data simultaneously to provide an expansive description of the process of returning to previous activities after breast cancer treatment. The qualitative method, which described the experience of resuming important activities, was the core component of the study and the quantitative method was the supplementary component, which provided the proportion of previous activities retained.

\section{Assumptions}

Assumptions of the approach used within the core component of this study, interpretative phenomenological analysis (IPA), can be organized into four broad categories: (a) sensitivity to context, (b) commitment and rigor, (c) transparency and coherence, and (d) impact and importance (Smith, Flowers, \& Larkin, 2009; Yardley, 2000). IPA assumes that the investigator will show empathy and negotiate the "power play" between the investigator and participant to conduct an interview that reflects context sensitivity to improve the validity of the data. While demonstrating sensitivity to the participant, the investigator was committed to listening attentively to each participant to provide a greater understanding of the phenomenon experienced by each participant. IPA's transparent rigorous method, including using a homogenous population, provides a clear description of the steps used for selecting participants, interviewing, and analyzing the transcripts to produce reliable data. Lastly, the investigator, using IPA, connected the 
emerging themes to the theoretical underpinnings of the study to provide coherence and relevance. For this study, the investigator demonstrated the implications of the results for occupational therapists who work with breast cancer survivors.

The investigator assumed the Activity Card Sort-modified scoring system would measure the proportion of activities retained because it has demonstrated provisional evidence of reliability, internal consistency, and construct validity when compared with measures of quality of life, performance status, and perceived cognitive impairments for oncology patients who had stem cell transplantation (Lyons et al., 2010). This descriptive data was used to enrich the depiction of the participants' process of returning to previous activities, not to predict proportion of activities retained for all breast cancer survivors.

\section{Limitations}

The limitations within this study arose from recruitment, data collection, and validity and reliability of the ACSm. Recruitment was slow due to (a) dependence on radiation oncologist for identifying potential participants; (b) initiation of a new electronic medical record system, which temporarily decreased patient volumes; and (c) specific inclusion criteria. The investigator did not conduct all of the interviews face-toface because some participants requested that the investigator conduct the interview telephonically, which may have changed the quality of the interviews. In addition, the data gathered from the interviews were susceptible to recall and social acceptance biases from the participants (Clarke, 2009; Smith et al., 2009). While the majority of the ACSm checklists were completed in a private room at the medical center, some participants completed the checklist at home or within the community, then faxed or mailed the 
checklist back to the investigator. The varying locations may have influenced how the participants completed the checklist. Lastly, the ACSm was not standardized with breast cancer survivors, so the results cannot be compared with normative data (Baum \& Edwards, 2008; Katz et al., 2003; Sachs \& Josman, 2003). 


\section{Chapter 2: Selected Review of Literature \\ Historic Overview}

Breast cancer survivors' activity level has been shown to not return to the prebreast cancer diagnosis baseline even months and/or years after treatments have been completed (Champion et al., 2014; Devoogdt et al., 2010; Fantoni et al., 2010; Irwin et al., 2003; Kopec et al., 2013; Kwan et al., 2011; Lindbohm et al., 2014; Lyons et al., 2013; Miedema et al., 2011; Pinto et al., 2002). Despite this awareness, there continues to be a limited understanding of what happens in the breast cancer survivor's life, which impacts her ability to participate at pre-breast cancer activity levels (Bloom, Stewart, Oakley-Girvan, Banks, \& Shema, 2011; Champion et al., 2014; Devoogdt et al., 2010). Most studies exploring this phenomenon have been epidemiologic, which have demonstrated associations between treatments, physical impairments, quality of life indicators, and various categories of activities (Bloom et al., 2011; Champion et al., 2014; Charlier et al., 2013; de Jong et al., 2006; Devoogdt et al., 2010; Fantoni et al., 2010; Hayes et al., 2005; Hidding et al., 2014; Irwin et al., 2003; Lindbohm et al., 2014; Mandelblatt et al., 2011; Nesvold, Reinertsen, Fossa, \& Dahl, 2011; Nilsson, Olsson, Wennman-Larsen, Petersson, \& Alexanderson, 2013; Ogce \& Ozkan, 2008; Rietman et al., 2004; Verbelen et al., 2014). Some investigators have assumed that the change in activity participation is related to the physical effects of treatment (Edelstein \& Bernstein, 2014; Hidding et al., 2014; Kenyon et al., 2014; Kopec et al., 2013; Lyons et al., 2013; Miedema et al., 2011; Player et al., 2014; Rietman et al., 2003; Swisher et al., 2010., 
Verbelen et al., 2014). Others have shown associations between activity participation and environmental factors, such as transportation, social support (Lindbohm et al., 2014; Lyons et al., 2013; Newman, 2013; Palmadottir, 2010; Shannon \& Bourque, 2005), and psychological factors (Champion et al., 2014; Edelstein \& Bernstein, 2014; Kenyon et al., 2014; Lindbohm et al., 2014; Lyons et al., 2013; Nesvold et al., 2011; Shannon, 2005). Adding to the complexity of this phenomenon is the fact that cancer survivors re-evaluate their lives when faced with a life-threatening cancer diagnosis and adjust their activities. Although reduced activity participation has been explored using a variety of methods, no one has described the experience of participating in activities during and after breast cancer treatment to understand it from the breast cancer survivor's perspective.

\section{Overview of People-Environment-Occupational-Performance Model}

The basic viewpoint of PEOP is that people are naturally motivated to explore their world and demonstrate mastery within it. This model provides a framework for organizing the environment, strategies, and/or resources used by individuals to adapt meaningful occupations (Christiansen \& Baum, 1997). The PEOP assumes that people develop their self-identity and a sense of fulfillment by participating in occupations (Christiansen \& Baum, 1997).

\section{Occupational Participation}

Occupational participation helps the breast cancer survivor maintain control and stability, experience a sense of self-worth, and enhance self-development (Gall \& Comblat, 2002; Palmadottir, 2010; Unruh et al., 2000; Vockins, 2004; Vrkljan \& MillerPolgar, 2001). The sense of control and stability is threatened by the diagnosis of breast cancer when routines, including work, are disrupted. Many women fear this passive life 
because it is associated with the loss of control and feelings of sadness. However, by maintaining a daily routine, many women are able to control negative feelings and experience some stability even when they feel quite sick. Women achieve this control and stability by avoiding being in bed and leaving the house regularly to run errands. Additionally, women feel a sense of control over breast cancer by eating a healthier diet, engaging in light indoor activities, and hiding the physical changes caused by treatment (Costanzo, Lutgendorf, \& Roeder, 2011; la Cour et al., 2009; la Cour et al., 2008; Nesbit, 2006; Palmadottir, 2010; Vrkljan \& Miller-Polgar, 2001; Wilcock, 1998).

Along with maintaining a sense of control and stability, women need to feel a sense of self-worth. Although many women stop working for at least a few weeks while undergoing treatment, these women return to work, so they can feel as if they are contributing. Yet, not all women want or are able to return to paid work (Desiron, Donceel, de Rijk, \& van Hoof, 2013; Lilliehorn, Hamberg, Kero, \& Salander, 2013), particularly cognitively demanding or unsatisfying jobs (Barnes, Robert, \& Bradley, 2014). In order to feel self-worth, these women engage in activities, such as caring for grandchildren, making things for their family, managing a special project, participating in breast cancer organizations, and/or volunteering (Cohen \& Numa, 2011; Fitzpatrick, Edgar, \& Remmer, 2013; Nesbit, 2006; Palmadottir, 2010; van der Spek et al., 2013). Other women re-examine their careers, resulting in the pursuit of a more self-fulfilling and meaningful career (Law, Baum, \& Baptiste, 2002; Lilliehorn et al., 2013;

Palmadottir, 2010; van der Spek et al., 2013). Along with maintaining a routine and engaging in self-respecting activities, survivors frequently take the initiative for selfdevelopment. By acquiring new creative skills and mastering complex techniques, 
women experience a sense of purpose and discover personal attributes (Nesbit, 2006;

Newman, 2013; Palmadottir, 2010; van der Spek et al., 2013).

\section{Impact of Treatment on Occupation Participation}

Breast cancer survivors' ability to participate in activities is affected by surgery, chemotherapy, and radiation. Many survivors do not return to their pre-treatment activity levels (Lyons, Erickson, \& Hegel, 2012). Investigators are struggling to describe and explain this inactivity (Bloom et al., 2011; Champion et al., 2014; Devoogdt et al., 2010). However, investigators have found an association between specific breast cancer treatments and a reduction in activity participation (Edelstein \& Bernstein, 2014; Kenyon et al., 2014; Kopec et al., 2013; Lyons et al., 2013; Miedema et al., 2011; Player et al., 2014; Rietman et al., 2003; Swisher et al., 2010; Verbelen et al., 2014).

Devoogdt et al. (2010) found that the total physical activity level of women decreased by $10 \%, 9 \%$, and $7 \%$ after 1,3 , and 6 months post surgery, and a $4 \%$ decrease persisted after 1 year. Similarly, Kopec et al. (2013) compared women who had sentinel lymph node dissection with those who had an axillary lymph node dissection, and both groups had functional limitations at 6 months post surgery. Limitations included a $31 \%$ reduction in the ability to push and pull objects and lift greater than $10 \mathrm{lbs}, 18 \%$ decreased ability to reach overhead, and $16 \%$ decline in recreation and social activities. In a prospective surveillance study of over 1,000 women diagnosed with breast cancer, Kwan et al. (2011) found both work and sedentary activities decreased significantly at 8 months post diagnosis. When investigators specifically examined return rates to sports and household activities, greater variability was found. Irwin et al. (2003) found a decrease of $11 \%$ in these activities; however, Devoogdt et al. (2010) found a 60\% 
decrease in sports and a $17 \%$ reduction in household activities. One explanation for the difference in these findings is the fact that Irwin et al. (2003) included women with in situ breast cancer and Devoogdt et al. (2010) did not.

Chemotherapy has also been found to affect survivors' ability to complete activities. de Jong et al. (2006) found that the age of the woman and being a mother were associated with higher activity levels, and the differences between the type of chemotherapy (cyclophosphamide, methotrexate, and 5-fluorouracil vs. doxorubicin) made little impact. Specifically, younger survivors and survivors who had children were more active than those who were older or did not have children. When specifically examining the impact of chemotherapy on daily life among women receiving doxorubicin for either Stage I or II breast cancer, Prigozin, Uziely, and Musgrave (2010) discovered greater than $40 \%$ of women experienced severe symptoms, including fatigue, distress, and sadness, which influenced their ability to work and participate in general activities. Huang, Chen, Liang, and Miaskowski (2014) illustrated how fatigue levels fluctuated for women receiving treatment for their breast cancer. Severity of fatigue reached its peak at 2 months after surgery and was the lowest at 12 months after surgery. Because fatigue did not disappear at the end of each cycle of chemotherapy, fatigue would worsen with each round, and depression and distress exacerbated the symptoms (Huang et al., 2014). Engaging women in meaningful physically active occupations has been found to reduce depression and fatigue among women undergoing and recovering from breast cancer treatment (Andrykowski, Beacham, \& Jacobsen, 2007; McNeely et al., 2006; Mock et al., 2005; Stagl, Antoni, Lechner, Carver, \& Lewis, 2014). 
Individuals with advanced cancer who were receiving chemotherapy spent most of their day completing activities related to self-care, such as sleeping, eating, resting, and personal hygiene, and very little time completing household cleaning and home management in the study by la Cour et al. (2008). This finding is consistent with other studies that have found survivors with more advanced cancers spent more hours resting and did not complete household tasks (J. Lee, Dibble, Pickett, \& Judith, 2005; Ogce \& Ozkan, 2008; Watters, Yau, O'Rourke, Tomiak, \& Getrler, 2003).

In addition to surgery and chemotherapy disrupting daily activities, radiation therapy also influences everyday activities. Knobf and Sun (2005) found that 3\% of women reported disruptions in their daily functioning prior to starting radiation therapy, which increased to $14 \%$ in the middle of therapy and $11 \%$ at the end of therapy. Many survivors described that the greatest disruption to their daily activities occurred during the late afternoon and evening when they needed to rest or nap due to fatigue. Furthermore, Matthews, Schmiege, Cook, and Sousa (2012) described the clustering of the fatigue with pain and insomnia among women receiving radiation therapy. These symptoms were magnified by depression and pessimism, consistent with the findings of Huang et al. (2014). Additionally, Knobf and Sun (2005) found that survivors who received a longer duration of the radiation therapy were less active. On the other hand, the longer the time interval between the last radiation therapy session and the measurement of activity level, the investigators discovered that the survivor was more active (Knobf \& Sun, 2005).

\section{Leisure}

Leisure activities, particularly physically demanding activities, appear to be one of the first activities stopped during treatment and one of the last to be resumed. Leisure 
activities are often stopped permanently. Rosenblum, Yurman, Gotfrid, Wolpart, and Binyamin (2005) found that the overall engagement in leisure activities significantly dropped (81\%) after surgery. Significant reductions were also found in the various leisure categories: $16.4 \%$ in highly physically demanding leisure activities, $6.7 \%$ in low physically demanding leisure activities, $6.5 \%$ reduction in social activities, and $6.6 \%$ reduction in daily living activities. Littman, Tang, and Rossing (2010) found similar results. Fifty percent of women reported a decrease in sports activities 1 to 12 months post surgery. In contrast, a study by Andrykowski et al. (2007) discovered a decrease in sports during adjuvant therapy, which rebounded after completion of adjuvant therapy. Shannon (2005) sought to understand why survivors did not return to leisure activities. The author learned that arm/shoulder pain, limited shoulder range of motion, lack of energy during radiation and chemotherapy, and nausea during chemotherapy were the most common reasons for not returning to pre-breast cancer leisure activities. Additionally, some women felt guilty for doing "leisure things" during treatment when they were unable to fulfill their occupational and/or familial roles. Those women who did not have passive leisure interests or who did not consider modifying their previous activities had the most difficult time adjusting. When survivors returned to leisure activities, they chose activites that relieved the psychological effects, such as fear, anxiety, and anger of cancer diagnosis and treatment. Another barrier for some survivors was the fact that little attention was given to leisure by their health professionals, except for instructions about the activities they could not do (Shannon, 2005). Phillips and McAuley (2013) and Charlier et al. (2013) demonstrated that women were more likely to 
be physically active if they believed that they could physically return to their preferred leisure and work activities.

When specifically examining physically demanding leisure activities, Ventura et al. (2013) found that the three most common reasons breast cancer survivors were not more physically active were (a) "lack of time," (b) "lack of self-discipline," and (c) "fatigue" (or lack of energy; p. 429). Approach motivations exercising for enjoyment were found to be associated with participating in physical activities more than avoidance motivations exercising to prevent an unpleasant condition. Examples of approach motivations were (a) "because it makes me feel good," (b) "to have a healthy body," and (c) "because I find exercise invigorating," and avoidance motivations included (d) "to avoid ill-health," (e) “to prevent health problems," and (f) "to prevent breast cancer recurrence" (Voege, Bower, Stanton, \& Ganz, 2014, p. 3). Furthermore, Midtgaard, Tveteras, Rørth, Stelter, and Adamsen (2006) illustrated how a structured exercise program compared to an unstructured exercise elevated the overall activity level among breast cancer survivors.

\section{Social Participation}

Social support from family, friends, co-workers, and support groups has been found to help breast cancer survivors manage some of the negative social psychological impact normally associated with breast cancer diagnosis and treatment (Berterco, 2000; Litchman, Taylor, \& Wood, 1987; Shannon \& Bourque, 2005; Waxler-Morrison, Hislop, Mears, \& Kan, 1991). Ogce and Ozkan (2008) and Waters et al. (2003) found that breast cancer survivors are able to maintain their social functioning throughout chemotherapy, 
except for those under the age of 50, who reported a reduced ability to function in their roles at home, work, and leisure (Bloom et al., 2011; Champion et al., 2014).

Kroenke et al. (2013) found women who had larger social networks, higher incomes, and a healthier lifestyle were more physically active, had a lower body mass index (BMI), and did not currently smoke. Additionally, these women were more likely to be married, have a living parent, have greater numbers of siblings and children, participate in religious and/or social activities, volunteer, and provide caregiving. More significant is the fact that women who had lower social support prior to treatment experienced higher levels of pain and depressive symptoms over time than women who were socially connected (Hughes et al., 2014).

\section{Returning to Work}

Work is commonly discontinued during breast cancer treatment and is not always resumed afterwards (Barnes et al., 2014; Desiron, 2010; Johnsson, Fornander, Rutqvist, \& Olsson, 2011; Lilliehorn et al., 2013). Bouknight, Bradley, and Luo (2006) and Fantoni et al. (2010) found that $82 \%$ of Dutch and French breast cancer survivors returned to work after 12 months. Among those Dutch survivors who eventually returned to work, the survivors' time off ranged from a couple of days to a couple of years. Within Hoving, Broekhuizen, and Frings-Dresen (2009) review of intervention studies of breast cancer survivors returning to work, they described that $44 \%$ of Dutch breast cancer survivors had lost their jobs within 5 years of treatment compared to $22 \%$ who had lost their job 3 months after surgery. Fantoni et al. (2010) found that women who were younger than 50, had a high educational level, or had support from colleagues were more likely to return to work than women who received chemotherapy, had serious 
lymphedema, or had a physically or psychologically demanding job. Additionally, women who had cognitively demanding and unsatisfying jobs, particularly if they received greater than five cycles of chemotherapy, were less likely to return to work after treatment (Barnes et al., 2014). Lilliehorn et al. (2013) found women who received chemotherapy were out of work twice as long as women who did not receive chemotherapy. Similar findings were described by Lindbohm et al. (2014). Low education, low physical quality of life, co-morbidities, and pain were associated with early retirement and other non-employment after cancer. These non-employed survivors experienced depression, anxiety, cognitive limitations, and fatigue more often than other survivors (Lindbohm et al., 2014; Moskowitz, Feuerstein, \& Todd, 2013).

This importance of returning to work is reflected in several other studies (Barnes et al., 2014; Bouknight et al., 2006; Desiron, 2010; Desiron et al., 2013; Fantoni et al., 2010; Hoving et al., 2009; Johnsson et al., 2011; Lilliehorn et al., 2013; Moskowitz et al., 2013; Noeres et al., 2013). Despite women's interest in returning to work, Silver, Baima, Newman, Galantino, and Shockney (2013) reported that unemployment rates were higher in patients with breast, gastrointestinal, and female-reproductive-organ cancers compared with controls. Cancer survivors were more likely to be unemployed than healthy controls (33.8\% vs. $15.2 \%)$. Moreover, a number of studies described how cancer survivors are at significantly increased risk for unemployment and early retirement as well as less likely to be reemployed (Desiron et al., 2013; Noeres et al., 2013; Silver et al., 2013).

\section{Impairments from Breast Cancer Treatment}

Statistically, $90 \%$ of women are surviving 5 years after diagnosis of breast cancer (Siegel et al., 2015) and are receiving extensive treatments: (a) mastectomy and axillary 
node dissection, (b) multiple types of chemotherapy, and (c) radiation therapy to multiple locations (breast, axilla, spine, and brain). Long-term consequences of cancer treatment for survivors include numbness, tightness, osteoporosis, joint stiffness, and pain (Siegel et al., 2012). According to Stubblefield and Custodio (2006), arm morbidity is experienced by seven of eight women after breast cancer treatment. In addition to lymphedema and shoulder restriction, survivors frequently experience the following types of pain after treatment: radiculopathy, plexopathy, neuropathy, myopathy, tendonitis, adhesive capsulitis, epicondylitis, de Quervain's tenosynovitis, post-mastectomy syndrome, edema, complex regional pain syndrome, cellulitis, arthritis, and metastases (Stubblefield \& Custodio, 2006).

Specifically, investigators have identified impairments experienced by breast cancer survivors after different types of treatments (Hidding et al., 2014). Swisher et al. (2010) found that $96 \%$ of breast cancer survivors, receiving a variety of treatments, experienced upper extremity problems, which included lymphedema, pain, weakness, frozen shoulder, and stiffness. Karki et al. (2005) found similar findings in a study of 106 women who primarily underwent lumpectomy, axillary node dissection, and radiation. The most common impairments experienced by these women were axilla scar tightness, limb numbness, and neck-shoulder pain. Kaya et al. (2010) found reduced shoulder function, pain, and reduced hand strength were more common among women who had a mastectomy. Verbelen et al. (2014) described the presence of reduced arm mobility, loss of strength, pain, axillary web syndrome, and sensory disorders in a systematic analysis of research articles examining shoulder and arm impairments among women who had sentinel lymph node dissections. 
When examining the effects of radiation therapy, reduced shoulder function and lymphedema were found to be frequent side effects (Hidding et al., 2014; Lasinski, 2013; Rietman et al., 2004). Radiation-induced brachial plexopathy caused by radiation fibrosis is experienced when nodal unit of ionizing radiation is greater than 50 Gray. Characteristics of brachial plexopathy include shoulder discomfort, progressive paresthesias, and weakness in the arm and hand (R. Kaplan, Yadav, Talavera, \& Foye, 2011). Additionally, the incidence of peripheral neuropathies among women receiving neurotoxic agents has become more common due to new life-saving chemotherapy protocols (Kuroi et al., 2009; Wickham, 2007).

Hayes et al. (2005) found that survivors had more difficulty completing tasks if they were older, less physically active, and had a history of lymphedema and axillary lymph node dissection. Moreover, survivors considered tasks more burdensome if the task required total-body strength, overall flexibility, or upper-body strength (Hayes et al., 2005). On the contrary, when breast cancer survivors were more active during adjuvant treatments, tasks were less burdensome and mortality decreased (Mandelblatt et al., 2011).

\section{Environment}

Most of the survivors' spent an average of $87 \%$ of their time at home, indicating that daily activities were taking place within a limited environment. Due to the increased amount of time spent at home, some survivors indicated that their home was associated with illness, which led to an increased desire to leave home. When survivors were not at home, they reported spending their time shopping, visiting with relatives, and going to medical appointments. Some survivors attempted to change their environments by going 
out and spending time with close friends and relatives and/or turning to their co-workers for support and social interaction. Social participation was limited by the hardship of treatment and dissatisfaction with their physical appearance (la Cour et al., 2008;

Palmadottir, 2010). The survivors' social circles were limited to immediate family and close friends. If the survivor lived alone, she spent an average of $84 \%$ of her time in solitude. However, many of these survivors indicated that they would like to participate in activities with others, particularly family, but did not want the conversation to center around breast cancer (Palmadottir, 2010).

When examining the relationship between environment and participation in physical leisure activities, Keegan et al. (2014) found an association between social and built-in environment and physical leisure activities in San Francisco. Breast cancer survivors who were residing in lower socioeconomic neighborhoods or more densely populated neighborhoods with poorer participation in leisure activities were less likely to participate in physically demanding activities than those residing in neighborhoods with more foreign-born residents and no parks.

\section{Methodological Underpinnings}

\section{Phenomenological Approach}

Phenomenology is a philosophical approach of studying experience. There are many different emphases and interests among phenomenologists, but they have all tended to share a particular interest in thinking about what the experience of being human is like in all of its various aspects, but especially in terms of the things that matter to people and constitute the lived world. Many phenomenologists have also been committed to thinking about how we might come to understand what our experiences of the world are 
like. Philosophical phenomenology makes explicit that it considers everything to be studied from the viewpoint of consciousness or subjectivity. Consciousness is given priority because it is the medium of access for any knowledge. Experience as it is experienced interests phenomenologists (Giorgi, 2009; Smith et al., 2009).

Phenomenological philosophers' perspectives. According to Husserl (1970), the founding principle of phenomenological inquiry is that experience should be examined in the way that it occurs and in its own terms. He was particularly interested in finding a means by which someone might come to know accurately his or her own experience of a given phenomenon, which might allow him or her to identify the essential qualities of that experience.

Heidegger differed from Husserl in how he approached phenomenological inquiry. He was concerned with the ontological question of existence itself and the meaning of practical activities and relationships. He is distinguished from the other philosophers by his interest in the importance of language and culture and its connection with meaningfulness (Heidegger, 1996). Merleau-Ponty (1996) approached phenomenology from yet another perspective. He suggests that humans see themselves as different from everything else in the world. This is because our sense of self is holistic and is engaged in looking at the world rather than being subsumed within it. $\mathrm{He}$ perceives the body-subject to be the means by which a person communicates with the world. The intentional quality and meaning of the "mineness" and "aboutness" of an experience are always personal to the body-subject. Sartre (1956) believed that our search for meaning is action-oriented, and our self-consciousness engages with the world we inhabit. He is distinguished from the other philosophers by his concern for what we 
will be rather than what we are and the development of the concept of nothingness. For Sartre, things that are absent are as important as those that are present in defining who we are and how we see the world (Giorgi, 2009; Moustakas, 1994; Smith et al., 2009).

Phenomenology within occupational therapy and occupational science. The primary phenomenon of inquiry within the discipline of occupational science and occupational therapy is occupation. In order to determine the essence of occupation, an intense examination of occupation is prerequisite to understanding the relationships between occupations and human beings or between occupations and adaptation or health. Within phenomenological research, the experience of being human, particularly experiences that matter to individuals within their lived world, is explored from various viewpoints. Particular attention is given to the appearances of how an object is consciously represented and the ideas and values that this object has to the individual (Cronin-Davis, Butler, \& Mayers, 2009; Gray, 1997; Padilla, 2003). Occupational science, occupational therapy, and phenomenological research are interested in understanding the experience of engaging in occupations and activities from the perspective of the individual. Each believes that occupation has arisen from an awareness of the self, and there is a substantial relationship between the self and occupation. Through participation in occupations, individuals are attempting to gain and exhibit control over the environment and express newly found awareness of self in action. Phenomenological research makes this connection, which is why this method is appropriate to gain an understanding of the survivors' experiences and associated meanings participating in important occupations. Results from the investigator's study 
will guide future occupational therapy research (Cronin-Davis et al., 2009; Gray, 1997; Padilla, 2003).

\section{Hermeneutics}

Hermeneutics is the theory of interpretation. Hermeneutic theorists are concerned about the (a) methods and purposes of interpretation itself, (b) possibilities of uncovering the intentions or original meaning, and (c) relationship between the context of a text's production and interpretation. Schleiermacher and Bowie (1998) believed that interpretation involved grammatical and psychological interpretation. Grammatical interpretation is concerned with exact and objective textual meaning while psychological interpretation refers to the individuality of the author or speaker. Within this holistic view, the text is not only shaped by the conventions and expectations of a writer's own linguistic community, but also by the individual work that the writer does with that language. They suggest that there is something unique about the techniques and intentions of a given writer, which will influence the interpretation of the text. They believe that if a detailed comprehensive and holistic analysis has been done, a better understanding of the speaker will be revealed. In contrast, Heidegger believes that things have certain visible and hidden meanings. He is concerned in part with examining the hidden meanings as they emerge. The investigator brings prior experiences, assumptions, pre-conceptions to the analysis that endangers the interpretation of the data (Schleiermacher \& Bowie, 1998). In contrast, Gadamer (1989) believes the phenomenon can influence experiences, assumptions, and preconceptions that impacts interpretation. By holding a number of conceptions, the investigator compares, contrasts, and modifies new and old concepts to make sense of the phenomenon studied. The aim of this process 
is to allow the new ideas to emerge and previously held ideas to lessen. The investigator will focus interpretation based on the meaning of the text; however, there is an understanding that the moment will strongly influence the interpretation (Gray, 1997; Moustakas, 1994; Smith et al., 2009; Wright-St. Claire, Kerse, \& Smyth, 2011).

\section{Hermeneutics within occupational therapy and occupational science.}

Hermeneutics aims to interpret meaning rather than only describe the experience. Occupational therapy and occupational science phenomenological hermeneutics research uncovers the meaning of occupation from the perspective of the participant. Within this study, the investigator sought to understand the survivors' perspectives of participating in important occupations by using personal experience, literature, and theory to interpret the survivors' experiences (Gray, 1997; Reed, Hocking, \& Smyth, 2010; Wright-St. Claire et al., 2011).

\section{Interpretive Phenomenological Analysis}

Interpretive phenomenological analysis (IPA) is a qualitative research approach, which examines how people make sense of their major life experiences. IPA is phenomenological because it is concerned with exploring experience in its own terms. Based on Husserl (1970), IPA goes "back to the things themselves" rather than affixing experience into predefined or overly abstract categories. IPA is particularly interested in what happens when the everyday flow of lived experience takes on a particular significance for people. This approach is increasingly being used to analyze interview data surrounding health and illness to uncover common central themes and discover individual differences (Cronin-Davis et al., 2009; Reynolds \& Prior, 2003; Smith et al., 2009). 
When people are engaged in "an experience" of something major in their lives, they begin to reflect on the significance of what is happening. IPA research aims to engage with these reflections. An IPA investigator investigates in detail how someone makes sense of a major transition in her life, such as the diagnosis and treatment of breast cancer. IPA is interested in the reflections and thoughts of the participants as they begin to understand what this major transition means to them. This analytic method assumes that the verbal accounts of the participants' experiences and associated meanings provide genuine insights into the cognitive and emotional responses to lived experiences, and the participants' stories are not simply “self-presentational devices” (Cronin-Davis et al., 2009; Reynolds \& Prior, 2003; Smith, 1996; Smith et al., 2009).

\section{IPA as a Phenomenological Method}

IPA is concerned with the detailed examination of human lived experience and aims to express the experience in its own terms rather than according to a predefined categorical system. IPA concurs with Heidegger's philosophy because the inquiry and analysis are interpretative or hermeneutic. IPA idiographic commitment situates participants within their particular contexts and explores their personal perspectives by providing a detailed examination of each case before moving toward more general claims (Cronin-Davis et al., 2009; Smith et al., 2009).

\section{Hermeneutics}

Hermeneutics is the art of interpretation in context. Within IPA, human beings are seen as sense-making creatures whose accounts provide a reflection of their attempts to make sense of their experiences. The understanding of the experience is always 
dependent on what participants tell the investigator about the experience, which the investigator interprets (Smith et al., 2009).

Within IPA, double hermeneutics is used because the investigator tries to make sense of the participant who is also trying to make sense of what is happening to him or her. Within the dual roles, the investigator employs the same mental and personal skills and capacities as the participant who is making sense of the experience. The participant provides a more spontaneous description of the experience; however, the investigator uses a deliberate and systematic approach to understand the experience through the participant's account of it (Smith et al., 2009; Smyth, Harries, \& Dorer, 2011).

\section{Idiographic}

IPA is idiographic because it is committed to gaining an understanding of how a specific group of people makes sense of what has happened to them. Due to this commitment, IPA studies usually include a small homogeneous sample that experienced a particular phenomenon (an event, process, or relationship). The IPA investigator provides a comprehensive analysis of the unique experience from a certain group's perspective (Savin-Baden \& Fisher, 2002; Smith et al., 2009).

\section{IPA within Occupational Therapy and Occupational Science}

Using in-depth interviews of a small homogenous group of people, occupational therapy investigators explore the meaning of occupational participation by seeking to understand how people make sense of their experiences. Investigators analyze these transcripts using idiographic descriptions of the participants' lived experience, engaging in occupations, and the investigator's interpretations of the experiences. These interpretations are influenced by occupational therapy and occupational science theories. 
Findings from occupational therapy IPA studies provide a deeper understanding of humans as occupational beings and support for occupational therapy (Clarke, 2009; Hawtin \& Sullivan, 2011; Pettican \& Prior, 2011; Reynolds \& Prior, 2003; Smyth et al., 2011; Tzanidaki \& Reynolds, 2011).

\section{Summary}

Impairments caused by surgery, chemotherapy, and radiation have been found to be associated with a reduction in activity participation (Champion et al., 2014; Devoogdt et al., 2010; Edelstein \& Bernstein, 2014; Fantoni et al., 2010; Hidding et al., 2014; Irwin et al., 2003; Kenyon et al., 2014; Kopec et al., 2013; Kwan et al., 2011; Lindbohm et al., 2014; Lyons et al., 2013; Miedema et al., 2011; Pinto et al., 2002; Player et al., 2014; Rietman et al., 2003; Swisher et al., 2010; Verbelen et al., 2014). Along with physical effects of treatment possibly leading to reduced activity levels, others have shown the influence of environmental factors, such as transportation and social support (Lindbohm et al., 2014; Lyons et al., 2013; Newman, 2013; Palmadottir, 2010; Shannon \& Bourque, 2005), and psychological factors (Champion et al., 2014; Edelstein \& Bernstein, 2014; Kenyon et al., 2014; Lindbohm et al., 2014; Lyons et al., 2013; Nesvold et al., 2011; Shannon, 2005) on activity participation (Andrykowski et al., 2007; Littman et al., 2010; Rosenblum et al., 2005; Shannon, 2005).

Specifically, women commonly discontinue physically and cognitively demanding or unsatisfying paid work during treatment and frequently do not return to these jobs after treatment (Barnes et al., 2014; Lindbohm et al., 2014; Moskowitz et al., 2013). While undergoing treatment, many women spend their time at home, leading to an association of home with illness and the desire to leave their home (Palmadottir, 
2010). Alternatively, the majority of women 50 years old or older are able to maintain social activities, which helps them manage some of the negative social psychological consequences normally associated with breast cancer diagnosis and treatment (Berterco, 2000; Litchman et al., 1987; Shannon \& Bourque, 2005; Waxler-Morrison et al., 1991). Currently, the literature lacks studies that provide a description of the survivor's experience, participating in activities during and after breast cancer treatment, and its effect on meaning and occupational performance. Phenomenological techniques, such as IPA, allow occupational therapy investigators to explore the connection among the individual's sense of meaning, environment, and occupational performance. Using hermeneutics, the investigators interpret the meaning of the occupational experience from the individual's perspective rather than only describing it. In the investigator's study, the transcripts from a small homogenous population of breast cancer survivors were analyzed along with results from the ACSm to provide a rich description of their experiences. The investigator's interpretations of these women's experiences and associated meanings returning to important activities were influenced by personal experiences, literature, and the PEOP (Christiansen \& Baum, 1997; Clarke, 2009; Hawtin \& Sullivan, 2011; Pettican \& Prior, 2011; Reynolds \& Prior, 2003; Smyth et al., 2011; Tzanidaki \& Reynolds, 2011). 


\section{Chapter 3: Methodology \\ Research Design and Methodology}

\section{Rationale}

A concurrent mixed method design was used in this study, which included IPA as the primary method and descriptive quantitative analysis as the secondary method. This mixed method design was chosen because the IPA method described the breast cancer survivors' lived experiences of participating in their most important activities, and the descriptive longitudinal method illustrated the change in activity participation during and after treatment (Creswell, 2009).

\section{Specific Procedures}

The investigator recruited 10 participants for the study through oncology providers, flyers posted within the radiation oncology clinic, and an electronic flyer on the Wake Forest Baptist Health research Web site. A radiation oncologist or potential participant contacted the investigator either by telephone or by e-mail to indicate interest in the study. The investigator provided the purpose, inclusion criteria, and expectations for the study to each potential participant by telephone or e-mail. If the prospective participant continued to express interest in the study, the investigator scheduled a time to review the informed consent with her. After the participant signed the informed consent, the participant completed the initial Activity Card Sort-modified scoring system (see Appendix A) during the first week of radiation therapy. If the participant left questions blank in the ACSm during any of the four visits, the investigator asked the participant to complete the unanswered questions. As directed by the participant, the investigator either contacted the participant by e-mail or telephone to schedule subsequent visits. Prior to 
the second visit, the investigator completed the patient profile (see Appendix B) based on information found in the electronic medical record. During the second visit, the investigator verified and updated the patient profile, administered the second ACSm and led a participant-directed, digitally recorded interview, centered on her experiences and associated meanings participating in her most important activities. The investigator conducted the interviews either in a private room or over the telephone based on the participant's preference and availability.

Subsequent assessments took place 3 and 6 months after completing radiation therapy. The participant completed the third ACSm during the 3-month follow-up visit. If a participant could not come to Winston-Salem to complete the questionnaire, the investigator mailed the questionnaire to her and she either mailed or faxed it back to the investigator. During the 6-month follow-up visit, the investigator updated the patient profile, administered the fourth ACSm, and led another participant-directed, digitally recorded interview, centered on her experiences and associated meanings participating in her most important activities. The investigator conducted the interviews either in a private room or over the telephone based on participant's preference and availability. After each completed visit, the investigator provided each participant with a \$20 Target gift card.

\section{Strengths and Weaknesses of Design}

Strengths. By combining the qualitative and quantitative research designs, the investigator obtained two different perspectives of the same phenomenon to strengthen the reliability and validity of the data. Specifically, the concurrent mixed method design utilized the PEOP model to illustrate the how the emergent themes from the interview fit 
within this model to show a possible relationship with resuming activities as measured by the ACSm (Creswell, 2009; Creswell, Klassen, Plano- Clark, \& Smith, 2011; Morse \& Niehaus, 2009; Tashakkori \& Teddlie, 2003).

The investigator's understanding of this phenomenon would not have been complete if the quantitative or qualitative method alone had been used. The concurrent mixed method allowed the investigator to answer two different research questions simultaneously by collecting qualitative and quantitative data at once to produce a rich description of this phenomenon (Creswell, 2009; Creswell et al., 2011; Morse \& Niehaus, 2009; Tashakkori \& Teddlie, 2003).

The investigator used the qualitative results from IPA for the participant to describe the experience of participating in her important activities and the associated meaning, which quantitative data did not capture (Lichtman, 2010; Moustakas, 1994; Munhall, 2007; Padilla, 2003; Portney \& Watkins, 2009; Smith et al., 2009). The investigator analyzed the types of activities currently and previously performed, and the percentage of global and category-specific activities retained at different time points, using the longitudinal descriptive method. By converging these data, the investigator obtained a rich illustration of the participants' experiences participating in activities and the associated meaning, description of their activity resumption at different time points, and demonstration of how the PEOP could be applied to this population (Creswell et al., 2011; Morse \& Niehaus, 2009; Portney \& Watkins, 2009; Tashakkori \& Teddlie, 2003).

Weaknesses. This concurrent mixed method design had several weaknesses related to recruitment, investigator expertise, and validity of using the ACSm with breast cancer survivors. The investigator had difficulty recruiting participants due to the (a) 
investigator's dependence on radiation oncologist to locate eligible participants, (b) specific inclusion criteria, and (c) locating women who were willing to participate in a study that did not have immediate benefit to her (Brocki \& Wearden, 2006). Quantitatively, the investigator's calculation of the proportion of activities resumed for each category and global category was dependent on the ACSm list of activities matching the participant's previous and current activities. Because it was unlikely that the ACSm included all relevant activities, the investigator's calculation of the proportion of activities resumed was likely lower than the "true" proportion. Moreover, the ACSm has not been validated with breast cancer survivors (Lyons et al., 2011; Lyons et al., 2010).

\section{Subjects}

\section{Sample}

The investigator used purposeful sampling to recruit 10 breast cancer survivors from the Comprehensive Cancer Center at Wake Forest Baptist Health, which is consistent with IPA because it is not concerned with generalizing. This homogenous subgroup of breast cancer patients allowed the investigator to explore the shared phenomenon of returning to important activities. The homogenous subgroup consisted of (a) women who consecutively had surgery, chemotherapy, and then radiation therapy for Stage I, II, or III breast cancer; (b) was between 40 and 65 years of age; (c) completed $12^{\text {th }}$ grade level of education; (d) and spoke English. Potential participants learned about the study through the study flyer posted within the radiation oncology clinic, on the Wake Forest Baptist Health research study Web site, and/or an oncology provider. The radiation oncologist or the participant contacted the investigator directly to express an interest in participating in this study. 


\section{Inclusion Criteria}

Participants in this study met the following criteria. The participants (a) expressed an interest in participating in survivorship research, particularly activity participation; (b) diagnosed with Stage I, II, or III breast cancer; (c) consecutively received surgery, chemotherapy, and radiation therapy; (d) spoke English; (e) had at least a $12^{\text {th }}$ grade equivalent level of education; and (f) were between 40 and 65 years of age.

\section{Exclusion Criteria}

The investigator excluded potential participants from the study. Participants were excluded if they were receiving ongoing treatment for their breast cancer beyond radiation therapy, excluding adjuvant therapy, or had a diagnosed cognitive impairment.

\section{Characteristics}

The participants in this study had the following characteristics. The characteristics included (a) diagnosed with Stage I, II, or III breast cancer; (b) consecutively received surgery, chemotherapy, and radiation therapy; (c) were between 40 and 65 years of age; and (d) did not receive additional treatment for their breast cancer, excluding adjuvant therapy.

\section{Ethics Considerations and Review}

Institutional review board. Prior to initiating this study, the investigator completed institutional review board (IRB) research protocol forms for this study, which were approved by the Nova Southeastern University IRB on July 13, 2012 (IRB number 06111207Exp.) and Wake Forest Baptist Health IRB on May 7, 2012 (IRB number IRB00020124). Nova Southeastern University IRB approved amendments on October 31, 2012, and January 23, 2013, and Wake Forest Baptist Health IRB approved 
amendments on August 1, 2012, October 23, 2012, and January 17, 2013. The amendments included (a) modification of the consent form to reflect Nova Southeastern University and Wake Forest University IRB requirements, (b) inclusion of Nova Southeastern University's name on the advertisement flyers, (c) acknowledgement of the principle investigator's receipt of a grant from Nova Southeastern University for $\$ 2000$, and (d) changing the wording of the flyer to improve clarity. Original flyer read, "Have Stage I, II, or III breast cancer. Have or will have surgery, chemotherapy, and radiation therapy for the treatment of their breast cancer." The amended version read, "Have Stage I, II, or III breast cancer, had surgery and chemotherapy, and will have radiation therapy. Study begins during the first week of radiation therapy." A portion of the exclusion criteria was changed from "excluding hormone therapy" to "excluding adjuvant therapy." The Wake Forest Baptist Health IRB approved the continuation of this study on March 28, 2013 and February 7, 2014, and Nova Southeastern University IRB approved the study's continuation on April 16, 2013 and February 12, 2014.

Informed consent. The investigator reviewed the informed consent forms with each potential participant for this study. The investigator provided a copy of the informed consent to each participant and read it to her. The investigator answered any questions related to the consent form and informed her that she could withdraw from this study at any time and neither her health care nor her legal rights would be adversely affected.

Confidentiality. To insure confidentiality, the investigator stored paper documents, such as the ACSm and consent forms, which included the participant's name and/or identification number, in a secure location. The investigator stored digital 
recordings of the interviews in an encrypted password-protected computer, using the participants' identification numbers.

After the investigator conducted the interview, the digital recording was sent to and from the medical transcriptionist electronically, using password-protected encrypted computers ("Health information privacy: Summary of the HIPAA privacy rule," 2011). After the transcript was received, the investigator assigned a pseudonym and unique numerical code to each transcript and changed any names, such as health care provider, family, and/or friend names, to a pseudonym. The investigator secured all electronic recordings, notes, transcripts, data analysis, and any personal identifiers in an encrypted password-protected computer and backup drive, which was kept in a secured location (Creswell, 2009; Creswell et al., 2011; Gibbs, 2007; Smith et al., 2009). To protect the identity of the participants, the investigator has omitted the specific months when the women were recruited. Because Wake Forest Baptist Health Comprehensive Cancer Center serves an average of 210 newly diagnosed women with breast cancer, participants cannot be easily identified (Gibbs, 2007).

\section{Recruiting Procedures}

The investigator used a multiple-stage critical case purposeful sampling to recruit breast cancer survivors during chemotherapy or after the initial visit with the radiation oncologist. Participants heard about the study through an oncology provider, a flyer posted within the radiation oncology clinic, or electronically on the Wake Forest Baptist Health research Web site, which included a confidential phone number and e-mail address to call to receive additional information about the study. The investigator contacted each inquiring participant by telephone or e-mail and provided (a) the inclusion 
and exclusion criteria, (b) time commitment, and (c) nature of the ACSm and interview. If the potential participant continued to express interest in the study, the investigator scheduled a time to review the informed consent with the potential participant in a private location (Creswell, 2009; Tashakkori \& Teddlie, 2003).

\section{Funding}

The investigator received a grant of $\$ 2,000$ from the Nova Southeastern University Health Professions Division Research Committee on July 2, 2012. The grant included $\$ 800$ for supplies and \$1,200 for the investigator's stipend.

\section{Study Setting}

Participants completed the ACSm in a private location of their choice, and the investigator conducted the digitally recorded interviews in a private room at the Wake Forest Baptist Health or over the telephone. Locations for completing the ACSm were a research room at the Comprehensive Cancer Center, conference room at CompRehab, participant's home, and a table at a restaurant. Interviews were conducted in the research room at the Comprehensive Cancer Center, conference room at CompRehab, or over the telephone.

\section{Measurement Tools}

\section{Activity Card Sort}

Instrument. The Activity Card Sort (ACS) is a comprehensive instrument for assessing participation in occupational performance of instrumental, social, and leisure activities (low and high physically demanding). The ACS has three different versions: (a) community-dwelling, healthy older adults; (b) older adults in a nursing facility; and (c) people recovering from a medical event. The instrument includes 80 picture cards of 
adults performing each activity. The sort method is flexible and reflects the question posed by the investigator (Baum \& Edwards, 2008).

Everard et al. (2000) demonstrated adequate concurrent validity using a paper and pencil version of the recovery version of the ACS as compared to the manual card sort. Additionally, they found the 30-day, test-retest reliability for the subscales ranged from 0.83 to 0.95 with a mean of 0.89 . For this study, a modified version of the recovering version of the ACS was used rather than the card-sort version because it was easier to administer to this population. Each participant assigned one of five categories: (a) never done, (b) do now as often as before breast cancer treatment, (c) do less or differently than before breast cancer treatment, (d) have not done since breast cancer treatment, or (e) new activity to each of the 80 activities listed. The method for scoring the ACSm is the same as scoring the ACS (Lyons et al., 2011).

After the ACSm was completed, the investigator calculated three different types of measures: (a) the number of current activities engaged, (b) the number of previous activities engaged, and (c) percentage of activities retained for each category and global activity. A score of $100 \%$ of activities retained indicated that the participant had resumed her previous activity level, and a score of zero indicated that the participant was no longer participating in any of her previous activities, nor had she added any new activities to her current routine. At the end of the ACSm, the participant listed her five most important activities (Baum \& Edwards, 2008).

Content validity. Baum and Edwards (2008) determined the content validity of the initial items chosen for inclusion in the ACS by asking 30 older adults living in the community to identify the activities that they performed within a course of a week and 
activities that were missing from a set of pictures presented to them. Using this data, another set of pictures was generated, and the same older adults were asked to consider activities performed within a course of a year and to identify activities that were missing from the pictures presented. This process resulted in a collection of 65 activities.

Another group of community dwelling adults was also recruited to suggest additional activities beyond the 65 identified activities. These adults recommended 15 additional leisure activities, which brought the total to 80 activities. These 80 activities were divided into four categories: instrumental, low-demand leisure, high-demand leisure activities, and social activities (Baum \& Edwards, 2008).

Predictive validity. In her study of 70 individuals with a history of cerebral vascular accident, Edwards (1999) found that the percentage of meaningful activities regained was a better predictor of quality of life (measured by the SF-36) than basic selfcare scores (measured by the Functional Independence Measure).

Reliability. Baum and Edwards (2008) reported a 1-week, test-retest reliability coefficient of the ACS recovery version as 0.90 . Other investigators reported similar results for 14- and 30-day, test-retest reliability. High internal consistency for each area of the ACS, except leisure, was found among caregivers of individuals with Alzheimer's disease, older adults without illness, individuals with multiple sclerosis, and individuals who were 1-year post-cerebral vascular accident (CVA). The correlation for each in the ACS was (a) instrumental $(r=0.82)$, (b) social $(r=0.80)$, (c) low-demand leisure $(r=$ $0.66)$, and (d) high-demand $(r=0.61)$. Additionally, a comparison of this same group of individuals demonstrated a significant group effect on all comparisons $(p<0.0001)$ of the total retained activity level and individual activity areas, except between those with 
multiple sclerosis (MS) and caregivers of an individual with Alzheimer's disease. Within instrumental activities of daily living (IADL), significant group effect was found between those with disabilities, but not between those who did not have a disability $(p<0.0001)$. No significant difference was found between healthy adults and those with MS or between those with a history of CVA and the caregivers of an individual with Alzheimer's disease within the category of low demand recreational activities. Similar results were found for social activities, except that there was a significant group effect between healthy adults and healthy older adults $(p<0.0001)$. Moreover, there were significant group effects between healthy adults and healthy older adults and between these same adults and those with history of MS, 1-year post-CVA, and caregivers of someone with Alzheimer's disease ( $p<0.0001$; (Katz et al., 2003).

Reliability and validity of the ACSm. Baum and Edwards (2008) tested the activity checklist version of the ACS by testing a sample of 20 community-dwelling adults between 65 and 87 . The authors interviewed the participants, using the ACS, and mailed them a checklist version of the ACS after the interview. The same participants were mailed another checklist about 30 days after the first checklist was returned. Concurrent validity of the checklist with the ACS was $0.90,0.78,0.82$, and 0.72 for instrumental, social, low-demand leisure, and high demand leisure activity subscales, respectively. Test-retest reliability with a time interval of 74 days was $0.95,0.83,0.91$, and 0.88 for the instrumental, social, low-demand leisure, and high-demand leisure activity subscales, correspondingly. 


\section{Semi-Structured Interview}

For this study, the interviewer created an informal and interactive atmosphere utilizing semi-structured questions to gain an understanding of the survivor's experiences and associated meanings while participating in her important activities during and after treatment (Tzanidaki \& Reynolds, 2011). The investigator referred to the interview guide and ACSm to direct the interview; however, the participant guided the interview. The investigator reviewed the list of the five most important activities listed by the participant prior to initiating the interview. The investigator started the interview with "Tell me about how it has been $\left(1^{\text {st }}\right.$ most important activity listed).” Follow-up questions were based on the answers provided. For instance, a follow-up question for a participant who listed caring for a grandchild was "How do you feel about watching your grandchild?" Follow-up questions were continued until there were no more questions to be asked. This process was repeated for each of the activities listed. Because each participant was encouraged to discuss issues that were relevant to her, not all questions were asked to each participant, and questions varied and/or were altered for each participant, depending on the participant's descriptions (Clarke, 2009; Coleman-Brueckheimer, Spitzer, \& Koffman, 2009; Flick, 2007; Kvale, 2009; Roulston, 2010; Smith, 1996; Smith et al., 2009; Tzanidaki \& Reynolds, 2011).

Reliability for this type of interview is influenced by selection and interviewer biases. The investigator may find it difficult to recruit participants because interviews are time consuming and personal, resulting in selection bias. Additionally, when the interviewer's questions appear biased, interviewees may avoid discussing sensitive topics. Consequently, a partial "picture" of the situation or a "socially desirable" image 
will be provided rather than a comprehensive account of the experience (Flick, 2007; Kvale, 2009; Roulston, 2010; Smith et al., 2009). To minimize these biases, the investigator used an interview guide to reduce potential interviewer bias and acknowledged the potential selection bias in the discussion of this document.

Validity for semi-structured interviews refers to the extent that the investigator has gained full access to the knowledge and meanings of informants. The investigator achieves validity when conducting an interview, which is clear, flexible, and responsive, by either reflecting or reframing responses to confirm accurate understanding of the interviewees' responses. Moreover, the interviewer probes meanings and covers the topic from a variety of angles during the interview. However, validity of the findings is threatened when the interviewer's tone or non-verbal behavior is questioning and data analysis impose particular beliefs or frame of reference (Flick, 2007; Kvale, 2009; Roulston, 2010).

If the interviewee does not trust the interviewer or if the interviewer's credibility is lacking, the interviewee will not feel comfortable answering probing questions, which will threaten the validity and reliability of the interview. This response bias is particularly present when the investigator seeks explanations to sensitive topics (Flick, 2007; Kvale, 2009; Roulston, 2010).

\section{Data Collection Procedures}

\section{Qualitative Data Collection Procedures}

The investigator scheduled the initial interview during the last week of radiation therapy and scheduled the second interview 6 months after completing radiation therapy. The investigator conducted a 45- to 60-minute, semi-structured interview in a private 
room at the Wake Forest Baptist Health Comprehensive Cancer Center, conference room at CompRehab, or over the telephone. The investigator recorded each interview using a digital recorder. After each interview, the investigator downloaded the interview onto a password-protected encrypted computer, then erased the interview from the digital recorder (Clarke, 2009; Cronin-Davis et al., 2009; Hawtin \& Sullivan, 2011; Pettican \& Prior, 2011; Reynolds \& Prior, 2003; Tzanidaki \& Reynolds, 2011).

\section{Quantitative Data Collection Procedures}

The participant completed the initial ACSm during the first week of radiation therapy after signing the consent form. The investigator completed the patient profile form by reviewing the electronic medical record. During a subsequent visit, the investigator verified the information found within the medical record and solicited missing information to complete the form. The participant completed the ACSm again, during the last week of radiation therapy, and 3 and 6 months after radiation therapy. If the participant left any questions blank in ACSm during any of the four visits, the investigator asked the participant to complete the unanswered questions. All data was deidentified and entered into a password-protected computer and will be kept secured for at least 3 years.

\section{Data Analysis}

\section{Data Reduction}

Interpretive phenomenological data analysis. The transcriptionist transcribed the interviews verbatim from the digital recordings into Microsoft Word ${ }^{\circledR}$. After the initial transcription had been completed by the transcriptionist, the investigator listened to the recordings again, and Jeffersonian conventions were inserted into the transcripts to 
convey the features of the participant's speech (Roulston, 2010). Once these conventions were inserted, the investigator began the interpretative phenomenological data analysis (Smith et al., 2009). This approach is inductive in nature, allowing ideas and themes to emerge from the personal accounts rather than imposing a predetermined theory. The approach adopts both an emic (insider) and etic (interpretative, outsider) positions. In other words, the investigator listened to the participant to hear and understand the participant's story and placed the experiences at the center of the account. Additionally, the investigator made sense of the data by bringing her own interpretations and theoretical ideas, but used verbatim quotes to ground these interpretations in the participant's actual experience (Smith et al., 2009).

This iterative analysis began by making descriptive comments. At this level of analysis, the investigator sought to understand things, which mattered to the participant. The investigator highlighted descriptions, such as sound bites, idiosyncratic figures of speech, and emotional responses in yellow, then used the comment function within Microsoft Word® to make descriptive comments, reflecting the participant's thoughts. For the second level of analysis, the investigator focused on participant's use of distinct pronouns, pauses, laughter, functional aspects of language, repetition, tone, and degree of fluency and metaphor used by highlighting them in green and commenting about how the participant's use of language conveyed significance and meaning. The linguistic and descriptive comments led to the next level of analysis: conceptual comments (Smith et al., 2009).

Within the third level of analysis, the investigator moved the analysis toward discovering the woman's overarching understanding of her participation or non- 
participation in her important activities during and after breast cancer treatment. The investigator developed conceptual comments by reflecting on the meaning the participant was trying to convey about her experiences participating in her important activities by reviewing the descriptive and linguistic comments. The investigator highlighted supporting descriptive and linguistic comments in blue (Smith et al., 2009).

Conceptual comments did not lead to answers to the questions posed or to understandings but were a bridge between comments and theme development. The investigator discovered the emerging themes after completing the conceptual comments and looking for interrelationships, connections, and patterns between them. The investigator reviewed each conceptual comment and developed a concise statement (Smith et al., 2009).

After the investigator analyzed each transcript, the co-investigator, who is an expert in IPA, reviewed the analysis. The investigator re-analyzed any transcripts identified by the expert, which did not consistently follow the IPA method. The investigator used this method of review after core themes were identified.

After core themes were identified, the investigator began cross-case analysis by examining the themes and their possible relationship to encouraging or discouraging participation in important activities. The investigator categorized themes based on the function of the language used by the participant and its relationship to activity retention. For instance, Participants 02 and 03 listed work as an important activity. They described their colleagues: "When I felt healthy I do my share and when I don't somebody else does it." "Give me that boost and extra to help me do this, that or whatever I needed." Their descriptions and other participants' descriptions of colleagues supported the 
development of the superordinate theme of "social support reduces the stress of life" and its encouragement of retaining important activities. Within each of the superordinate themes, emergent themes were listed that supported the superordinate theme's relationship to activity retention.

Quantitative data analysis. The investigator calculated frequency, mean, range, and standard deviation using Microsoft Excel® 2013 and proportion of activity participation resumed for each participant at each time point using a calculator. The frequency and percentage of the following characteristics were charted: (a) race; (b) marital status; (c) members in the household; (d) laterality of breast cancer; (e) breast cancer type, stage and size; (f) breast surgery type; (g) complications; (h) chemotherapy type; (i) being a caregiver; and (j) employment status, including occupation and hours worked per week before, during, and 6 months post radiation therapy. The mean, range, mode, and standard deviation for the number of (a) co-morbidities, (b) past surgeries, (c) medications, (d) lymph nodes removed, and (e) positive lymph nodes were calculated. The investigator calculated the proportion of activity participation resumed for each specific and global category for each participant at each time point and the means of the proportion of activities resumed by all the participants for each category and global category at each time point (Creswell, 2009; Morse \& Niehaus, 2009; Onwuegbuzie \& Leech, 2006).

\section{Data Display}

Qualitative data. After the interpretative phenomenological analysis was completed, the investigator charted the emergent themes for each participant. After the investigator charted these themes, the investigator discovered that many of the emergent 
themes were related. Using the analytic process of subsumption and function, the investigator grouped these emergent themes under an overarching superordinate theme and displayed this relationship of the themes to activity retention in a chart. Lastly, the investigator created a master theme list for each superordinate theme, which included supporting passages and notations from the participants' transcripts (Smith et al., 2009).

Quantitative data. The investigator plotted the percentage of activities retained for each category and global category at each time point on separate graphs for each participant (Lyons et al., 2011). Using the combined data from all the participants, the investigator charted the means of the proportion of activities retained for each category and global category at each time point. To illustrate the proportion of important activities within each category for each time point, the investigator displayed the data within separate pie graphs (Onwuegbuzie \& Teddlie, 2003) .

\section{Data Transformation and Comparison}

The investigator created a matrix for each activity category from the data collected at the end of radiation therapy and 6 months post radiation therapy. The horizontal axis of each matrix is the dichotomous category of below or above the overall mean proportion of activity retention at that time point (e.g., instrumental, social, low demand leisure, and high demand leisure activities) and the vertical axis includes the superordinate themes generated from IPA. Cells within each of the matrices include supporting quotes from the transcripts for each corresponding dichotomous category and theme (Onwuegbuzie \& Teddlie, 2003). 


\section{Data Integration}

The investigator integrated the qualitative and quantitative data into a coherent whole within the PEOP. Specifically, the "person" or intrinsic factors were illustrated using data from the patient profile and emergent themes, which described the person. Next, the "environment" or extrinsic factors were portrayed by listing the environments described within the transcript and emergent themes, which depicted extrinsic factors. Occupation and performance were described using the ACSm scores and the emergent themes, which were derived from the participants' description of their experiences engaging in their important activities.

After this data was integrated, this data was compared within two separate tables. The first table compared a high-participating survivor with a low-participating survivor using person or intrinsic factors, and the second table made the same comparison but used environment or extrinsic factors. This process of data integration and comparison was completed at the end of radiation therapy and 6 months post radiation therapy (Johnson \& Onwuegbuzie, 2004; Onwuegbuzie \& Teddlie, 2003).

\section{Assumptions, Limitations, and Delimitations of Methods}

\section{Assumptions}

The investigator assumed that the sample of 10 women are representative of breast cancer survivors who (a) are between the ages of 40 to 65 years of age; (b) have a minimum of a high school equivalent education; and (c) have received surgery, chemotherapy, and radiation therapy consecutively for their Stage I, II, or III breast cancer. Each woman accurately compared her current activity participation level with her previous level for the 80 activities listed within the ACSm. During the interviews, 
each woman felt comfortable answering the questions honestly and did not provide socially appropriate responses.

\section{Limitations}

Although the sample size may have been adequate for qualitative method section of this study, 10 participants do not provide sufficient power to generalize the results to the population of breast cancer survivors. The study sample included women who (a) are from a small geographical area; (b) sought treatment from an academic medical center within the southeastern United States; (c) racially represent African-Americans, Caucasions, and mixed race of Caucasion and American Indian; and (d) have at least a 12-year equivalent education. The reliability of the ACSm may have been threatened due to the dependence of the breast cancer survivor's ability to compare her current participation level with the activities she was doing prior to her breast cancer diagnosis (Njie-Carr, 2014).

\section{Delimitations}

The investigator implemented several steps to ensure the integrity of the data. First, the sample population was audited one time during the study by the investigator. During this audit, one participant was excluded because she had received neoadjuvant chemotherapy, which was not identified during the selection process. The investigator rechecked the data entered into Microsoft Excel® program from the ACSm checklists and recalculated the rates of activity resumption to ensure the data were correct. Once interviews were completed and transcribed, the investigator analyzed each transcript in detail and closely followed the IPA method of analysis to reduce bias. Following the analysis, an expert in IPA reviewed all transcript analyses and theoretical ideas 
formulated from the data analysis. When indicated by the expert's recommendations, the investigator re-analyzed data, so the IPA method of analysis was completed correctly and consistently (Smith et al., 2009). Lastly, the concurrent mixed method reduced the limitations within IPA and strengthened the findings discovered within the transcripts by using the quantitative data from the ACSm to the descriptions of the women's resumption of important activities (Creswell, 2009; Morse \& Niehaus, 2009).

To encourage participants to complete all four visits, the investigator scheduled follow-up visits around physician appointments or on other days and times that were convenient to the participants. Some of the ACSm checklists were completed from home and interviews were conducted over the phone if requested by the participants. As a result, $80 \%$ of the participants completed all four visits.

\section{Summary}

A concurrent mixed method was chosen for this study because it converged both qualitative and quantitative data to provide a comprehensive analysis of breast cancer survivors' experiences for participating in her important activities (Creswell, 2009; Creswell et al., 2011; Morse \& Niehaus, 2009; Tashakkori \& Teddlie, 2003). Qualitative data was analyzed utilizing IPA to provide an understanding of the experience of resuming important activities by each woman from her perspective within the context of her breast cancer diagnosis and treatment (Savin-Baden \& Fisher, 2002; Smith et al., 2009). This data was converged with descriptive quantitative data gathered from the ACSm to provide a rich description of their experiences and associated meanings in relation to the women, their environment, and occupational performance. 


\section{Chapter 4: Results \\ Introduction to the Chapter}

This chapter will summarize the women's experiences and associated meanings connected with their important activities during treatment and the 6 months after their proportion of activities retained for instrumental, low-demand leisure, high-demand leisure and social activities during the first and last weeks of radiation therapy, 3 months, and 6 months post radiation therapy. By combining the qualitative and quantitative data, an in-depth description of each woman's experiences illustrates the challenges faced and the strategies used to regain the ability to participate in her most important activities.

The inclusion and exclusion criteria for the study provided a population of women who shared the experience of consecutively having surgery, chemotherapy, and then radiation therapy for their breast cancer. In addition to this common experience, most of these women had (a) children older than 18, (b) breast cancer on their non-dominant side, (c) surgically received a lumpectomy, (d) hormone-positive tumor, and (d) full-time work prior to their breast cancer diagnosis. However, these women did vary by their breast cancer stage and/or type, chemotherapy received, marital status, household responsibilities, work, leisure interests, social support, important activities, and/or level of education.

\section{Experiences and Associated Meanings Participating in Important Activities}

During treatment. Although these women did not share the same experiences, they did describe how their side effects, such as pain and fatigue, fear of infection, and personal and/or treatment-related stress, affected their ability to participate in their important activities. "Well I mean I tried lifting a few things and it hurt [brief laugh] so 
okay you need to do this a little bit differently." In addition to sharing similar challenges, these women explained how using various strategies to reduce stress and treatment side effects and receiving support from others improved their ability to remain engaged in life. "I can play my music and get relaxed and go into work and I'm fine."

During treatment, many women described their future, which included (a) teaching women about the importance of early detection of breast cancer, (b) providing drug-abuse prevention education to teenagers, and (c) improving their economic condition by advancing their education. "Oh yes, Lord. Yea and I'm gonna be very vocal about women going to get breast exams and getting a mammogram." Their plans reflected how they were finding meaning by improving the health condition of their family, community, and themselves.

Six months post treatment. While these women's experiences returning to important activities were dissimilar, they did describe how positive and negative emotions, fatigue, and the experience of having cancer and receiving treatment changed their life and influenced the resumption of activities. Their experiences led some women to (a) make lifestyle changes; (b) gain a greater appreciation for their life, work, and family; (c) improve themselves by furthering their education; and/or (d) serve their community. Their actions reflected how they were finding renewed meaning for the life, work, and family. "I think we are. I think that we both come to feel like we need to celebrate more and travel more and have good times, spend more money [laughs], do for ourselves and each other cause you don't know." They also expressed a desire to improve their community and themselves. "I'm going of course stay on top of my health, 
um exercising, I did Weight Watchers and I've lost [pause] 30 or 35 pounds. . . I see no limits only the limitations I place upon myself."

\section{Connections among Survivors, Environments, and Occupational Experiences}

Within this sample, women appeared to be at greater risk of not regaining previous activity level in a few particular situations. Those risks were if they participated in activities within a limited number of environments, experienced negative social support, had greater co-morbidities, received additional treatments for other conditions, felt greater fatigue, and worked greater than 40 hours a week.

\section{Findings}

\section{Data Reduction}

\section{Qualitative.}

Last week of radiation therapy. Four superordinate themes emerged from the analysis and interpretation of the interviews conducted during the last week of radiation therapy: (a) individual outlook influences how activities are approached, (b) social support reduces the stress of life, (c) side effects influence how activities are completed, and (d) personal and treatment stresses and struggles modified their perspectives on life. Each of these superordinate themes and coresponding subthemes appeared to either positively and/or negatively influence the woman's ability to retain her activity level. Fatigue and fear of infection, treatment side effects, and personal and treatment stresses and struggles seemed to have an adverse effect on activity retention. However, the individual's outlook, including strategies to reduce stress and treatment side effects, looking toward the future, and making personal changes, appeared to encourage activity retention. Although many women expressed gratitude for the support received from 
others, some of the women did not. Support from others appears to either reduce or encourage activity retention during treatment for these women.

Six-months post radiation therapy. Three superordinate themes emerged from the analysis and interpretation of the interviews conducted: (a) emotional effect on activities, (b) life after cancer has changed due to cancer diagnosis and treatment, and (c) side effects continue to influence daily activities. Each of these superordinate themes and coresponding subthemes appeared to either positively and/or negatively influence the woman's ability to regain her activity level. Fatigue and other side effects seemed to have an adverse effect on regaining activity levels. However, an appreciation for life, family, and work and a desire to make lifestyle changes appeared to lead to activity participation. Current cancer status influenced the women's emotional state, which appeared to either encourage or discourage participation in important activities, particularly activities related to lifestyle changes.

Quantitative. The radiation oncologists approached at least 20 breast cancer patients. Of these 20 patients, five did not meet the study criteria and an additional five potential participants met the criteria but did not want to participate in the study. An undetermined number of potential participants read the flyer and Web site or was approached by an oncology provider regarding the study. Most of the women enrolled in the study were members of a minority group and married, and had a child over 18 years old, and attended some college (see Tables 1 and 2). Most of the women's breast cancer had the following characteristics: (a) Stage II, (b) hormone positive, (c) tumor size between 1 to $2 \mathrm{~cm}$, and (d) located within the left breast. The majority of the participants had a lumpectomy and received one or more of the following chemotherapy agents: 
Cytoxan, Adriamycin, and Taxotere. There were equal numbers of caregivers versus non-caregivers within this sample. Interestingly, there were more women with the diagnosis of triple negative breast cancer, $40 \%$ in this sample compared to 15 to $20 \%$ found within the population of women with breast cancer ("Triple negative breast cancer," 2014). 
Table 1

Sample Demographics

\begin{tabular}{|c|c|c|c|}
\hline Characteristic & $\bar{x}$ & Range & $S D$ \\
\hline Age & 46.6 & $41-60$ & 6.98 \\
\hline Characteristic & $n$ & Percentage & \\
\hline \multicolumn{4}{|l|}{ Race } \\
\hline African-American & 6 & 60 & \\
\hline Caucasian & 2 & 20 & \\
\hline Mixed Race ${ }^{\mathrm{a}}$ & 2 & 20 & \\
\hline \multicolumn{4}{|l|}{ Marital Status } \\
\hline Married & 5 & 50 & \\
\hline Single & 2 & 20 & \\
\hline $\begin{array}{l}\text { Divorced / significant } \\
\text { other }\end{array}$ & 1 & 10 & \\
\hline Separated & 2 & 20 & \\
\hline \multicolumn{4}{|l|}{ Others in the household } \\
\hline Child(ren) under 18 years & 2 & 20 & \\
\hline Child(ren) 18 or older & 8 & 80 & \\
\hline $\begin{array}{l}\text { Spouse or significant } \\
\text { other }\end{array}$ & 4 & 40 & \\
\hline Other adult relative & 1 & 10 & \\
\hline None & 1 & 10 & \\
\hline \multicolumn{4}{|l|}{ Level of Education } \\
\hline High school & 3 & 30 & \\
\hline Some college & 3 & 30 & \\
\hline Associate degree & 2 & 20 & \\
\hline Bachelor's degree & 1 & 10 & \\
\hline Graduate degree or higher & 1 & 10 & \\
\hline \multicolumn{4}{|l|}{ Caregiver } \\
\hline Yes & 5 & 50 & \\
\hline No & 5 & 50 & \\
\hline
\end{tabular}


Table 2

Breast Cancer Characteristics

\begin{tabular}{lll}
\hline \multicolumn{1}{c}{ Characteristic } & $n$ & Percentage \\
\hline Breast cancer side & & \\
$\quad$ Dominant & 2 & 20 \\
$\quad$ Non-dominant & 8 & 80 \\
& & \\
Breast cancer type & & \\
ER $^{\mathrm{a}} \&$ PR ${ }^{\mathrm{b}}$ positive & 4 & 40 \\
HER-2 ${ }^{\mathrm{c}}$ negative & & \\
ER \& PR positive & 2 & 20 \\
HER-2 positive & & \\
triple negative & 4 & 40 \\
& & \\
Breast cancer stage & & \\
Stage I & 2 & 20 \\
Stage II & 7 & 70 \\
Stage III & 1 & 10
\end{tabular}

Tumor size

$\begin{array}{lll}<1 \mathrm{~cm} & 1 & 10 \\ 1-2 \mathrm{~cm} & 6 & 60 \\ 2-3 \mathrm{~cm} & 2 & 20 \\ >3 \mathrm{~cm} & 1 & 10\end{array}$

Breast surgery

Lumpectomy $\quad 70$

Mastectomy 30

Hormone therapy

Yes $\quad 7 \quad 70$

$\begin{array}{lll}\text { No } & 3 & 30\end{array}$

Type of chemotherapy

$\begin{array}{lll}\text { CTSU }^{\text {d }} & 1 & 10 \\ \text { Cytoxan } & 7 & 70 \\ \text { Adriamycin } & 5 & 50 \\ \text { Carboplatin } & 1 & 10 \\ \text { Herceptin } & 1 & 10 \\ \text { Taxol } & 4 & 40 \\ \text { Taxotere } & 6 & 60\end{array}$

${ }^{\mathrm{a}}$ Estrogen ${ }^{\mathrm{b}}$ Progesterone ${ }^{\mathrm{c}}$ Human epidermal factor receptor ${ }^{\mathrm{d}}$ National Cancer Institute Clinical trial, number S1007 
A significant difference in the number of co-morbidities and medications was not found among these women except for Participant 12, who had six conditions and took 10 medications (see Table 3). All of the women had sentinel lymph node dissection except for Participant 07 who had an axillary lymph node dissection, involving the removal of 19 axillary lymph nodes. Half of the participants did not have positive lymph nodes, and the other half had one to six positive lymph nodes.

Table 3

Medical History Characteristics

\begin{tabular}{lllll}
\hline \multicolumn{1}{c}{ Characteristic } & \multicolumn{1}{c}{ Range } & Mode & $S D$ \\
\hline Co-morbidities & 2.6 & $0-6$ & 3 & 1.69 \\
Past surgeries & 1.8 & $0-4$ & 2 & 1.25 \\
Medications & 5.10 & $1-10$ & $1,5,8$ & 2.84 \\
$\begin{array}{l}\text { Number of lymph } \\
\text { nodes removed }\end{array}$ & 5.0 & $1-19$ & 4 & 4.92 \\
$\begin{array}{l}\text { Number of positive } \\
\text { lymph nodes }\end{array}$ & 1.08 & $0-3$ & & \\
\hline
\end{tabular}

All of the women were working prior to their cancer diagnosis (see Table 4), except for one who was retired. The majority of these women were working full time (70\%). The women working full time were employed as a librarian, post office supervisor, nurse, order processor, optician, hospice certified nursing attendant (CNA), and in-home daycare provider, and those working part time were a daycare provider and odd-job worker. Once treatment started, two of the women who were working full time went on medical leave. One of these two women's employer gave her the choice of continuing to work full time, but had to meet productivity expectations, or go on medical leave. She elected to go on medical leave. The other woman chose to go on medical leave. Three of the women's employment ended during treatment. Two of these women 
worked in daycare, and the other woman had multiple odd jobs. The women who moved from full-time work to part-time work were the post office manager and the optician. Both of their employers were flexible with their hours and allowed time off. The remaining two women continued to work full time as an oncology nurse and medical librarian. Similar to the part-time employees, their employers were flexible with their hours and supportive of their need to take days off.

Six months after radiation was completed, all of the women who completed the study returned to work, except for the woman who was retired prior to diagnosis. The post office supervisor increased her hours to greater than 40 hours per week, and the process operator resumed working full time and began an additional part-time job as a housekeeper in the school system. The nurse, optician, and librarian continued to work between 30 to 40 hours per week. One of the daycare providers who was unemployed during treatment found work within a restaurant and church daycare for less than 30 hours per week. The hospice CNA returned to working 24 hours a week and provided care for her teenage daughter's newborn baby. Two of the 10 participants did not complete the forth visit, therefore, their employment status was unknown. 
Table 4

Employment Prior, During, and 6 Months Post Radiation Therapy

\begin{tabular}{|c|c|c|c|c|c|c|}
\hline \multirow[b]{2}{*}{ Characteristic } & \multicolumn{2}{|c|}{ Prior } & \multicolumn{2}{|c|}{ During } & \multicolumn{2}{|c|}{6 months } \\
\hline & $n$ & Percentage & $n$ & Percentage & $n$ & Percentage \\
\hline Unemployed & 0 & 0 & 3 & 30 & 0 & 0 \\
\hline Medical Leave & 0 & 0 & 2 & 20 & 0 & 0 \\
\hline Retired & 1 & 10 & 1 & 10 & 1 & 12.5 \\
\hline$<30$ hours/week. & 2 & 20 & 2 & 20 & 2 & 25 \\
\hline $40 \geq 30$ hours/ week. & 6 & 60 & 2 & 20 & 3 & 37.5 \\
\hline$>40$ hours /week. & 1 & 10 & 0 & 0 & 2 & 25 \\
\hline
\end{tabular}

\section{Data Display}

\section{Qualitative.}

Last week of radiation therapy. The model (see Figure 1) displayed below provides a visual representation of the relationship among the superordinate and emergent themes of the women's experiences during treatment, which influenced their ability to participate in important activities. As the women progressed through their treatments, many of them developed strategies to continue important activities and reduce personal stress. "I figured out a way to adapt it. . . W We have a magnet that picks up screws." "I can play my music and get relaxed and go into work and I'm fine."

When women could not participate in an activity, many would discuss how they would be able to return to the activity when their treatment side effects were gone. "I hope that I can start doing a little bit of strength training at home and more walking and um when I stop hurting.” Other women were participating or planning to participate in early-detection breast cancer activities. "I have talked to them and you know uh. You are in your forties, now and never had a mammogram go get one." One woman planned to teach teenage drug abuse prevention due to her son's recent death, "I have a problem 
with the way they teach drugs. . . . They tell these kids that it's not fun [pause] to get drunk and in reality its funny as crap, it's the consequences that's not funny." A few women planned to return to school, "I enrolled in the Ashford University for Healthcare Business Administration."

Some women described positive lifestyle changes that they were going to make to prevent the return of cancer. "I try to eat more vegetables and raw vegetables and stuff like that." "My husband bought me a treadmill so some days when I feel good I'll get on that but hopefully when this is over with I'll be able to get on it every day."

All of the women received emotional and/or physical support through telephone conversations, visitations, preparation of meals, running errands, and a variety of other forms. When the women were experiencing treatment side effects, important activities were completed either by others or by the women who received support from family and friends. "A lot of people have to be 'adjusted' so they don't give me those type of patients but if they do everybody comes to help out." "That's been a big change especially when I first started chemo. I still wanted to get up and do everything that I normally did but you know I just physically could not so that was a change them saying 'mom sit down we got it."'

Treatment side effects and fear of infection limited participation in important activities for many of the women. "I was having ... dry eye syndrome with the chemotherapy.... I just have to read shorter periods of time, be on the computer shorter periods of time." "I've not really gone out to many public places where there would be a large concentration of people." 
Most of the women struggled simultaneously with personal stresses, such as death of family members, separation from a spouse, dying relative, working, and caring for dependents and/or disabled relatives along with their cancer diagnosis and treatment side effects. Women who experienced significant personal loss and stress seemed less influenced by the cancer diagnosis and side effects than the other women were. "It hurt me worse with Brandy [pause] than with cancer [pause] and Robert, and I know that he was saved and I would love to have him back."

None of the women who experienced separation from a spouse or death of a child made any statements that discussed how their side effects limited their important activities. However, one of these women illustrated how personal stress touched her relationship, "When I want to be left alone. I don't want to snuggle if I'm crying. I don't want a hug. I want to cry. I want to be mad. I want to be [pause] handling it on my own." 


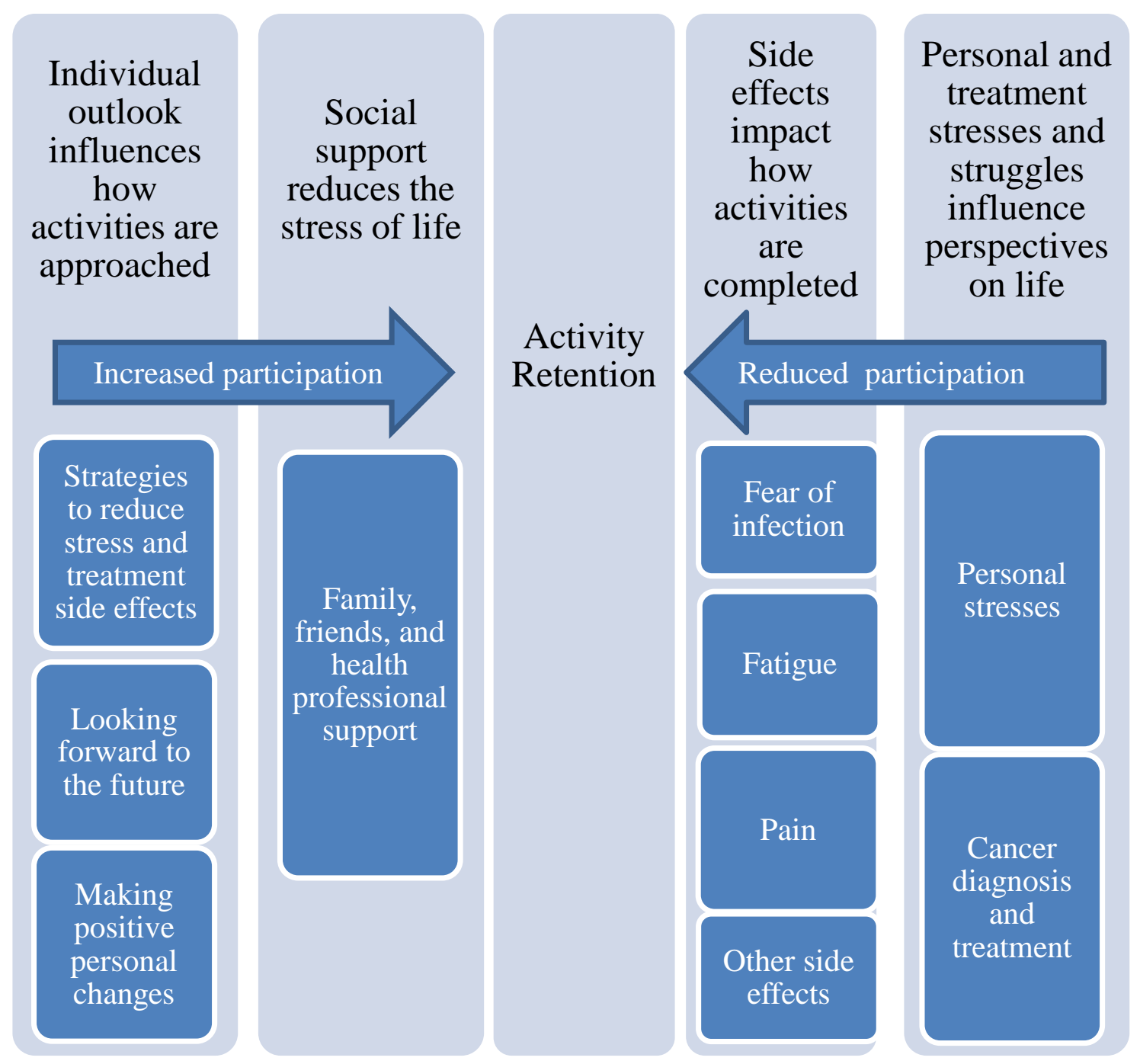

Figure 1. Superordinate and emergent themes related to activity retention during the last week of radiation therapy

Six months post radiation therapy. The model (see Figure 2) displayed below provides a visual representation of the relationship among the superordinate and emergent themes of the women's experiences during treatment, which influenced their ability to participate in important activities. As the women recovered from their treatments, many of them gained an appreciation for their life, work, and family. "I'm not worrying about what happens tomorrow and um just glad to be alive." "I think that we both come to feel like we need to celebrate more and travel more and have good 
times, spend more money . . cause you don't know." "Work has been great. I haven't missed any more days out of work . . I haven't been as tired while I'm at work."

Unlike during treatment, women discussed the process of slowly returning to some of their activities that they could not participate in during treatment due to side effects, specifically fatigue. "I'm getting more energy, not an abundance of it . . . I was able to cut my grass, it took a lot of energy. . . I'm getting back into it." However, the concern that the cancer may have returned led to one participant to revert to her previous lifestyle. "After they told me that about [cancer] had spread I didn't make any more juice. I was like I'm not bothering with any of that stuff I'm just going to eat whatever I want and don't worry about it because there is nothing I can do."

Other women were participating in community activities or planning to continue their education. "Me and my sister got a community center opened up over there in the neighborhood.... got a class going Mommy and Me class going and a Bible study class going so that's where I'm going every day of the week and it's been going great." "I think eventually they're going to require that all the nurses have their bachelor's degree in nursing, and I want to make sure I have that before they make it mandatory.”

Many of the women described positive lifestyle changes as a means to prevent the return of cancer. "Trying to stay away from greasy foods ... trying to do everything to avoid this from coming back." "I did Weight Watchers and I've lost 30 or 35 pounds... . I see no limits only the limitations I place upon myself." "I hated [emphasis added] weights but now I'm beginning to love weights and you know put them into my exercise because I feel like I need that." 
Most women provided examples of returning to doing instrumental and social activities. "I clean those rooms mostly, so it's not a lot of cleaning up, just sweeping and dusting and wash a couple dishes and I clean my bathroom every day." "We went to Hawaii in February for two weeks then to Chicago for a meeting, then we went to San Francisco for a meeting, so yea we've traveled a bunch." "I've gone to a concert so just being out more socially."

Many of the women felt like they have changed since their diagnosis and treatment. "Me going through treatments have made me stronger. I won't say I can do anything but I'm not afraid to try new things. Like I signed up for swimming lessons to try to get over my fear of deep water, and my instructor says that I'm doing great." "I can say my emotions are a whole lot you know stronger than they were before. I'm very emotional." "Well they can see a difference in me too, even my kids they see a more happier me now." 


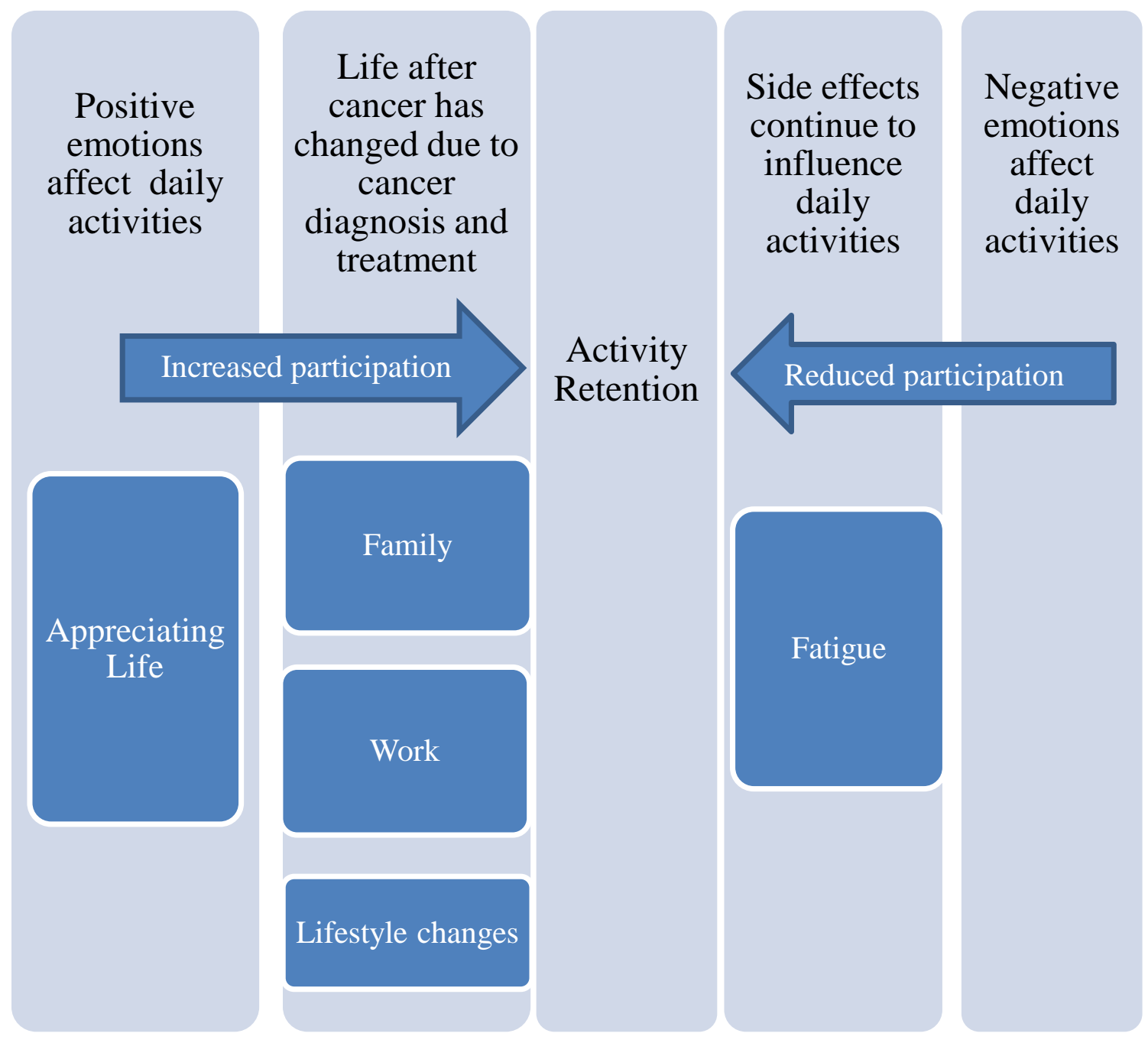

Figure 2. Superordinate and emergent themes related to activity retention at 6 months post radiation

Quantitative. Instrumental activities did not change significantly from the first week to the last week of radiation therapy. The majority of women experienced the greatest proportion of activity resumption between the end of radiation therapy and 3 months post radiation. Half of the women experienced a reduction in their participation in instrumental activities at 6 months post radiation (see Figure 3). 


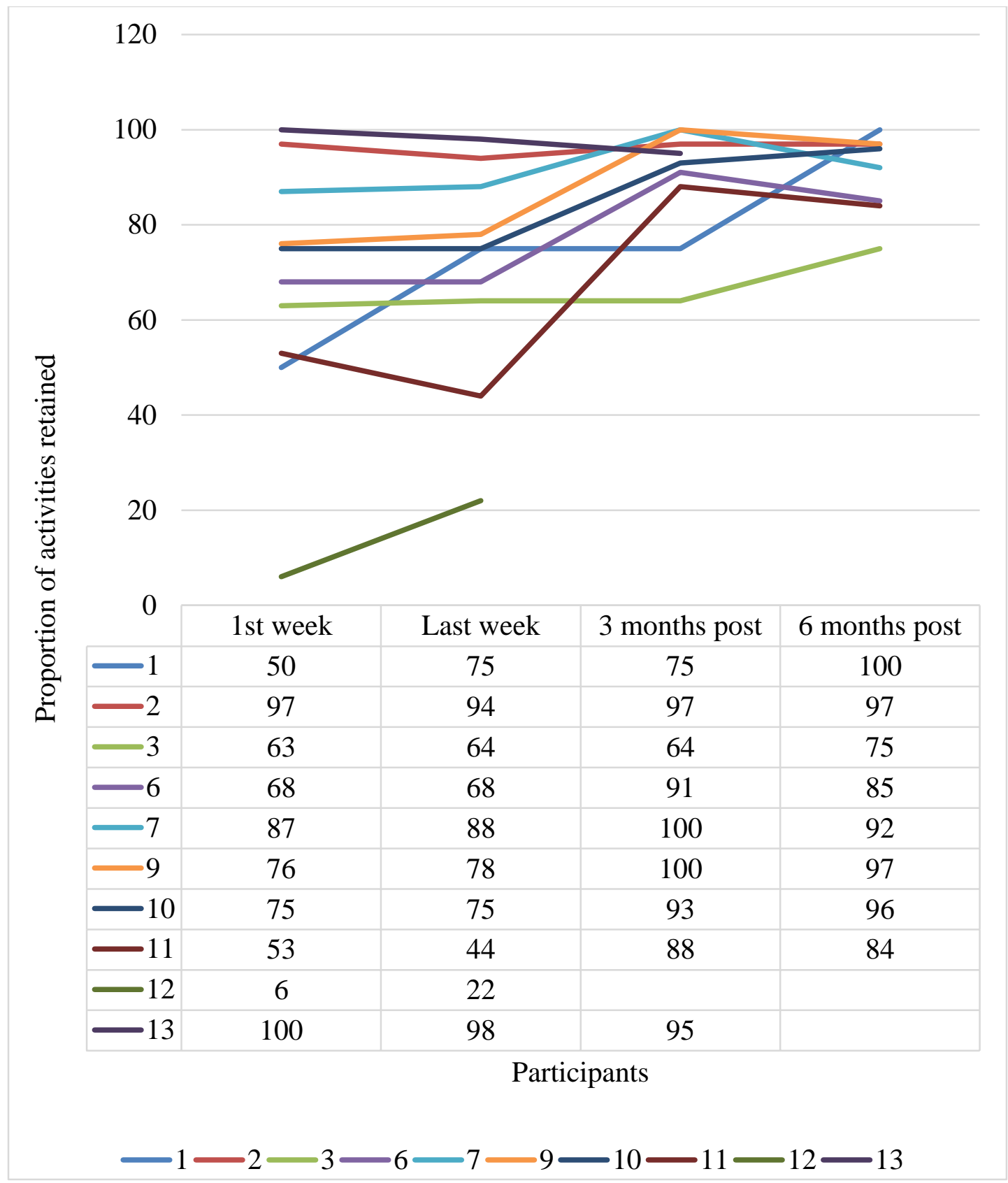

Figure 3. Instrumental Activity Card Sort-modified scoring system score summary

Four of the 10 women reduced their participation in low-demand leisure activities during radiation therapy. Six women increased their participation in low-demand leisure activities at 3 months post radiation therapy, and one maintained it at 100\%. Participant 13 had acquired many new low-demand leisure activities (141\%) during radiation, which decreased at 3 months post radiation (95\%). By 6 months post radiation therapy, all of 
the women either increased their low-demand leisure activities or declined minimally (see Figure 4).

\begin{tabular}{|r|r|r|r|r|}
\hline & 160 & & & \\
\hline
\end{tabular}

Figure 4. Low-demand Leisure Activity Card Sort-modified scoring system score summary

All but three women experienced a reduction in their participation in high-

demand leisure activities during radiation therapy. These three women had regularly exercised prior to cancer diagnosis, and two of them had listed exercise as a priority for them. However, all of the women were participating in more high-demand leisure activities at 3 months post radiation compared to the last week of radiation therapy. At 6 
months post radiation therapy, the majority of women participated in more high-demand leisure activities, except for three women. One of these women was working one fulltime and a part-time job, another was working part time but was also caring for her teenage daughter's new born baby, and the last woman was undergoing further tests for a possible cancer reoccurrence (see Figure 5).

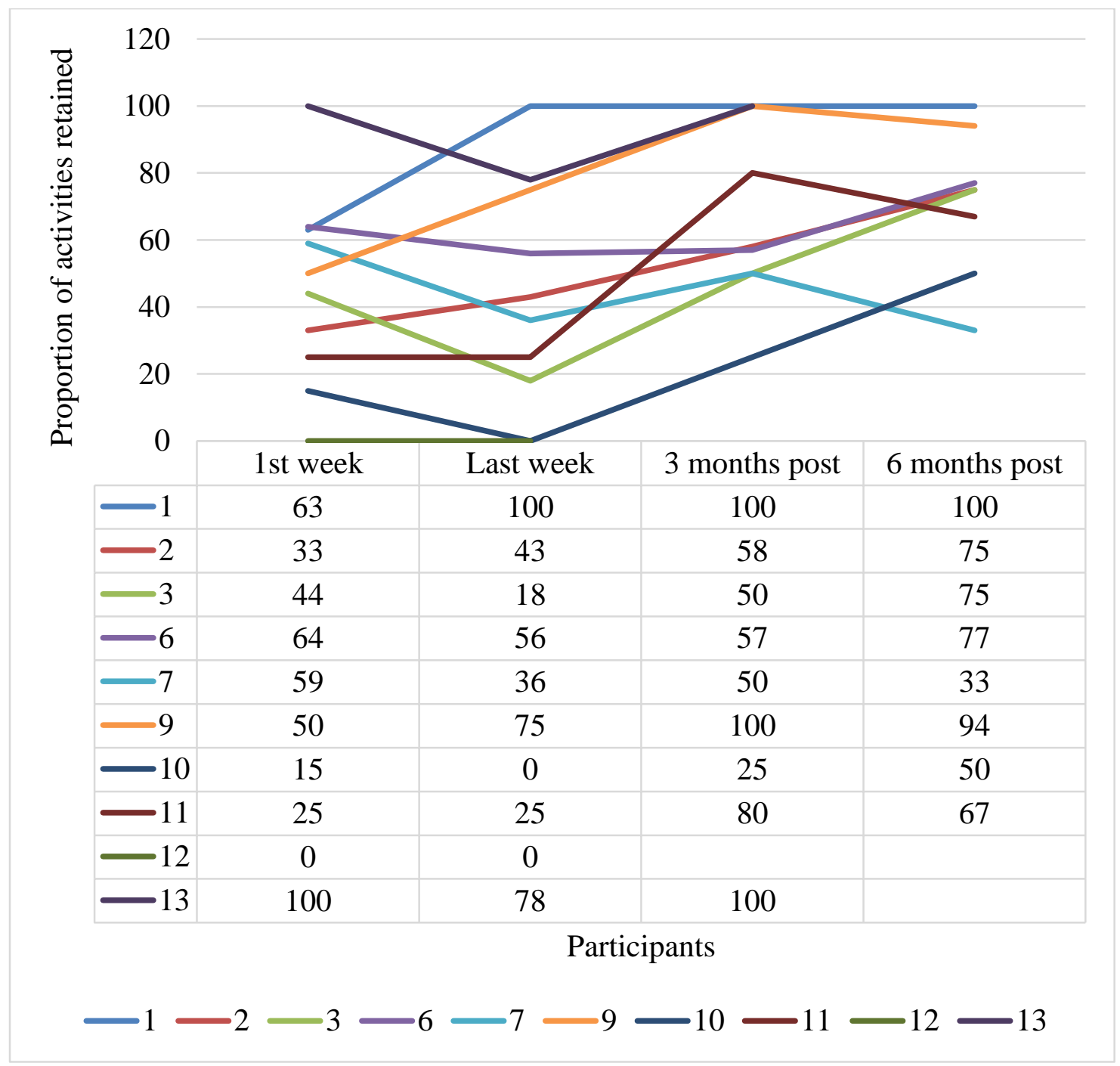

Figure 5. High-demand Leisure Activity Card Sort-modified scoring system score summary

Eight of the 10 women experienced a reduction or no change in their social activities during radiation therapy. The two women who did not experience a reduction 
in their social activities after radiation therapy may have been less social at the beginning of radiation therapy due to fatigue from medical complications experienced during chemotherapy therapy. One of the 10 women had not resumed any of her social activities after chemotherapy nor radiation therapy. She had experienced significant pain and fatigue and seemed to be depressed. At 3 months post radiation therapy, all the women had experienced an improvement in their social activities, except for two women. One had returned to working a couple of part-time jobs, and the other was managing multiple social issues. At 6 months post radiation, half of the women had either increased or maintained their social activities, and the other half had reduced these activities (see Figure 6). 


\section{0}

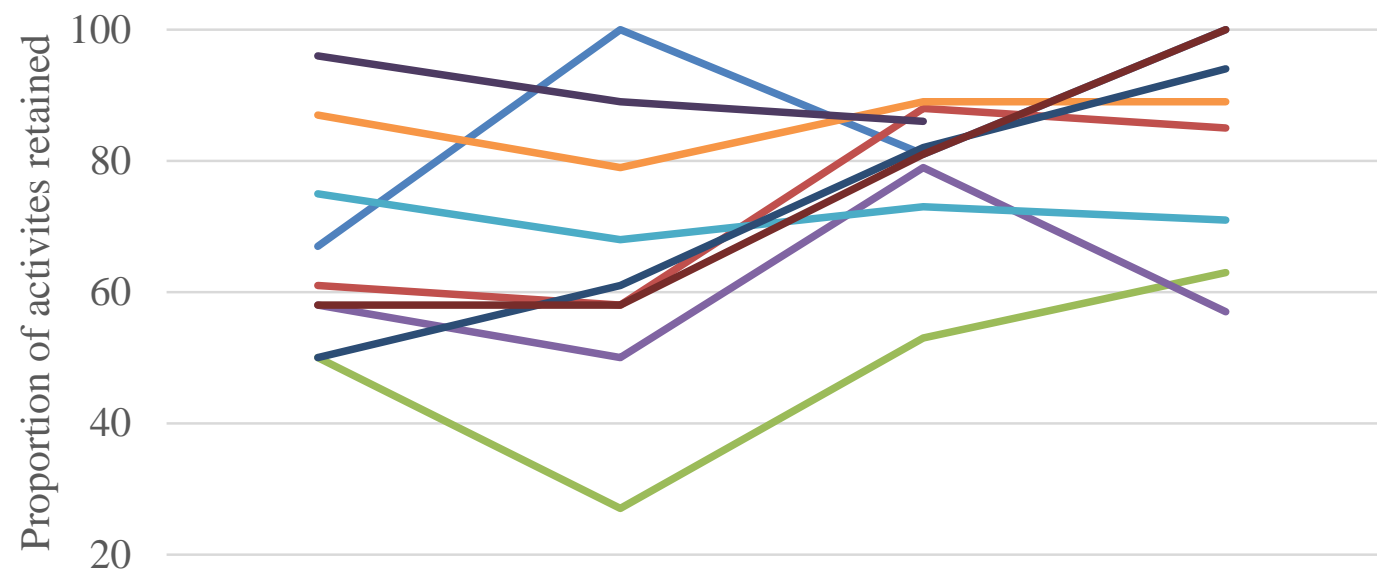

\begin{tabular}{|c|c|c|c|c|}
\cline { 2 - 5 } \multicolumn{1}{r|}{} & 1st week & Last week & 3 months post & 6 months post \\
\hline-1 & 67 & 100 & 81 & 100 \\
\hline-2 & 61 & 58 & 88 & 85 \\
\hline-3 & 50 & 27 & 53 & 63 \\
\hline-6 & 58 & 50 & 79 & 57 \\
\hline-7 & 75 & 68 & 73 & 71 \\
\hline-9 & 87 & 79 & 89 & 89 \\
\hline-10 & 50 & 61 & 82 & 94 \\
\hline-11 & 58 & 58 & 81 & 100 \\
\hline-12 & 0 & 0 & & \\
\hline-13 & 96 & 89 & 86 & \\
\hline
\end{tabular}

Participants

$$
-1-2-3-6-7-9-10-11-12-13
$$

Figure 6. Social Activity Card Sort-modified scoring system score summary

Most of the women had retained more of their low-demand leisure activities compared to any of the other activity categories at the beginning of radiation therapy. Proportion of activities retained for each activity category did not change significantly during radiation therapy, except low-demand leisure activities, which decreased. Activity resumption increased incrementally in each category at 3 months and 6months post 
radiation therapy (see Figure 7).

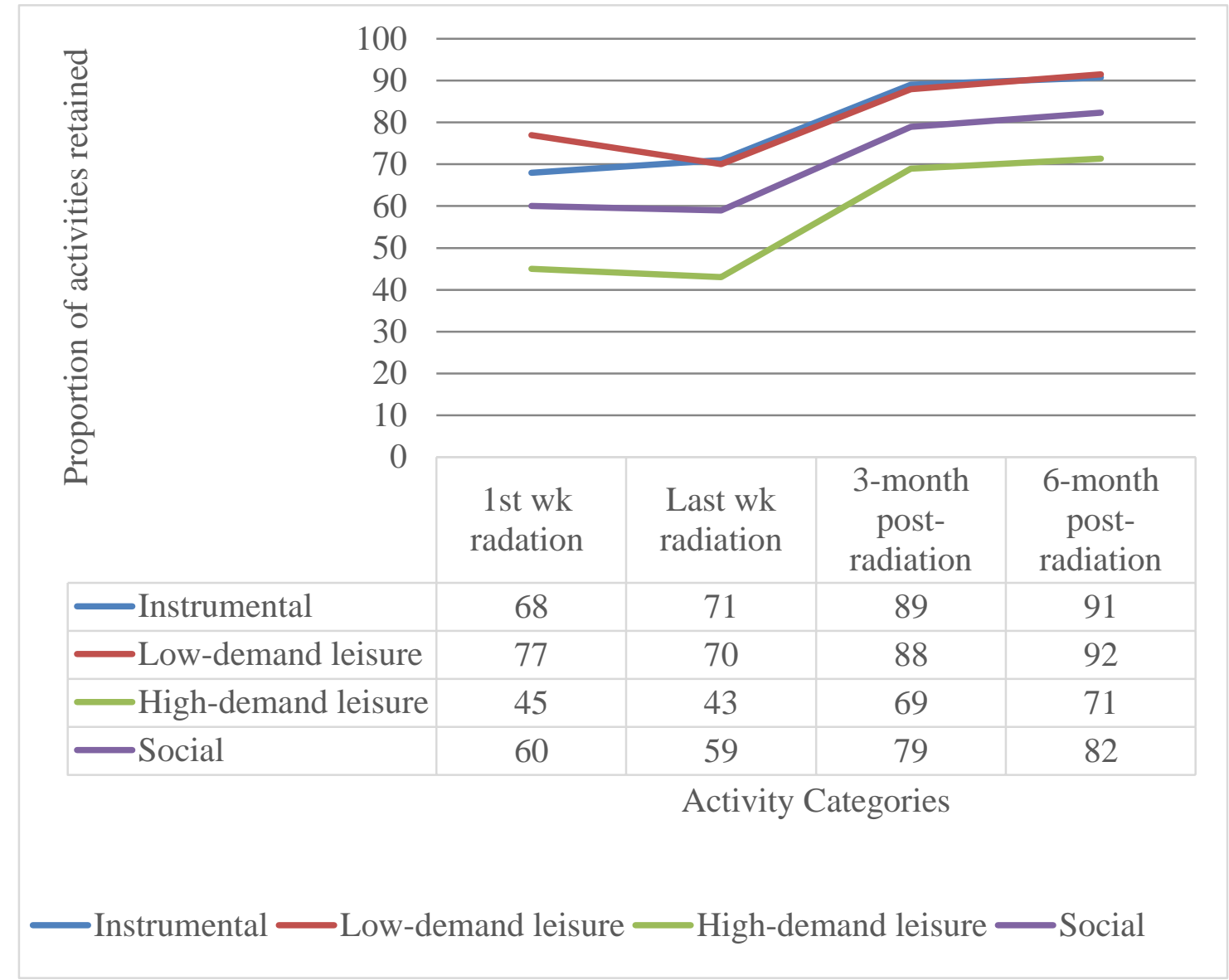

Figure 7. Mean proportion of activity retention for each category by time period At each time point, participants consistently listed about $75 \%$ of their important activities as both instrumental or social activities and the remaining $25 \%$ as either low-or high-demand leisure activities. During the first week of radiation therapy and 3 months post radiation, women listed more instrumental activities followed by social activities as being important. This finding was reversed during the last week of radiation therapy and 6 months post radiation. The level of importance for resuming more versus less physical leisure activities varied. High-demand leisure activities were listed as the third most important category at the beginning of radiation therapy and 6 months post radiation therapy. At the end of radiation therapy, women listed a similar number of low-demand 
and high-demand leisure activities as being important. Low-demand leisure activities were listed more often than high-demand leisure at 3 months post radiation (see Figure 8 and Table 5).

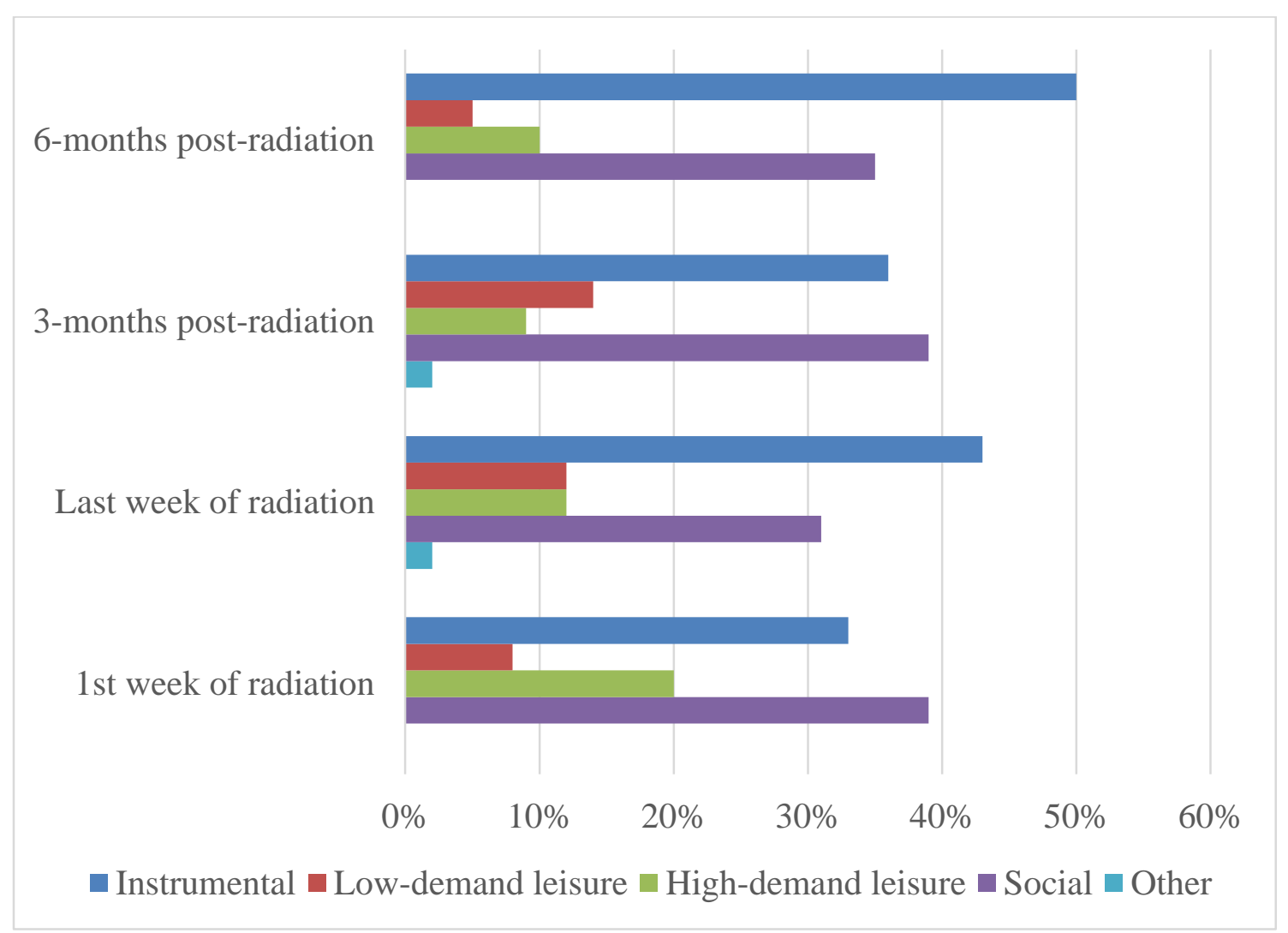

Figure 8. Proportion of important activities within each activity category at each time period 
Table 5

List of Important Activities by Category and Time Period

\begin{tabular}{|c|c|c|c|c|}
\hline Category & $1^{\text {st }}$ week & Last week & 3 months & 6 months \\
\hline Instrumental & $\begin{array}{l}\text { Work x6 } \\
\text { Childcare x4 } \\
\text { Maintain home } \\
\text { x3 } \\
\text { Maintain } \\
\text { relationships x2 } \\
\text { Cook vegetarian } \\
\text { Become } \\
\text { healthier } \\
\text { Manage } \\
\text { finances } \\
\text { Care for family }\end{array}$ & $\begin{array}{l}\text { Family x6 } \\
\text { Work x5 } \\
\text { Maintain home } \\
\text { x5 } \\
\text { Cook x2 } \\
\text { Care for family } \\
\text { x2 } \\
\text { Manage } \\
\text { finances x2 } \\
\text { Shop } \\
\text { Eat right } \\
\text { Stay cancer free } \\
\text { Take care of } \\
\text { pets } \\
\text { Rest }\end{array}$ & $\begin{array}{l}\text { Work x6 } \\
\text { Maintain home } \\
\text { x2 } \\
\text { Maintain } \\
\text { relationship } \\
\text { with husband } \\
\text { x2 } \\
\text { Cook } \\
\text { Manage } \\
\text { finances } \\
\text { Support } \\
\text { children's } \\
\text { education } \\
\text { Stay healthy } \\
\text { Shop } \\
\text { Care for family } \\
\text { Go to MD } \\
\text { visits }\end{array}$ & $\begin{array}{l}\text { Work x5 } \\
\text { Maintain home } \\
\text { x3 } \\
\text { Cook x3 } \\
\text { Care for } \\
\text { children x2 } \\
\text { Independence } \\
\text { Maintain car } \\
\text { Pay bills } \\
\text { Shop } \\
\text { Relax at home } \\
\text { Care for home } \\
\text { and family }\end{array}$ \\
\hline $\begin{array}{l}\text { Low- } \\
\text { demand } \\
\text { leisure }\end{array}$ & $\begin{array}{l}\text { Read x2 } \\
\text { Listen to music } \\
\text { Quilt and sew }\end{array}$ & $\begin{array}{l}\text { Read x4 } \\
\text { Quilt x2 }\end{array}$ & $\begin{array}{l}\text { Read x2 } \\
\text { Quilt, sew and } \\
\text { other hobbies } \\
\text { x2 } \\
\text { Play with dog } \\
\text { Watch TV }\end{array}$ & $\begin{array}{l}\text { Quilt } \\
\text { Read }\end{array}$ \\
\hline $\begin{array}{l}\text { High- } \\
\text { demand } \\
\text { leisure }\end{array}$ & $\begin{array}{l}\text { Exercise x5 } \\
\text { Walk x3 } \\
\text { Yard work x2 } \\
\text { Outdoor } \\
\text { activities, } \\
\text { Sports, dance }\end{array}$ & $\begin{array}{l}\text { Exercise } \mathrm{x} 4 \\
\text { Camp } \\
\text { Dance }\end{array}$ & $\begin{array}{l}\text { Exercise x } 3 \\
\text { Yard work }\end{array}$ & $\begin{array}{l}\text { Exercise x3 } \\
\text { Yard work }\end{array}$ \\
\hline
\end{tabular}




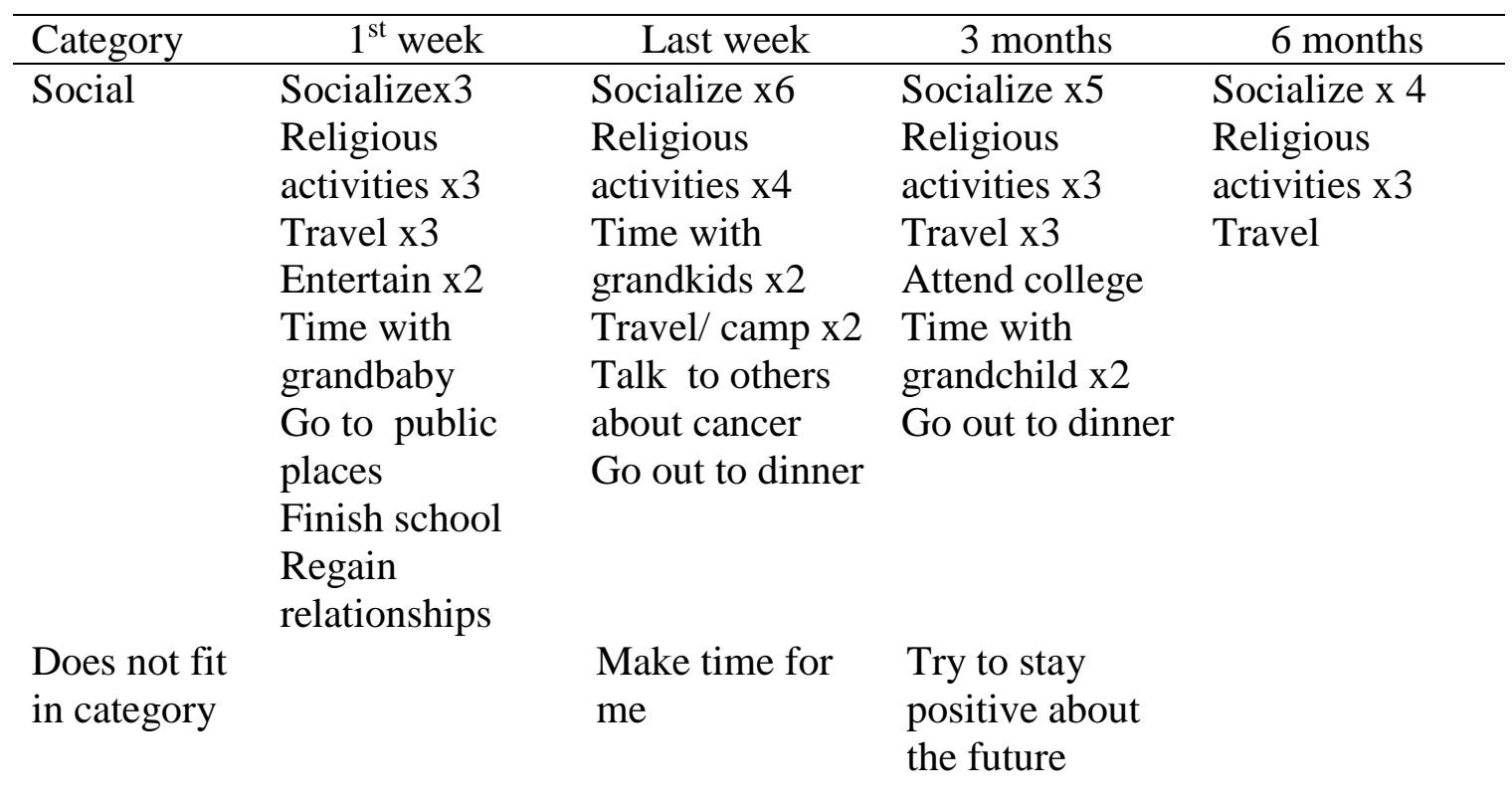

\section{Data Transformation and Comparison}

\section{Last week of radiation therapy.}

Instrumental. All the women described how treatment side effects reduced their ability to complete these activities (see Table 6). Fatigue reduced or changed the ability to provide childcare, complete housework, and return to work. Fear of infection, neuropathies, and muscle weakness led to adapting the work environment. Diminished smell necessitated the use of timers to prevent food from burning. Axillary seroma prevented the ability to complete overhead tasks for one participant. Peripheral neuropathies impaired gripping and manipulating objects.

Two participants retained less than $71 \%$ of their instrumental activity level after radiation. Participant 11 may have had less time to complete instrumental activities because she traveled 80 miles each day to and from radiation therapy and accompanied her pregnant teenage daughter to her doctor appointments. Participant 12 experienced significantly more pain and neuropathies than the other women, which significantly reduced her mobility, overhead reaching, and grasping. 
Additionally, Participant 12 described only one strategy to compensate for her impairments. "I got this little strainer like you can cook spaghetti [laughs] so I reach up and try to knock things down. And if anything fall on the floor kind of big I can't squat down ... I have to get the broom handle or the pink stick they gave me for the exercise and try to get it up." Participant 11 did not describe any strategies to retain her ability to complete any instrumental activities. Both Participant 11 and 12 appeared to have unique emotional struggles. Participant 11 had a teenage daughter who was pregnant and Participant 12's friends apparently abandoned her after her diagnosis. Participant 11 described returning to work, "I'm really [emphasis added] ready to go back to work. I really [emphasis added] miss that because I love love, love my job" and making positive lifestyle changes, "Not eating fried foods, sweets, and white bread stuff like that." Both participants relinquished many of their instrumental activities to family, "It's been very, very hard. Um, I would say my family does $90 \%$ of the cooking and cleaning and everything," and "Bob will wash the clothes, he cooks and he makes sure that I take my medicine." 
Table 6

Above and Below $71 \%$ Retention of Instrumental Activities by Superordinate Themes

\begin{tabular}{|c|c|c|}
\hline $\begin{array}{c}\text { Superordinate } \\
\text { Theme }\end{array}$ & $\begin{array}{c}\text { Instrumental } \\
<71 \%\end{array}$ & $\begin{array}{c}\text { Instrumental } \\
>71 \%\end{array}$ \\
\hline $\begin{array}{l}\text { Side effects } \\
\text { impact how } \\
\text { activities are } \\
\text { completed }\end{array}$ & $\begin{array}{l}12 \text { "I had got this seroma on my } \\
\text { left arm after they took out my } \\
\text { lymph nodes... now I can't raise } \\
\text { that arm up like to reach over my } \\
\text { head... if I really had to do my } \\
\text { hair I couldn't." }\end{array}$ & $\begin{array}{l}10 \text { "When my white counts were } \\
\text { low . . I could wear mask and the } \\
\text { patients didn't seem to mind. } \\
\text { They understood because they } \\
\text { knew what I was going through." }\end{array}$ \\
\hline & $\begin{array}{l}12 \text { "I don't have any feelings in } \\
\text { [my fingers], they call that } \\
\text { neuropathy, and it's hard for me } \\
\text { to to grip things and try to open } \\
\text { or turn bottles or anything. }\end{array}$ & $\begin{array}{l}01 \text { "Radiation is when I really } \\
\text { really started back trying to cook. } \\
\text { During chemo I did not do } \\
\text { anything...that most of the time I } \\
\text { just ate no I mean slept." }\end{array}$ \\
\hline $\begin{array}{l}\text { Personal and } \\
\text { treatment } \\
\text { stresses and } \\
\text { struggles } \\
\text { influence } \\
\text { daily life }\end{array}$ & $\begin{array}{l}11 \text { "I take [teenager daughter] to } \\
\text { her doctor appointments . . . tried } \\
\text { to get everything the baby . . . } \\
\text { going to be another burden [big } \\
\text { sigh]." } \\
12 \text { "I was in shock. I mean I was } \\
\text { just numb. The day they had told } \\
\text { me [my cancer diagnosis].... I } \\
\text { don't even know how I made it } \\
\text { back home [laughs]." }\end{array}$ & $\begin{array}{l}01 \text { "...I am not like going around } \\
\text { in the kitchen a lot by it being } \\
\text { open up like that I try not to be } \\
\text { around no kind of food you know } \\
\text { around my kids and stuff. And uh } \\
\text { I am trying to get through the } \\
\text { stress part out where I don't like I } \\
\text { said do a lot of crying..." } \\
06 \text { "I haven't been able to work } \\
\text { like overtime ... it helped out a } \\
\text { lot in paying things like college } \\
\text { and going on trips and stuff like } \\
\text { that." }\end{array}$ \\
\hline
\end{tabular}

(continued) 


\begin{tabular}{|c|c|c|}
\hline $\begin{array}{c}\text { Superordinate } \\
\text { Theme }\end{array}$ & $\begin{array}{c}\text { Instrumental } \\
<71 \%\end{array}$ & $\begin{array}{c}\text { Instrumental } \\
>71 \%\end{array}$ \\
\hline $\begin{array}{l}\text { Individual } \\
\text { outlook } \\
\text { influences } \\
\text { how activities } \\
\text { are } \\
\text { approached }\end{array}$ & $\begin{array}{l}11 \text { "I'd like to get healthy and be } \\
\text { able to see my grandbaby } \\
\text { graduate .. . not have to go } \\
\text { through this again." } \\
11 \text { "I'm really [emphasis added] } \\
\text { ready to go back to work ... } \\
\text { once I get back to work I think } \\
\text { everything else will fall into } \\
\text { place, you know I'll start feeling } \\
\text { better and things will be the new } \\
\text { norm once I go back to work." } \\
12 \text { "I can't reach up in the } \\
\text { cabinets ... I got this little } \\
\text { strainer like you can cook } \\
\text { spaghetti [laughs] so I reach up } \\
\text { and try to knock things down. . . } \\
\text {. I have to get the broom handle } \\
\text { or the pink stick they gave me for } \\
\text { the exercise and try to get it up." }\end{array}$ & $\begin{array}{l}09 \text { "Try to do more try to focus } \\
\text { more on eating right and more so } \\
\text { than eating to live." } \\
13 \text { "I guess I got tired of being a } \\
\text { victim [pause] and you know } \\
\text { decided you know "you can do } \\
\text { more than [pay my bills]."' } \\
06 \text { "I'll be glad to get back to } \\
\text { myself again you know like ... or } \\
\text { doing little things around the } \\
\text { house, doing yard work." } \\
10 \text { "I'm an optician and that was a } \\
\text { little tricky with handling } \\
\text { screwdrivers and tiny screws and } \\
\text { repairs ... I figured out a way to } \\
\text { adapt it ... . we have a magnet that } \\
\text { picks up screws." } \\
06 \text { "If I can't get up those } 14 \text { steps } \\
\text { you know I felt like I'm too tired } \\
\text { to go into work } 12 \text { hours so that } \\
\text { was the gage." }\end{array}$ \\
\hline $\begin{array}{l}\text { Social } \\
\text { support } \\
\text { reduces the } \\
\text { stress of life }\end{array}$ & $\begin{array}{l}11 \text { "Um previously I took care of } \\
\text { everything most of the cooking, } \\
\text { cleaning and everything um but } \\
\text { they do most of it now . . . For a } \\
\text { long time they wouldn't even let } \\
\text { me drive." }\end{array}$ & $\begin{array}{l}02 \text { "we cover each other's shifts at } \\
\text { the reference desk . . . so when I } \\
\text { felt healthy I do my share and } \\
\text { when I don't somebody else } \\
\text { does." } \\
06 \text { "in the yard, yard work my } \\
\text { uncle is there and comes over to } \\
\text { do it for me so I don't have to do } \\
\text { that (laugh) which is good." }\end{array}$ \\
\hline
\end{tabular}


Low-demand leisure. Peripheral neuropathy, fatigue, dry eye syndrome, and reduced attention were the side effects described that decreased the women's ability to quilt and read. Personal and treatment stresses did not seem to influence participation in low-demand leisure activities. Only one participant discussed how she would continue a low-demand leisure activity, journaling, after her treatments ended. Many of the women prayed, read educational information about their treatments, and listened to music to reduce the stress of treatments and its side effects (see Table 7).

Table 7

Above and Below 70\% Retention of Low-Demand Leisure Activities by Superordinate Themes

\begin{tabular}{|c|c|c|}
\hline $\begin{array}{c}\text { Superordinate } \\
\text { Theme }\end{array}$ & $\begin{array}{c}\text { Low-demand leisure } \\
<70 \%\end{array}$ & $\begin{array}{l}\text { Low-demand leisure } \\
>70 \%\end{array}$ \\
\hline $\begin{array}{l}\text { Side effects } \\
\text { impact how } \\
\text { activities are } \\
\text { completed }\end{array}$ & $\begin{array}{l}12 \text { "And I can't focus to read } \\
\text { [emphasis added]. Then words } \\
\text { get blurry cause the chemo } \\
\text { messes with your vision too so } \\
\text { you can't focus. . . Well for } \\
\text { me my attention span it kinda } \\
\text { gets lost with stuff fast." } \\
12 \text { "I couldn't focus on it ... } \\
\text { my mind wasn't even on it. I } \\
\text { could be looking at television } \\
\text { and I couldn't have told you } \\
\text { what I just saw [laughs].” }\end{array}$ & $\begin{array}{l}02 \text { "I was having a lot of dry eye } \\
\text { syndrome with the chemotherapy } \\
\text { and it is finally resolving on its } \\
\text { own. . . I I can read for longer } \\
\text { periods of time." } \\
09 \text { "I actually think I read less } \\
\text { [emphasis added] during that time } \\
\text { because I couldn't focus you know } \\
\text { for about a } 4 \text { or } 5 \text { month period ... } \\
\text { it was like everything I read } \\
\text { seemed like somebody had cancer. } \\
\text { I was like I can't even read a book } \\
\text { (laughter)." }\end{array}$ \\
\hline $\begin{array}{l}\text { Personal and } \\
\text { treatment } \\
\text { stresses and } \\
\text { struggles } \\
\text { influence daily } \\
\text { life }\end{array}$ & & $\begin{array}{l}10 \text { "It beats on the internet surfing } \\
\text { and find out all the bad things, yes } \\
\text { it does ... . Look on the internet for } \\
\text { information but don't believe } \\
\text { [emphasis added] everything you } \\
\text { read on there. . . Look for } \\
\text { information specific to you." }\end{array}$ \\
\hline
\end{tabular}




\begin{tabular}{|c|c|c|}
\hline $\begin{array}{l}\text { Superordinate } \\
\text { Theme }\end{array}$ & $\begin{array}{c}\text { Low-demand leisure } \\
<70 \%\end{array}$ & $\begin{array}{c}\text { Low-demand leisure } \\
>70 \%\end{array}$ \\
\hline \multirow[t]{2}{*}{$\begin{array}{l}\text { Individual } \\
\text { outlook } \\
\text { influences how } \\
\text { activities are } \\
\text { approached }\end{array}$} & $\begin{array}{l}01 \text { "I got closer and closer to } \\
\text { God, you know praying and } \\
\text { going in reading certain } \\
\text { scriptures in the Bible to make } \\
\text { me feel good, you know uh ... } \\
\text { now I do most of the reading } \\
\text { alone." }\end{array}$ & $\begin{array}{l}10 \text { "I'm sure I will. I'm sure I'll } \\
\text { keep [my journal] for a long time } \\
\text { because it's a long journey... This is } \\
\text { new. I've never done that before. } \\
\text { Don't know really why I felt } \\
\text { compelled until she told me about } \\
\text { that. I just felt like it'd be a good } \\
\text { idea to remember..." }\end{array}$ \\
\hline & $\begin{array}{l}03 \text { "I did look up some things } \\
\text { [on the internet] and it can be } \\
\text { overwhelming ... I would read } \\
\text { stuff and then I would have to } \\
\text { go back and get clarity ... . and } \\
\text { just asking questions of the } \\
\text { healthcare providers." }\end{array}$ & $\begin{array}{l}10 \text { "I picked up a magazine from } \\
\text { the American Cancer Society, the } \\
\text { TLC for the hats and that is where I } \\
\text { got several hats. . . That was } \\
\text { probably the best thing is picking } \\
\text { up information from here." }\end{array}$ \\
\hline \multirow[t]{2}{*}{$\begin{array}{l}\text { Social support } \\
\text { reduces the } \\
\text { stress of life }\end{array}$} & & $\begin{array}{l}10 \text { "then [my husband] had went } \\
\text { on Amazon and ordered the breast } \\
\text { cancer husband book and read it } \\
\text { from cover to cover." }\end{array}$ \\
\hline & & $\begin{array}{l}11 \text { "every single [emphasis added] } \\
\text { morning at } 6: 30 \text { I get a prayer over } \\
\text { my phone. . . Every morning I get } \\
\text { that text and I've got it since I was } \\
\text { diagnosed" }\end{array}$ \\
\hline
\end{tabular}

High-demand leisure. Fatigue and fear of infection limited the women's ability to participate in high-demand leisure activities, such as exercise, gardening, hunting, and camping. None of the women indicated that personal stresses or struggles influenced their ability to complete these activities. Only the women who had retained less than $43 \%$ of their high-demand leisure activity level looked toward the future when they could exercise and dance. "I am hoping that I can start doing a little bit of strength training at home and more walking and um when I stop hurting I can go to the beginner Yoga classes even a week from now if I feel okay." "I'm gonna be a brand new granny again so and I got to be able to do the 2-step ... I got a goal, a goal.” Only one participant 
indicated that she walked regularly with a friend who provided emotional support to her.

"I get to talk to her and tell her how I feel about this and crying on her shoulder ... she

has really gotten a lot more closer to me" (see Table 8).

Table 8

Above and Below $43 \%$ Retention of High-Demand Leisure Activities by Superordinate

Themes

Superordinate High-demand leisure High-demand leisure

Theme $<43 \% \quad>43 \%$

Side effects impact

how activities are

completed

\begin{abstract}
10 "we're a very active family and being outdoors. Camping, outdoors, cooking out, and it's been hard to to kinda bring it all down in the house. It's been hard."

02 "have not been allowed to swim by my doctors ... for the uh threat of infection and now by the radiation people."
\end{abstract}

09 "I haven't been able to do much exercise, that's kind of hard [emphasis added] for me . . . I was so tired and I was like 'what is wrong with me?' 'I am tired' ... As more time went by the less [emphasis added] steps I got in so every week I said I really [emphasis added] got to get more done."
Personal and treatment stresses and struggles influence daily life

Individual outlook influences how activities are approached
03 "the time that I would normally come for treatment I will get up and walk because it's not too warm."

11 "I'm going to make [exercise] a priority [emphasis added]after this ... I think that will give me more energy and help me sleep, help with depression."

02 "I am hope that I can start doing a little bit of strength training at home."
Individual outlook influences how activities are approached 


\begin{tabular}{|c|c|c|}
\hline $\begin{array}{l}\text { Superordinate } \\
\text { Theme }\end{array}$ & $\begin{array}{c}\text { High-demand leisure } \\
<43 \%\end{array}$ & $\begin{array}{l}\text { High-demand leisure } \\
>43 \%\end{array}$ \\
\hline $\begin{array}{l}\text { Social support reduces } \\
\text { the stress of life }\end{array}$ & & $\begin{array}{l}01 \text { "I have ... my best friend in } \\
\text { the whole wide world; we have } \\
\text { been friends for over } 30 \text { years. . } \\
\text {. She will come and get me... } \\
\text { I get to talk to her and tell her } \\
\text { how I feel about this and crying } \\
\text { on her shoulder." }\end{array}$ \\
\hline
\end{tabular}

Social. Fear of infection was the primary reason women did not socialize when receiving their treatment, and fatigue was second. For one woman who had retained less than $59 \%$ of her social activity level, her friends expected her to be the same, "Cause you know they want me to be back to the same as I was before this happened and I'm not that same girl no more." Another woman who retained less than 59\% of her social activity level, her daughter avoided her, "I told her that 'I noticed that she wasn't around more. Is it because I'm sick?' and she was like 'no' ... I was like 'we haven't hung out at all since all of this and we need to hang out more.' . . Now after that talk she's been home more."

Most women who were participating at $59 \%$ or less than their previous social activity level looked toward the future when they will be able to go out dancing, entertain friends and family, travel, and return to school. Those who were participating at greater than $59 \%$ of their social activity level were participating in new social activities. One woman was educating women about completing self-breast exam and obtaining mammograms, "I have talked to them and showed them how they showed me so, it's been an experience, me teaching others what I went through.” Another woman began organizing family social events, "We are communicating more and keeping up with each other, and ya know, finding ways to spend time together." Only the women who had retained greater than $59 \%$ social activity level were socializing to reduce stress by talking 
to friends or professionals, visiting with family to distract themselves from the pain, organizing visitations to avoid fatigue or infection, and associating with "positive" people to reduce emotional stress.

All the women received social support from others by talking on the phone, "probably have done more talking on the phone, too, which I'm not a big phone person but I've done more of that," visiting others, "Yea everybody comes by the house. I am the center of everybody, which is fine, I don't care," texting messages, "Every single [emphasis added] morning at 6:30 I get a prayer over my phone," and talking with other breast cancer patients, "I'm gonna tell ya, I get my socializing on here at the hospital [laughs]. Because, you're dealing with people who know what you're going through."

Table 9

Above and Below 59\% Retention of Social Activities by Superordinate Themes

\begin{tabular}{lll}
$\begin{array}{c}\text { Superordinate } \\
\text { Theme }\end{array}$ & \multicolumn{1}{c}{$\begin{array}{c}\text { Social } \\
<59 \%\end{array}$} & \multicolumn{1}{c}{$\begin{array}{c}\text { Social } \\
>59 \%\end{array}$} \\
\hline $\begin{array}{l}\text { Side effects } \\
\text { impact how } \\
\text { activities are } \\
\text { completed }\end{array}$ & $\begin{array}{l}\text { 06 "when someone would come } \\
\text { over with a cold it was awful }\end{array}$ & $\begin{array}{l}07 \text { "The first part of chemo I } \\
\text { really couldn't even get up and go } \\
\text { to church cause I was so tired and } \\
\text { drained and sick." }\end{array}$ \\
& $\begin{array}{ll}\text { 12 "people act like they can catch } \\
\text { it so your friends don't come } \\
\text { around as much as they used to." }\end{array}$ & $\begin{array}{l}10 \text { "we don't do a lot of traveling } \\
\text { or eating out because you don't } \\
\text { want to get exposed to germs ... } \\
\end{array}$ \\
& & so we eat in."
\end{tabular}

Personal and 12 "Cause you know they want treatment me to be back to the same Linda stresses and as I was before this happened and struggles I'm not that same girl no more." influence daily life 


\begin{tabular}{|c|c|c|}
\hline $\begin{array}{c}\text { Superordinate } \\
\text { Theme }\end{array}$ & $\begin{array}{l}\text { Social } \\
<59 \%\end{array}$ & $\begin{array}{l}\text { Social } \\
>59 \%\end{array}$ \\
\hline \multirow[t]{3}{*}{$\begin{array}{l}\text { Individual } \\
\text { outlook } \\
\text { influences } \\
\text { how activities } \\
\text { are } \\
\text { approached }\end{array}$} & $\begin{array}{l}03 \text { "When he's out of school ... } \\
\text { we'll run to the beach a few days } \\
\text { on my days off. ....We'll go to the } \\
\text { zoo." }\end{array}$ & $\begin{array}{l}01 \text { "all of my sisters ... had } \\
\text { mammograms and a whole lot of } \\
\text { my friends ... I have talked to } \\
\text { them and showed them how they } \\
\text { showed me." }\end{array}$ \\
\hline & $\begin{array}{l}12 \text { "I would go over [to my } \\
\text { friend's home] ... I miss that ... } \\
\text { and going to the beach." }\end{array}$ & $\begin{array}{l}07 \text { "I haven't been around much } \\
\text { negativity. . . . People have been } \\
\text { positive." }\end{array}$ \\
\hline & $\begin{array}{l}02 \text { "I was allowed one healthy } \\
\text { person at a time. I would ask } \\
\text { people to email me ... I would } \\
\text { [tell them they could] . . . come } \\
\text { over or you know I'm not feeling } \\
\text { real good right now." }\end{array}$ & \\
\hline \multirow[t]{2}{*}{$\begin{array}{l}\text { Social } \\
\text { support } \\
\text { reduces the } \\
\text { stress of life }\end{array}$} & $\begin{array}{l}06 \text { "Yea everybody comes by the } \\
\text { house. I am the center of } \\
\text { everybody . . I'm usually hardly } \\
\text { ever by myself ever." }\end{array}$ & $\begin{array}{l}01 \text { "I spend most of my time on } \\
\text { the phone now as opposed to } \\
\text { before." }\end{array}$ \\
\hline & $\begin{array}{l}12 \text { "Well I'm gonna tell ya, I get } \\
\text { my socializing on here at the } \\
\text { hospital . . . that's about the only } \\
\text { socializing I get cause right now." }\end{array}$ & $\begin{array}{l}07 \text { "We would go out to eat, they } \\
\text { would come over to the house, we } \\
\text { sit and talk. I would go over to } \\
\text { their house sit and talk." }\end{array}$ \\
\hline
\end{tabular}

\section{Six months post radiation therapy.}

Instrumental. Participant 02 and Participant 09 have respectively experienced a cancer reoccurrence or the possibility of a cancer reoccurrence that has created fear for both of them in their daily life. "When you are getting ready to go to bed . . I focused on [the cancer] more often." Unlike during treatment, side effects were not the focus of these women. However, for those who had not regained greater than $91 \%$ of their instrumental activities, side effects continued to influence their daily life. "Write that down so I don't forget it" and "I absolutely [emphasis added] take more naps." For those who overcame their side effects, they expressed relief. "I got my taste buds and 
everything back. That's been going pretty well." "I have gotten to where I can pick [the tiny screws] up so I know it's getting better."

Some women expressed how the diagnosis and treatment of cancer influenced their perspective on daily life. "I love [emphasis added] it. I never appreciated work as much." "You better enjoy every minute that you can enjoy with her [grandchild] and don't complain because you could not even be here to see her." "Grateful for, you know, being able to do the things."

Most of the women returned to work and completed daily activities. "I got back to . . cooking and sitting down, having conversations." "I mean I ended up getting detailed to a high level position, I'm working about 60 hours a week.” Participant 11 struggled with work because of her additional responsibilities. "But um that has been I think that [work] has been harder because I've had to care for her [grandchild] on top of going back to work."

Lifestyle changes, including diet and exercise, were in the center of these women's minds as a way to prevent reoccurrence. "The dietician lady, she set me up. ... I don't have to use a lot of grease. ... Trying to do everything to avoid this from coming back." "of course stay on top of my health, um exercising, I did Weight Watchers and I've lost 30 or 35 pounds." "I decided that I really need to focus on vegetables for a good 6-8 weeks and just kind of focus on that." 
Table 10

Above and Below $91 \%$ Retention of Instrumental Activities by Superordinate Themes

\begin{tabular}{|c|c|c|}
\hline $\begin{array}{c}\text { Superordinate } \\
\text { Theme }\end{array}$ & $\begin{array}{c}\text { Instrumental } \\
<91 \%\end{array}$ & $\begin{array}{c}\text { Instrumental } \\
>91 \%\end{array}$ \\
\hline \multirow[t]{3}{*}{$\begin{array}{l}\text { Emotional } \\
\text { effect on } \\
\text { activities }\end{array}$} & & $\begin{array}{l}02 \text { "I'm sure it has taken a lot out } \\
\text { of [her spouse]. . . . He doesn't } \\
\text { tell me." }\end{array}$ \\
\hline & & $\begin{array}{l}09 \text { "When you are getting ready } \\
\text { to go to bed. . . I I focused on that } \\
\text { [cancer] ... Those words were } \\
\text { just like in my mind ... 'hot } \\
\text { spots.", }\end{array}$ \\
\hline & & $\begin{array}{l}09 \text { "before [CT scan] I was like I } \\
\text { really need to eat everything I } \\
\text { think I might like ... I said "this } \\
\text { is the only comfort." }\end{array}$ \\
\hline
\end{tabular}

Side effects $\quad 06$ "I'm getting more energy to continue to do more things which is great ... influence daily Clean out my car, wash my car." activities

Life after cancer has changed due to cancer diagnosis and treatment
06 "write that down right now so you don't forget it ... that's helped a lot it really has."

03 "Grateful for being here, grateful for you know being able to do the things. ... I was able to keep going."

06 "I feel like [my children] are transitioning into being adults without me having to guide them."

11 "But um that has been I think that [work] has been harder because I've had to care for her [grandchild] on top of going back to work."
07 "I got my taste buds and everything back."

10 "Um, I still use tweezers to pick up tiny screws [due to neuropathy] but I have gotten to where I can pick them up so I know it's getting better."

09 "you better enjoy every minute that you can enjoy with her [grandchild] and don't complain because you could not even be here to see her."

09 "'I really got to get to Whole Foods' ... I decided that I really need to focus on vegetables for a good 6-8 weeks and just kind of focus on that and I don't eat meat but maybe 3 times a week."

10 "I love [emphasis added] it. I never appreciated work as much." 
Low-demand leisure. Low-demand leisure activities, such as reading, created positive emotional states. "I like the suspense or the romance [novels] better because there is nothing really negative there for me to focus on" or improve understanding of personal feelings, "I just read an article that cancer survivors are more subject to anxiety than they are to depression and I think I understand that." Participant 07 who reports greater emotions during religious services also experienced the murder of a daughter and recent divorce. For Participant 10, one of her CT scans indicated a possible reoccurrence, "If you're doing nothing, you will focus on [cancer] ... but if you're busy and you're doing something else ... you don't really think about it."

Similar to instrumental activities, side effects did limit these women from completing low-demand leisure activities. Participant 07 did not want to shop for clothes until she "stopped" gaining weight from her anti-estrogen medication, and Participant 09 who is an avid reader was frustrated by her reduced memory. "I cannot believe I can't remember half as well as I used to ... I was reading ... my memory has really gotten bad." 
Table 11

Above and Below 92\% Retention of Low-Demand Leisure Activities by Superordinate Themes

\begin{tabular}{|c|c|c|}
\hline $\begin{array}{c}\text { Superordinate } \\
\text { Theme }\end{array}$ & $\begin{array}{c}\text { Low-demand leisure } \\
<92 \%\end{array}$ & $\begin{array}{l}\text { Low-demand leisure } \\
>>92 \%\end{array}$ \\
\hline $\begin{array}{l}\text { Emotional } \\
\text { effects on } \\
\text { activities }\end{array}$ & $\begin{array}{l}07 \text { "I've been getting you know } \\
\text { getting in the "word.' I can say } \\
\text { my emotions are a whole lot } \\
\text { you know stronger than they } \\
\text { were before." }\end{array}$ & $\begin{array}{l}02 \text { "I just read an article that } \\
\text { cancer survivors are more subject } \\
\text { to anxiety than they are to } \\
\text { depression and I think I } \\
\text { understand that." } \\
09 \text { "I like the suspense or the } \\
\text { romance better because there is } \\
\text { nothing really negative there for } \\
\text { me to focus on." }\end{array}$ \\
\hline $\begin{array}{l}\text { Side effects } \\
\text { continue to } \\
\text { influence } \\
\text { daily activities }\end{array}$ & $\begin{array}{l}07 \text { "I haven't really shopped } \\
\text { that much. ... I think taking } \\
\text { that Tamoxifen I've been } \\
\text { gaining weight . . . I wasn't } \\
\text { going to do too much shopping } \\
\text { until I see what's going on with } \\
\text { the pill." }\end{array}$ & $\begin{array}{l}09 \text { "I cannot believe I can't } \\
\text { remember half as well as I used to } \\
\text {.. I I was reading my memory has } \\
\text { really gotten bad." }\end{array}$ \\
\hline $\begin{array}{l}\text { Life after } \\
\text { cancer has } \\
\text { changed due } \\
\text { to cancer } \\
\text { diagnosis and } \\
\text { treatment }\end{array}$ & $\begin{array}{l}03 \text { "I've still not really gone to } \\
\text { services but I'm more reflective } \\
\text { and I just I see things in a } \\
\text { different light . . I I may not go } \\
\text { every Sunday but it's important } \\
\text { to get that worshiping back in } \\
\text { there... . and getting back to my } \\
\text { roots." }\end{array}$ & $\begin{array}{l}01 \text { "I like scary movies though. } \\
\text { When the grandkids come over } \\
\text { we get down with popcorn and } \\
\text { we sit down and we look at the } \\
\text { scary movies." } \\
10 \text { "My older son got engaged } \\
\text { and he staged ... an engagement } \\
\text { and he had me hide in the woods } \\
\text { in camouflage and take pictures } \\
\text { because I do photography." }\end{array}$ \\
\hline
\end{tabular}

High-demand leisure. Emotions and side effects, other than fatigue, did not limit participation in high-demand leisure activities. "Now I am trying to get back to doing my yard work slowly... . I was able to cut my grass, it took a lot of energy . . Now I have to cut half the back." In fact, Participant 11 noted that she was experiencing less fatigue because she was more active. "I think just being more active [emphasis added] now that 
I've gone back to work. That's made a huge [emphasis added] difference because the more I do I feel like the more energy."

For those who had regained more than $71 \%$ of their high-demand activities reported regularly exercising. "I think adding strength training is one thing. . . Y Yoga classes when I can I'm not doing as much walking as I'd like to but some of that has been the weather." Compared to these women, the women who had retained less than a $71 \%$ of their high-demand activities did not report exercising. One of the women was working two jobs, another was retired and been concerned about a cancer reoccurrence, and the third woman was caring for a newborn grandchild. 
Table 12

Above and Below $71 \%$ Retention of High-Demand Leisure Activities by Superordinate Themes

\begin{tabular}{|c|c|c|}
\hline $\begin{array}{c}\text { Superordinate } \\
\text { Theme }\end{array}$ & $\begin{array}{l}\text { High-demand leisure } \\
<71 \%\end{array}$ & $\begin{array}{l}\text { High-demand leisure } \\
>71 \%\end{array}$ \\
\hline $\begin{array}{l}\text { Emotional } \\
\text { effects on } \\
\text { activities }\end{array}$ & & \\
\hline $\begin{array}{l}\text { Side effects } \\
\text { continue to } \\
\text { influence } \\
\text { daily } \\
\text { activities }\end{array}$ & & $\begin{array}{l}06 \text { "Now I am trying to get back } \\
\text { to doing my yard work slowly. . } \\
\text {. I was able to cut my grass, it } \\
\text { took a lot of energy. . . . now I } \\
\text { have to cut half the back." }\end{array}$ \\
\hline $\begin{array}{l}\text { Life after } \\
\text { cancer has } \\
\text { changed due } \\
\text { to cancer } \\
\text { diagnosis and } \\
\text { treatment }\end{array}$ & $\begin{array}{l}\text { 10." Um, I have a garden area } \\
\text { that I'm working on outside .... } \\
\text { My husband mows so I help him } \\
\text { mow some. I haven't gone back } \\
\text { to weed eating." } \\
11 \text { "Um well really just drinking } \\
\text { more water and I think just being } \\
\text { more active [emphasis added] } \\
\text { now that I've gone back to work. } \\
\text { That's made a huge [emphasis } \\
\text { added] difference." }\end{array}$ & $\begin{array}{l}02 \text { "I think adding strength } \\
\text { training is one thing. . . . Yoga } \\
\text { classes when I can I'm not doing } \\
\text { as much walking as I'd like." } \\
03 \text { "[Work] requires a lot of } \\
\text { walking but we have bikes and . . } \\
\text {. to promote my own healthiness I } \\
\text { prefer to ride the bike." } \\
06 \text { "I feel like I've been able to try } \\
\text { new things just things I want to } \\
\text { try. Like I want to go flying, } \\
\text { that's terrifying but I want to go." }\end{array}$ \\
\hline
\end{tabular}

Social. Emotionally, Participants 07 and 02 illustrated how their social support system was present and emotionally supportive. "Everybody that was around me ... try to keep me positive." "my closest girlfriends ... who after the fact ... told me how they cried when they would get off the phone with me."

Side effects were not affecting the women's ability to socialize; however, they talked about how their socializing improved as side effects disappeared. When the risk of infection was diminished after treatment, Participant 03 felt more comfortable socializing 
around groups of people. Participant 02 felt comfortable removing her wig when her family encouraged her, and she did not feel that she had a "marine crew cut."

Many women felt that it was important to plan events because they had a greater appreciation for the family and friends. Some women were more specific. "Always planning things. ... I'm supposed to be going to her mom's birthday celebration early next year." "[My sister is] planning on a trip to come down here for a whole month." Others were more general about what they were going to do in the future. "[My spouse and I have] come to feel like we need to celebrate more and travel more and have good times, spend more money." "I want to start doing more stuff for me because I do realize life is precious."

Other women were envisioning a future, which included self-improvement or community involvement. For instance, Participants 02 and 03 were making plans to improve themselves by advancing their education. "I wanted to take [a course] a couple years ago and at the time it didn't work out." "They're going to require that all the nurses have their bachelor's degree in nursing, and I want to make sure I have that." Participant 01 initiated her own community service project. "I'm doing that, too, and got a class going 'Mommy and Me' class going and a Bible study class going so that's where I'm going every day of the week." 
Table 13

Above and Below $82 \%$ Retention of Social Activities by Superordinate Themes

\begin{tabular}{|c|c|c|}
\hline $\begin{array}{c}\text { Superordinate } \\
\text { Theme }\end{array}$ & $\begin{array}{l}\text { Social } \\
<82 \%\end{array}$ & $\begin{array}{l}\text { Social } \\
>82 \%\end{array}$ \\
\hline $\begin{array}{l}\text { Emotional } \\
\text { effects on } \\
\text { activities }\end{array}$ & $\begin{array}{l}07 \text { "I did have my moments } \\
\text { where I was a little depressed } \\
\text { but I tried to pretty much stay } \\
\text { positive ... everybody that was } \\
\text { around me... try to keep me } \\
\text { positive." }\end{array}$ & $\begin{array}{l}02 \text { "I was a little surprised by } \\
\text { two of my closest girlfriends ... } \\
\text { who after the fact ... told me } \\
\text { how they cried when they would } \\
\text { get off the phone with me." } \\
02 \text { "I may email everybody now } \\
\text { and tell them the mammogram } \\
\text { was good, because it was kind of } \\
\text { something that I have been } \\
\text { waiting on." }\end{array}$ \\
\hline $\begin{array}{l}\text { Side effects } \\
\text { continue to } \\
\text { influence daily } \\
\text { activities }\end{array}$ & $\begin{array}{l}03 \text { "I've gone to a concert so just } \\
\text { being out more socially, just } \\
\text { doing things more socially. [I } \\
\text { didn't during treatment because } \\
\text { of the] risk of infection and just } \\
\text { during treatment tired." }\end{array}$ & $\begin{array}{l}02 \text { "my hair was long enough } \\
\text { that it didn't look too much like } \\
\text { a marine crew cut ... it was } \\
\text { very, very, very windy ... my } \\
\text { daughter and her boyfriend said } \\
\text { 'don't wear the wig."'" }\end{array}$ \\
\hline $\begin{array}{l}\text { Life after cancer } \\
\text { has changed due } \\
\text { to cancer } \\
\text { diagnosis and } \\
\text { treatment }\end{array}$ & $\begin{array}{l}03 \text { "[my friends and I are] } \\
\text { constantly talking . . . always } \\
\text { planning things. . . I'm } \\
\text { supposed to be going to her } \\
\text { mom's birthday celebration early } \\
\text { next year... . it's more like } \\
\text { sisters." }\end{array}$ & $\begin{array}{l}01 \text { "My oldest granddaughter } \\
\text { and oldest grandson come every } \\
\text { weekend. Ever since I've been } \\
\text { diagnosed with the breast cancer } \\
\text { last year." } \\
02 \text { "It's good to have a husband } \\
\text { or a significant other, not } \\
\text { everybody who goes through } \\
\text { this journey does and fortunately } \\
\text { I do." }\end{array}$ \\
\hline
\end{tabular}

\section{Data Integration}

Last week of radiation therapy. A comparison between Participant 09, who retained $78 \%$ of instrument, $100 \%$ of low-demand leisure, $75 \%$ of high-demand leisure and $79 \%$ of social activities at the end of radiation therapy, with Participant 12, who retained $22 \%$ of instrumental, $11 \%$ of low-demand leisure, and $0 \%$ of high-demand and social activities, was made. 
Using the PEOP model, Tables 14 and 15 compared these participants who were African-American women receiving treatment for Stage II breast cancer and lived within Winston-Salem, North Carolina. When comparing Participant 09 and 12, many dissimilarities emerged. Participant 12 has more co-morbidities (six vs. three), took more medications (10 vs. four), has a more aggressive cancer (triple negative vs. hormone positive and HER2 negative), more side effects (eight vs. one), and described activity participation within fewer environments (four vs. seven). Three of the four environments described by Participant 12 were within the medical center compared to Participant 09 who only described two of the seven environments. Participant 12 had a significant other who assisted her with personal care activities and completed household tasks. In contrast, Participant 09 is married and continued to complete most of her personal and household activities independently or with some assistance. Lack of support from friends was described by Participant 12, but not Participant 09. Participant 12 had more plans for activities she was going to do in the future (six vs. three) than Participant 09, and participant 12 used strategies (three) to manage the stress of cancer diagnosis and its treatment, which was not described by Participant 09. 
Table 14

Last Week of Radiation: Low versus High Activity Retention Organized by Person in the PEOP Model

$$
\text { Person }
$$

Intrinsic Factors

\begin{tabular}{|c|c|c|}
\hline \multirow[b]{2}{*}{ Characteristic } & \multicolumn{2}{|c|}{ Participant 12 versus Participant 09} \\
\hline & Low & High \\
\hline $\operatorname{ACSm} \bar{x}$ & $8 \%$ & $85 \%$ \\
\hline Ethnicity & African American & African American \\
\hline Age & 45 & 59 \\
\hline Marital status & Divorced & Married \\
\hline Education & High school & Bachelor's degree \\
\hline Working & Unemployed & Retired \\
\hline Dependents & none & one \\
\hline Side effects & $\begin{array}{l}\text { Axillary seroma } \\
\text { Reduced attention } \\
\text { Reduced ability to visually focus } \\
\text { Neuropathy } \\
\text { Shoulder restrictions } \\
\text { Pain } \\
\text { Stress }\end{array}$ & Reduced attention \\
\hline Cancer Type & Triple negative & $\begin{array}{l}\text { Hormone positive and HER-2 } \\
\text { negative }\end{array}$ \\
\hline $\begin{array}{l}\text { Cancer } \\
\text { Stage }\end{array}$ & Stage II & Stage II \\
\hline Treatment & $\begin{array}{l}\text { Lumpectomy Cytoxan, } \\
\text { Adriamycin and Taxol }\end{array}$ & $\begin{array}{l}\text { Lumpectomy Cytoxan and } \\
\text { CTSU }\end{array}$ \\
\hline $\begin{array}{l}\text { Co- } \\
\text { morbidities }\end{array}$ & 6 & 3 \\
\hline Medication & 10 & 4 \\
\hline
\end{tabular}




\begin{tabular}{|c|c|c|}
\hline \multicolumn{3}{|c|}{$\begin{array}{c}\text { Person } \\
\text { Intrinsic Factors }\end{array}$} \\
\hline \multirow[b]{2}{*}{ Characteristic } & \multicolumn{2}{|c|}{ Participant 12 versus Participant 09} \\
\hline & Low & High \\
\hline $\begin{array}{l}\text { Personal and } \\
\text { treatment } \\
\text { stresses and } \\
\text { struggles }\end{array}$ & $\begin{array}{l}\text { Cancer diagnosis } \\
\text { Anxiety } \\
\text { Depression }\end{array}$ & $\begin{array}{l}\text { Parenting stresses } \\
\text { Caring for chronically sick sister } \\
\text { Daughter's fear of her cancer } \\
\text { diagnosis } \\
\text { Reduced emotional support for a } \\
\text { sibling }\end{array}$ \\
\hline $\begin{array}{l}\text { Look toward } \\
\text { the future and } \\
\text { personal } \\
\text { changes }\end{array}$ & $\begin{array}{l}\text { Transform to a better person } \\
\text { Stay positive and incrementally } \\
\text { push herself } \\
\text { Look forward to cooking, dancing } \\
\text { and going to the beach } \\
\text { Plans to teach breast exam } \\
\text { Plans on returning to school }\end{array}$ & $\begin{array}{l}\text { Changing diet } \\
\text { Socializing with family more } \\
\text { Planning on doing what "should } \\
\text { be done" rather than what others } \\
\text { want done. }\end{array}$ \\
\hline $\begin{array}{l}\text { Strategies to } \\
\text { reduce stress } \\
\text { and treatment } \\
\text { side effects }\end{array}$ & $\begin{array}{l}\text { Praying and self-talk } \\
\text { Learn chemotherapy side effects } \\
\text { Adaptations to stoop and reach } \\
\text { for objects }\end{array}$ & \\
\hline
\end{tabular}


Table 15

Last Week of Radiation: Low versus High Activity Retention Organized by Environment in the PEOP Model

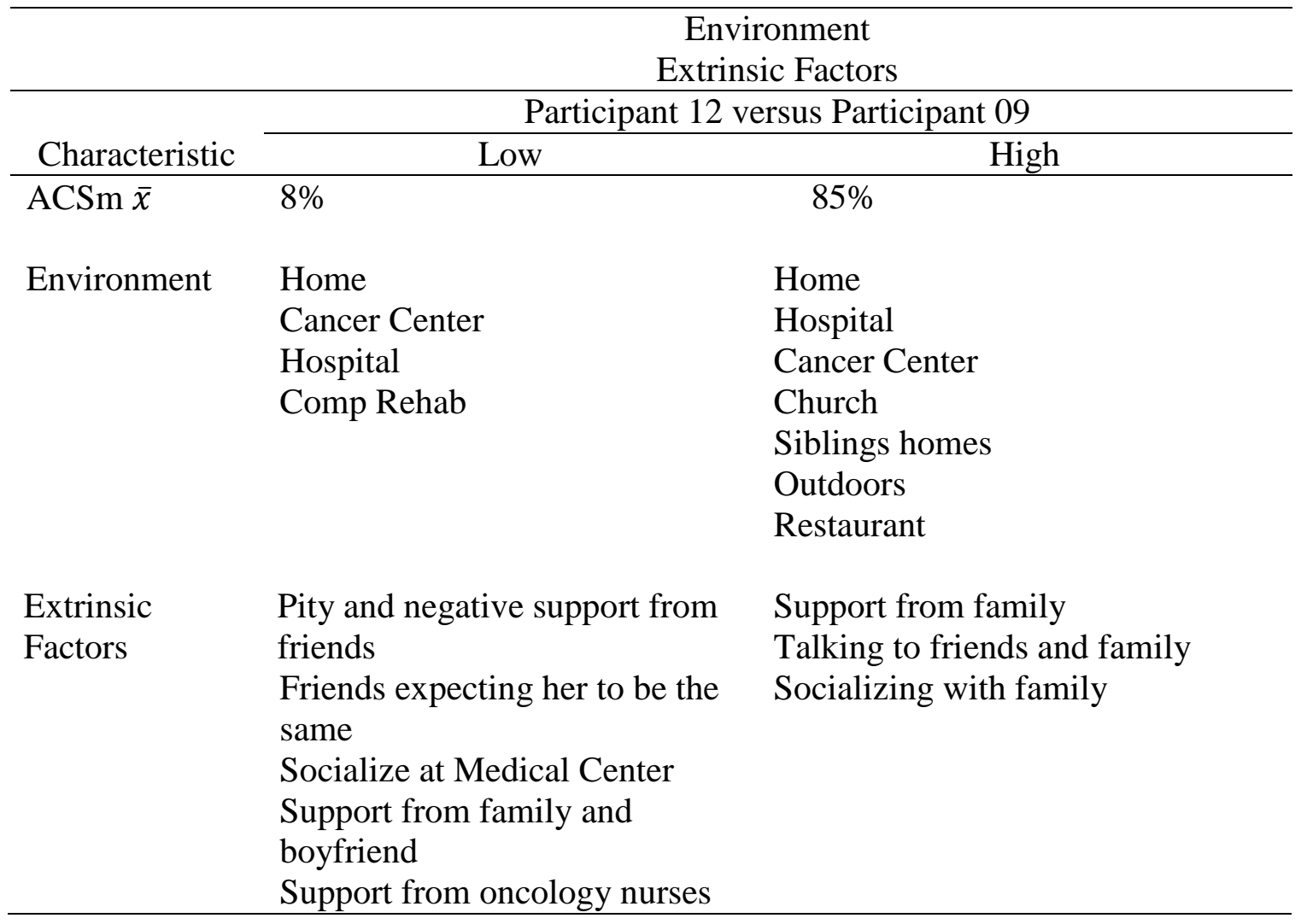

Six months post radiation therapy. Using the PEOP model, a comparison was made between Participant 01 and 03 (see Tables 16 and 17). Participant 01 retained $100 \%$ of instrument, low-demand leisure and high-demand leisure, and social activities, and Participant 03 retained $75 \%$ of instrumental, $78 \%$ of low-demand leisure and $75 \%$ of high-demand, and $63 \%$ of social activities.

These participants were single, African-American women who were treated for triple negative breast cancer, had lumpectomies, had the same number of co-morbidities, took a similar number of medications, and lived within Winston-Salem, North Carolina. When comparing Participant 03 with 01, a few dissimilarities emerged. Participant 03 had a more advanced cancer (Stage II vs. Stage I), recently had bilateral salpingo- 
oophorectomy, described participating in activities within fewer environments (five vs. 11), and had been working more hours (> 40 hours/week vs. $<30$ hours/week).

Participant 03 is a mother of a disabled son compared to Participant 01 who has adult children. Fatigue continued to limit Participant 03's ability to complete daily activities compared to Participant 01 who did not mention fatigue. However, Participant 01 continued to struggle emotionally with her breast cancer diagnosis, which was not described by Participant 03.

Table 16

Six Months Post Radiation: Low versus High Activity Retention Organized by Person in the PEOP Model Person Intrinsic Factors

\begin{tabular}{lll}
\hline \multirow{2}{*}{ Characteristic } & \multicolumn{2}{c}{ Participant 03 versus Participant 01 } \\
\cline { 2 - 3 } ACSm $\bar{x}$ & $73 \%$ & \multicolumn{1}{c}{ High } \\
\hline Ethnicity & African-American & \multicolumn{1}{c}{ African-American } \\
Age & 47 & 54 \\
Marital status & Single & Single \\
Education & Associate degree & High school \\
Work & Post office supervisor & Restaurant set-up and child care \\
pependents & Disabled son & none \\
Side effects & Mild fatigue & Fatigue \\
& & $\begin{array}{l}\text { Pain } \\
\text { Fear of infection }\end{array}$ \\
& & Lifting restrictions after surgery \\
Sancer Type & Triple negative & Stress \\
& & Triple negative
\end{tabular}




\begin{tabular}{|c|c|c|}
\hline \multicolumn{3}{|c|}{$\begin{array}{c}\text { Person } \\
\text { Intrinsic Factors }\end{array}$} \\
\hline \multirow[b]{2}{*}{ Characteristic } & \multicolumn{2}{|c|}{ Participant 03 versus Participant 01} \\
\hline & Low & High \\
\hline $\begin{array}{l}\text { Cancer } \\
\text { Stage }\end{array}$ & Stage II & Stage I \\
\hline Treatment & $\begin{array}{l}\text { Lumpectomy } \\
\text { Cytoxan } \\
\text { Adriamycin } \\
\text { Taxol }\end{array}$ & $\begin{array}{l}\text { Lumpectomy } \\
\text { Cytoxan } \\
\qquad \text { Taxotere }\end{array}$ \\
\hline $\begin{array}{l}\text { Co- } \\
\text { morbidities }\end{array}$ & 3 & 3 \\
\hline Medication & 6 & 5 \\
\hline $\begin{array}{l}\text { Emotions } \\
\text { affect } \\
\text { activities }\end{array}$ & $\begin{array}{l}\text { Wanting support only from close } \\
\text { friends } \\
\text { Grateful for her recovery, } \\
\text { including minimal side effects }\end{array}$ & $\begin{array}{l}\text { Fear of cancer returning } \\
\text { Thinking about cancer makes her } \\
\text { cry } \\
\text { Concerned about the influence of } \\
\text { chemotherapy on her body } \\
\text { Relief when she heard she was } \\
\text { cancer free } \\
\text { Happier since she recovered from } \\
\text { treatment }\end{array}$ \\
\hline $\begin{array}{l}\text { Life after } \\
\text { cancer has } \\
\text { changed due } \\
\text { to cancer } \\
\text { diagnosis and } \\
\text { treatment }\end{array}$ & Diet and exercise to lose weight & $\begin{array}{l}\text { Diet and exercise to lose weight } \\
\text { Reducing stress } \\
\text { Taking care of herself, a priority } \\
\text { Feeling happy }\end{array}$ \\
\hline
\end{tabular}


Table 17:

Six Months Post Radiation: Low versus High Activity Retention Organized by

Environment in the PEOP Model

Environment
Extrinsic Factors

\begin{tabular}{|c|c|c|}
\hline \multirow[b]{2}{*}{ Characteristic } & \multicolumn{2}{|c|}{ Participant 03 versus Participant 01} \\
\hline & Low & High \\
\hline $\operatorname{ACSm} \bar{x}$ & $73 \%$ & $100 \%$ \\
\hline Environment & $\begin{array}{l}\text { Work } \\
\text { Home } \\
\text { Parent's home } \\
\text { Stores } \\
\text { Concert }\end{array}$ & $\begin{array}{l}\text { Apartment complex } \\
\text { Park near home } \\
\text { Restaurant (work) } \\
\text { Church daycare (work) } \\
\text { Medical Center } \\
\text { Friends and family's home }\end{array}$ \\
\hline $\begin{array}{l}\text { Extrinsic } \\
\text { Factors }\end{array}$ & $\begin{array}{l}\text { Support from family } \\
\text { Support from friends and cancer } \\
\text { center staff } \\
\text { Children provide comfort } \\
\text { Regaining financial } \\
\text { independence }\end{array}$ & $\begin{array}{l}\text { Support from family } \\
\text { Spending time grandchildren }\end{array}$ \\
\hline
\end{tabular}

\section{Summary of Results}

These women incrementally regained their activitiy levels from the beginning of radiation therapy to 6 months after this treatment ended. Low-demand leisure activites were retained the greatest at the beginning of radiation therapy compared to the other areas, but was the only area to decrease during radiation therapy. Activity participation remained constant for the other activity areas during radiation therapy. At 3 months and 6 months post radiation therapy, women incrementally moved toward previous activity levels. The proportion of instrumental and social activities did not appear to be associated with women's interest in returning to these activities. These women consistently listed about $75 \%$ of their important activities as either instrumental and/or social activities and the remaining $25 \%$ as either low- or high-demand leisure activities at 
each time point. However, instrumental activities were consistently retained at a higher proportion at each time point compared to the other categories.

Fatigue and fear of infection, treatment side effects, and personal and treatment stresses and struggles seemed to reduce a woman's activity retention during radiation therapy. Fatigue continued to be a reason for reduced activity retention at 6 months post radiation therapy. However, the women's personal outlook, including strategies to reduce stress and treatment side effects, looking toward the future, and making personal changes, appeared to encourage activity retention during treatment. At 6 months post treatment, an appreciation for life, family and work, and a desire to make lifestyle changes seemed to positively influence activity participation. Although the women expressed gratitude for the support received from others during radiation therapy, support appeared to either reduce or encourage activity retention during treatment for these women. Current cancer status influenced the women's emotional state at 6 months post radiation, which appeared to either encourage or discourage participation in important activities, particularly activities related to lifestyle changes.

All of the women, except for the one who was retired, were working prior to their cancer diagnosis. The majority of these women were working full time (70\%). Once treatment started, two of the women who were working full time went on medical leave. Three of the women's employment ended during treatment. Six months after radiation was completed, all of the women who completed the study returned to work, except for the woman who was retired prior to diagnosis. Two of the three women whose employment ended during treatment did not complete the study. 
When examining the differences at the end of radiation therapy between the woman who retained a greater proportion of her participation in activities with the woman who did not, the woman who retained significantly less of her participation in activities had more co-morbidities, took more medications, experienced more side effects, and described participating in activities primarily within the Medical Center. She also had a significant other who provided personal care and completed the housework. She had few friends who were providing support and more plans for what she was going to do in the future. Additionally, she used a few strategies to reduce her stress. Both of these participants were African-American women with Stage II breast cancer who were not working during treatment and lived within Winston-Salem, North Carolina.

At 6 months post radiation, Participant 03, who had retained a lower proportion of her activities had a more advanced cancer (Stage II vs. Stage I) and recently had bilateral salpingo-oophorectomy, described participating in activities within fewer environments (five vs. 11) and worked more hours (> 40 hours/week vs. $<30$ hours/week) than Participant 01 who had retained a higher proportion of her activities. Participant 03 is a mother of a disabled son compared to Participant 01 who does not have any dependents. Fatigue continued to limit Participant 03 's participation in daily activities compared to Participant 01 who did not mention fatigue. However, Participant 01 continued to struggle emotionally with her breast cancer diagnosis, which was not described by Participant 03 . When examining these pairs of women who had high versus low activity retention, women appear to be at a greater risk for not regaining previous activity level if they (a) participated in activities within a limited number of environments, (b) had a more advanced cancer, (c) had greater number of co-morbidities, (d) received additional 
treatments for other medical conditions (e) experienced fatigue, and (f) worked greater than 40 hours a week. 


\section{Chapter 5: Discussion}

\section{Introduction to the Chapter}

The investigator used a concurrent mixed method to explore the experience of returning to important activities. The investigator simultaneously examined the proportion of activity retention with the descriptions of the experiences and associated meanings participating in important activities. The need to investigate this phenomenon evolved from the dearth of literature in occupational therapy, describing breast cancer survivors' experiences in returning to important activities.

Ten women who consecutively received surgery, chemotherapy, and then radiation for their breast cancer participated in this study from the beginning of their radiation therapy until 6 months after radiation therapy ended. All of the women received treatment at Wake Forest Baptist Health. Participants had the following characteristics: (a) between 41 and 60 years of age; (b) 60\% African-American, 20\% Caucasian, and 20\% mixed race of Caucasian and American Indian; and (c) 50\% married, $20 \%$ single, $10 \%$ divorced and 10\% separated. Eighty percent of the women had children 18 years and older, and 50\% had an adult in the household. Education level varied: (a) 10\% graduate degree, (b) 10\% bachelor's degree, (c) 20\% associate degree, (d) 30\% some college, and (e) 30\% high school diploma.

The inclusion criteria specified the stage and type of treatment provided to the participants in this study, but not identifiable characteristics of the breast cancer. The participants' breast cancer characteristics were the following: (a) $80 \%$ had breast cancer on their non-dominant left side; (b) 40\% were hormone positive and HER-2 negative, $40 \%$ triple negative, and $20 \%$ had hormone positive and HER-2 negative breast 
cancer; and (c) 20\% Stage 1, 70\% Stage II, and 10\% Stage III. Tumor sizes varied: 10\% were less than $1 \mathrm{~cm}, 60 \%$ were between 1 to $2 \mathrm{~cm}, 20 \%$ were between 2 to $3 \mathrm{~cm}$, and $10 \%$ were greater than $3 \mathrm{~cm}$.

The concurrent mixed method provided the ability to understand the phenomenon of women returning to important activities within the context of the PEOP model (Johnson \& Onwuegbuzie, 2004). The qualitative method was primary, which included the use of IPA. This transparent and rigorous method provided clear steps for selecting participants, interviewing, and analyzing the transcripts, which produced reliable data that the investigator merged with the descriptive quantitative data using the framework for analyzing mixed data developed by Onwuegbuzie and Leech (Onwuegbuzie \& Leech, 2006; Onwuegbuzie \& Teddlie, 2003). The investigator chose Onwuegbuzie and Leech's method for analyzing mixed method data because the method allowed the investigator to integrate the data systematically and with less bias.

Using the rigorous framework for analyzing mixed data, the investigator was able to analyze the emergent themes during the last week of radiation therapy and 6 months post radiation therapy in conjunction with the ACSm results at four designated time points within the context of the PEOP model. From this analysis, similarities and differences arose between participants who retained a lower proportion of their activities compared to those who retained a higher proportion.

Within this chapter, the investigator examines the following research queries of this study through the themes, ACSm results, and PEOP analysis: 
- What are the breast cancer survivors' experiences and associated meanings participating in important activities during and after breast cancer treatment?

- Are there connections among survivors, environments, and occupational performance?

Through this examination, the investigator compares and contrasts the findings from this study with other studies related to breast cancer epidemiology, treatment, and rehabilitation. Next, the investigator discusses the results of this study and other studies in relation to the PEOP and its implications to occupational therapy interventions.

Finally, the investigator offers recommendations for future research in this area and then summarizes the study's limitations and delimitations.

\section{Discussion}

\section{Last week of radiation therapy}

During the interviews within the last week of radiation therapy, four superordinate themes and 10 emergent themes developed. The women's outlook about how activities were approached and the social support received seemed to encourage the women's participation in their important activities. However, side effects along with personal and treatment related stresses and struggles appeared to discourage participation.

Individual outlook influences how activities are approached.

Looking forward to the future and making positive personal changes. These women's experiences of being diagnosed with breast cancer and receiving treatment led them to envision a different future for themselves. Similar to the study by Cohen and Numa (2011), two participants from this study voluntarily encouraged other women in 
their communities to have mammograms performed. However, most of the participants were not volunteering within their community but were looking forward to returning to their "normal" life of working, parenting, completing household tasks, and socializing with friends and family. Others were envisioning a future life, which included more rest, time for themselves, and self-improvement activities, such as advancing their education, making diet changes, and exercising. Some of the participants were more philosophical when envisioning their future. These women discussed the desire to reduce the need for perfectionism, keep a postive attitude, enjoy the simple things in life, and participate in activites that are important to them. In parallel to this study, the survivors in Hogan's (2014) study experienced “(a) improved personal relationships, (b) greater personal resources, (c) new priorities, (d) new perspective, and (e) new activies” (p. 200).

Strategies to reduce stress and treatment side effects. The women adapted a variety of strategies to reduce their stress during treatment, at home, and work. Some of the techniques were psychological and spiritual. Many of them regularly prayed, listened to music, used "mantras," focused on "positive thoughts," concentrated on the "next step," and read scriptures alone or in Bible study groups. Similarly, Gall and Comblat (2002) described religious coping strategies, and Johnsson et al. (2011) identified "problem-solving and emotion-focused" coping strategies among survivors who managed their emotional distress. Other participants in this study found engaging in activites with close friends or family reduced stress, such as watching movies, socializing, and walking. Comparable to these participants, other investigators have described the benefits of survivors participating in activities with friends and family to diminish stress (Parry, 2008; Unruh \& Elvin, 2004; Unruh et al., 2000; Vrkljan \& Miller-Polgar, 2001). Along 
with the psychological and occupational strategies, several of the participants experienced a reduction in their anxiety after they and their caregivers learned more about breast cancer and its treatments from health care providers. Palmadottir (2010) illustrated similar benefits in her study.

In order to continue with daily obligations, a number of women planned to work and complete needed activities on days that they anticipated experiencing fewer side effects. They also organized errands to conserve energy, scheduled time to rest after or before physically demanding daily activities, and modified activities to reduce the impact of side effects. Lyons et al. (2013) described similar "adjustments" made by older cancer survivors in her study. Additionally, Player et al. (2014) offered recommendations for adaptations for breast cancer survivors, specifically for those experiencing fatigue and mild cognitive deficits.

Social support reduces stress of life. All of the women expressed gratitude to friends and family who supported them during cancer treatment and other personal stresses. Due to this support, many of the women gained a greater appreciation for their family, friends, and colleagues, who offered support by providing or sharing meals, listening, praying, visiting, making them laugh, maintaining the household, helping children with homework, encouraging them to complete daily activities, giving financial assistance, supporting them at work, and distracting them from physical pain. Although the women appreciated the help from others, many women expressed that it was difficult to accept help. In line with these findings, Palmadottir (2009) described similar types of support from family and friends, and Fantoni et al. (2010) and Lindbohm et al. (2014) 
demonstrated the association between survivors successfully working and having supportive colleagues.

Side effects influence how activities are completed. Post-surgical impairments reduced some women's ability to lift, bend, and reach overhead, resulting in modifying how activities were completed. Hayes et al. (2010); Karki et al. (2005), and Verbelen et al. (2014) described similar impairments among survivors in their studies. Although post-surgical impairments restricted some women's ability to complete activities, chemotherapy side effects made a greater impact on women's daily life. Fear of infection, fatigue, pain, and peripheral neuropathies were the most common side effects experienced by these women. Fatigue and neuropathies were side effects described in other studies, and pain was described in relation to post-surgical complications (de Jong et al., 2006; Downie et al., 2006; Kuroi et al., 2009; Mols et al., 2014; Prigozin et al., 2010). Within the investigator's study, fear of infection was a barrier to socializing and returning to work; however Nilsson et al. (2013) only described its connection with returning to work. Along with these common side effects of chemotherapy, a few women experienced a change in their ability to read due to "dry eye syndrome" and reduced ability to concentrate. Several studies have described these side effects but not in relation to function (Downie et al., 2006; Edelstein \& Bernstein, 2014; Jansen et al., 2011; Kheir et al., 2014). Lastly, similar to post-surgical impairments, radiation burns and fatigue did not seem to have the same level of impact on daily activities as chemotherapy side effects. Open wounds or irritated skin were unique to radiation therapy, which reduced women's ability to participate in activities, requiring movement of their upper arms, 
including exercise. These impairments were also described in Knobf and Sun (2005) and Poirier's (2011) studies.

\section{Personal and treatment stresses and struggles influence perspectives on life.}

In addition to the stress of a cancer diagnosis and subsequent treatment, these women experienced a variety of different stresses and struggles in their personal life. These stresses included life changes of family members, personal lifestyle alterations, financial pressures, transportation to treatment, parental responsibilities, family members' physical illnesses, household responsibilities, and deaths of children. The consequences of these situations resulted in the participants' reduced ability to engage in some activities.

Emotionally, these women were struggling with the uncertainty of their diagnosis and the lasting results of treatment side effects. They realized that the treatment would reduce the cancer but also resulted in fatigue, pain, neuropathies, and other side effects. For some of the women, the realization brought on feelings of depression and anxiety. These women's emotions were amplified when family or friend's support was either negative or absent. Lindbohm et al. (2014) and Moskowitz et al. (2013) also described these feelings but not specifically related to a reaction to side effects; however, Lindbohm et al. (2014) described how lack of support in the workplace intensified these feelings. Additionally, family change and concern either positive or negative added to these women's stress. Positive life changes included a husband's promotion and a child's engagement. Unfortunately, not everyone experienced positive family changes. Negative family stresses, such as a death of a child, were emphasized by these participants, but were not found to be a primary focus within the research literature for women undergoing treatment for breast cancer. 
Day-to-day life was a struggle for many of the women because they needed help from others due to pain and fatigue. Some women struggled with accepting or asking for help from family for transportation to treatment and doing housework and yard work. In contrast, some women did not receive the support needed, such as parenting. In parallel with these findings, Lyons et al. (2013) described social support either being positive or negative among individuals with a variety of cancers. Moreover, some of the women continued to work during treatment and struggled with when or if to "call in sick." Other women had difficulty paying their bills due to either being on medical leave or needing to work fewer hours. The women, who described this difficulty returned to full-time work immediately after treatment, which is consistent with the study of Noeres et al. (2013).

\section{Six Months Post Treatment Therapy}

At 6 months post radiation therapy, three superordinate themes and five emergent themes surfaced during these interviews. Life was not the same for these women. This change encouraged them to participate in activities that were important and/or necessary. They also had a greater appreciation for their life, which influenced the activities that they chose to engage. However, fatigue and the negative emotions associated with the fear of the cancer returning did limit their participation in some activities.

Positive emotions affect daily activities, specifically appreciation. Most of the women came to the realization that they could have died from breast cancer. Because of this awareness, many of them felt grateful for many things, such as experiencing fewer or no residual side effects and having supportive people in their lives. This gratefulness led to celebrating more, appreciating every moment, spending more time with friends and family, and being happy. Consistent with this finding, van der Spek et al. (2013) and 
Gall and Comblat (2002) described survivors experiencing increased meaning within their relationships.

\section{Life after cancer has changed due to cancer diagnosis and treatment. Gall}

and Comblat (2002) described how participating in religious activities led to them feeling more connected and experiencing a new awareness of their life, which was also illustrated among the women in this study. As the women recovered and realized the severity of the diagnosis, they "looked" at life differently and experienced greater "happiness." This realization led one woman to try new things. Others described how their priorities and interests changed, which included "treasuring" time with family, not “stressing" over things, and experiencing greater emotions during religious services. This type of post-traumatic growth was also described by Cohen and Numa (2011) and Ruini and Vescovelli (2013). In their studies, the breast cancer survivors reported an increased awareness of new possibilities, greater appreciation for life, and enhanced spirituality.

Work. Women returned to work to regain financial independence and/or increase a sense of self-worth. Some of the women worked reduced hours during treatment, and others were on medical leave. Poirier (2011) also demonstrated that women reduced their work hours during treatment. As the women either increased their hours of work or returned to work, they reported that their colleagues provided support to make this possible, particularly for a woman who was working 60 hours a week. Support was provided by offering physical assistance, allowing time to rest, modifying work duties, adjusting work schedules, and treating them normally. Emotionally, one woman struggled with the fact that some of her colleagues provided emotional support and others 
did not. Another woman was not sure that her job would remain modified and if she could complete her physically demanding job. Bouknight et al. (2006) and Fantoni et al. (2010) showed that survivors who returned to work received support from their colleagues and employers, were more educated, and younger than 50 years of age. Increased work hours and responsibilities at home reduced some of these women's ability to participate in leisure activities. One woman reported that she no longer had time to watch movies as she did during treatment because she was working 60 hours a week and caring for a disabled child. Another woman's teenage daughter had a baby, and she was the primary caregiver. As a result, she did not have time to exercise. In agreement with these findings, Charlier et al. (2013) found that increased work hours was one reason for not resuming physical activities

Emotionally, working was more than a job. Some identified themselves by their professional roles, such as oncology nurse, manager, nursing assistant, librarian, and optician. Returning to work for these women was an indicator that they were "back to themselves." For these women, performing their job well was a priority. When they were able to return to work successfully, they "felt good" and "gratified." Similar to the investigator's study, Lilliehorn et al. (2013) found survivors returned to work because it generated structure and they "missed it" (p. 270).

Family. A new appreciation for family emerged for most of the women after treatment, which was also described in the study by Cohen and Numa (2011). Many of the women described a variety of activities that they returned to doing with their family, such as dancing, cooking, spending time together, playing with or caring for grandchildren, and teaching parenting skills. As the women regained energy and their 
risk for infection was reduced, they were able to resume more family activities.

Similarly, van der Spek et al. (2013) described how women found renewed meaning in activity participation after diagnosis.

Along with this new appreciation for family, some of the women felt greater concern for family members. Some women were concerned about family who had lifethreatening conditions and their husbands who were ignoring their physical and mental health. Others expressed a desire to help their children, such as caring for newborn babies, wanting to provide financial support, and encouraging their pursuit of higher education. This renewed awareness of the survivor's responsibility to care for family was also illustrated by Gall and Comblat (2002).

Women who felt reluctant to ask family for help with household chores found that this need brought them closer to them. Women described how their adult children independently completed housework and helped with caring for siblings. Other women described how parents and adult children provided financial support when they could not work as many hours. van der Spek et al. (2013) described how these experiences increased the intensity and meaning of these relationships for survivors.

Lifestyle changes. Changing health habits and taking care of themselves were a focus for most of the participants to reduce their risk for cancer reoccurrence. These centered on exercising, reducing stress, and changing diet. Exercise included strength training, walking, and yoga. These women felt that the exercise was restorative, led to greater independence with household tasks, and contributed to their weight loss. For one woman, participating in the LIVESTRONG program not only improved her physical strength but also provided social support for her. Survivors in the study by Costanzo et 
al. (2011) provided similar reasons for exercising and changing diet. In contrast, many of the participants were not able to regularly exercise due to work and family responsibilities. In line with these women's reasons for either exercising or not exercising, Charlier et al. (2013) found determinants for increasing physical activity were self-efficacy, enjoyment, and social support, but barriers were lack of support and/or time.

Side effects continue to influence daily activities. Despite the fact that it was 6 months since their treatment ended, women continued to experience side effects. Fatigue continued to be the predominate side effect, but they also experienced vaginal dryness, reduced memory, hot flashes, neuropathies, and weight gain. Yet, women expressed joy when their ability to taste was restored and their hair grew to a "normal" length.

Most of the women struggled with fatigue, which was also demonstrated in a variety of studies (Charlier et al., 2013; de Jong et al., 2006; Huang et al., 2014; Knobf \& Sun, 2005; Penttinen et al., 2011). Each participant reported that the level of fatigue was not as severe as it was during treatment. Because their fatigue lessened, they had energy to participate in activities, such as tutoring a child. The women reported that they managed their fatigue by resting, "pacing" themselves, eating and drinking small amounts throughout the day, and walking. The next most common side effect to linger was reduced memory and concentration, which was also seen by Deprez et al. (2012) and Jansen et al. (2011). Similar to managing fatigue, the women described using compensatory techniques to remember important things, such as writing things down. Only one woman complained of persistent peripheral neuropathies in her hands, but she felt that this was improving and not limiting her ability to complete daily activities. 
Lingering side effects were detected by Kuroi et al. (2009) in their study, which evaluated peripheral sensation among breast cancer patients who received neurotoxic chemotherapy agents. Lastly, another woman did not want to buy any new clothes until she lost the weight gained during chemotherapy.

Negative emotions affect daily activities. Participants, who had persistent side effects or a recent scan indicating that the cancer may have returned, experienced fear, anxiety, and depression. In line with these results, Cantarero-Villanueva et al. (2011) and Rowland, Hewitt, and Ganz (2006) found breast cancer survivors struggled with depression, fear and anxiety more than the "general population." In addition to side effects and fear of cancer returning, some women were managing the stress of other health conditions, parenting a disabled son, adjusting to a separation from her husband, and caring for her teenage daughter's newborn baby. These stresses led some women to feel more emotionally sensitive, overwhelmed, and/or exhausted. In parallel with these experiences, Penttinen et al. (2011) found "an increase of depressive symptoms due to loss of supportive environment during the treatments and to increase pressure and social demands of family and working life" (p.1218).

\section{Activity Retention}

The women in this study experienced an overall reduction in activity participation at the beginning of radiation therapy that continued to diminish until radiation therapy ended, and then it consistently increased over the next 6 months. In line with these findings, several studies have described a decline in activity participation during and after treatment, particularly physically demanding ones (de Jong et al., 2006; Devoogdt et al., 2010; Hidding et al., 2014; Littman et al., 2010). Similarly, Andrykowski et al. (2007) 
and Ogce and Ozkan (2008) described the pattern of reduction and resumption of activities for breast cancer survivors. This relationship was also illustrated in a study by Lyons et al. (2011) who also administered the ACSm at three time points after stem cell transplantation. They found that activity resumption incrementally improved particularly within the first 3 months post treatment, which was similar to the results in the investigator's study.

\section{Important Activities}

Until this current study, no other study to date has focused on the experience of breast cancer survivors resuming their important activities. van der Speck (2013) described important experiences and sources of meaning, but did not mention specific important activities. Additionally, Lyons et al. (2013) stated that older cancer survivors participated in important activities but did not record them.

\section{Theoretical Model}

The PEOP model (Christiansen \& Baum, 1997) demonstrates the relationship between an individual's necessary and meaningful daily occupations that are limited because of a health condition or disability. Specifically, the intrinsic and extrinsic factors, which either are a result of or led to the health condition or disability, are the focus of this model. In collaboration with the individual, interventions are developed to minimize or eliminate these factors to restore the individual's occupational performance. According to Christiansen and Baum (1997), there are five major strategies for improving performance: (a) modification of physical environments, (b) application of technical aids and devices, (c) strategies for sensory and neuromotor remediation, (d) occupation as a therapeutic medium or means, and (e) teaching or learning strategies (Ludwig, 2004). 


\section{Environment or Extrinsic factors}

Within the PEOP model, extrinsic factors include interpersonal, societal, cultural and physical environments (Ludwig, 2004). Interpersonal factors emerged during the interviews. The women repeatedly expressed gratefulness to friends and family who supported them during cancer treatment and with other personal stresses by assuming or supporting the participants with a variety of activities during or after treatments.

Consistent with these participants, other studies have described the importance of social support to encourage activity participation (Charlier et al., 2013; Phillips \& McAuley, 2013). Unlike Devoogdt et al. (2010), who described that women continued to complete instrumental activities if they had a spouse, the investigator's study found the opposite pattern. Participants were less likely to complete their instrumental activities if a spouse or significant other was available to help.

Many of the women described receiving information about their cancer and treatment from health care providers and/or on the Internet. They described how receiving information from a health care provider reduced their stress compared to reading information on the Internet. The impact of professional advice and support was also described by T. Lee et al. (2009), Palmadottir (2009), and Palmadottir (2010).

As the participants were recovering during the 6 months post radiation therapy, interpersonal factors were the center of the themes that emerged. Family and friend's support continued to be important, particularly as many of the women returned to paid employment. Additionally, having supportive colleagues and an accommodating environment were described frequently by the women who continued to work during treatment and/or returned to work shortly after treatment ended. The women who 
returned to working greater than 40 hours a week were those who were single. This finding is in line with several studies, demonstrating that workplace accoommodations, supportive colleagues, not having a spouse, and/or being self-employed led to successful resumption of work (Bouknight et al., 2006). By returning to work, these participants reported regaining their financial independence and/or a sense of self-worth. However, long work hours and personal responsibilities appeared to reduce their ability to participate in leisure or social activities. Other investigators have described similar relationships. Reduced time, particularly due to working, was described as a barrier to returning to physically demanding leisure activities (Charlier et al., 2013).

\section{Person or Intrinsic Factors}

"Intrinsic factors are those within the person, such as psychological, physiological, and neurobehavioral influences. Motivation, experience, beliefs, abilities and skills are intrinsic enablers of performance," according to the PEOP model (Ludwig, 2004, p. 389). During the last week of radiation therapy, these women applied a variety of psychological techniques to manage stress and treatment side effects. When the women were unable to fully engage in meaningful activities, they would envision a future, which included participation in community service and routine occupations, or a change in personal perspective, such as reducing perfectionism. These participants descriptions are consistent with those illustrated by Hogan (2014) who explored posttraumatic growth among breast cancer survivors.

Not all of the women were able to apply these positive techniques. Some struggled emotionally with the uncertainty of their diagnosis and the lasting results of treatment side effects, which led to feelings of depression and anxiety. These emotional 
struggles were also described by Cantarero-Villanueva et al. (2011), Hong et al. (2007), and Huang et al. (2014). These women's emotions were amplified when family or friend's support was either negative or not present. Comparable portrayal of survivors was found in the research of Bouknight et al. (2006), Fantoni et al. (2010), Hughes et al. (2014), and Lindbohm et al. (2014), who also described the negative impact of reduced social support.

In addition to the psychological intrinsic factors identified by these women, physiological factors were also described. Many of the women experienced post-sugical impairments (reduced upper-body function, pain, diminished sensation, and/or lymphedema), chemotherapy side effects (fear of infection, fatigue, pain, impaired cognition and peripheral neuropathies), and/or radiation side effects (burns, reduced upper-body function and fatigue). Similar findings have been described by a variety of investigators (Cantarero-Villanueva et al., 2011; Edelstein \& Bernstein, 2014; Hidding et al., 2014; Karki et al., 2005; Kaya et al., 2010; Kenyon et al., 2014; Kopec et al., 2013; Levy et al., 2012; Mols et al., 2014; Nilsson et al., 2013; Player et al., 2014; Smoot et al., 2010; Swisher et al., 2010; Verbelen et al., 2014).

At 6 months post radiation therapy, psychological factors were primarily described by these women. Most of the women felt grateful for many things, including surviving breast cancer, experiencing fewer or no residual side effects, and having supportive people in their lives. This gratefulness led to celebrating more, appreciating every moment, spending more time with friends and family, trying new things, and experiencing greater emotions during religious services. Similar post-traumatic growth has be depicted in the studies by Ruini and Vescovelli (2013) and Hogan (2014). 
Not all psychological factors experienced by these women were positive. Women who had persistent side effects or had a recent scan, indicating that the cancer may have returned, experienced fear, anxiety, and depression, which was also described by Cantarero-Villanueva et al. (2011) Additionally, women who were concerned about the long-term consequences of chemotherapy on their bodies thought about cancer all the time. These women would use psychological techniques to "occupy" their mind to remove the thought of cancer, and others would allow themselves to psychologically face their own mortality. These positive coping techniques were also illustrated in the study by Ruini and Vescovelli (2013). Along with direct effect of cancer treatment, women were psychologically managing personal stress and/or other health conditions, such as parenting a disabled son, adjusting to separation from husband, caring for a teenage daughter's newborn baby, and adjusting to the death of a child. Similarly, Ogce and Ozkan (2008) described functional status within the household and community was reduced among survivors who were experiencing negatively psychological symptoms.

Physiological factors did not disappear at 6 months post radiation therapy. Many women continued to experience side effects, particularly fatigue, which is the most common persistent side effect described in various studies (Cantarero-Villanueva et al., 2011; de Jong et al., 2006; Downie et al., 2006; Huang et al., 2014; Poirier, 2011; Schmidt et al., 2014; Seifert, 2010). They also experienced vaginal dryness, reduced memory, hot flashes, neuropathies, and weight gain.

Simultaneously, many women realized that they needed to make lifestyle changes to reduce the risk of cancer reoccurrence. These changes centered on exercising, reducing stress, and modifying their diet. Charlier et al. (2013) and Phillips and 
McAuley (2013) have explored the intrinsic factors that led survivors to exercise either during or after treatment and showed similar reasons. In contrast, Loh, Chew, and Lee (2011) demonstrated that when survivors were unaware of the association between exercise and reduced probability of cancer reoccurrence, they were less likely to exercise than those who were aware of this association, Additionally, T. Lee et al. (2009) demonstrated that survivors who had reduced coping ability or misinterpreted lymphedema risk-reduction behaviors provided by professionals were less likely to engage strenuous arm activities.

\section{Occupations}

Instrumental activities of daily living. Returning to work among other instrumental activities was reported consistently as one of the five most important activities to resume during and after cancer treatment for women in this study. The importance of returning to work is reflected in several other studies (Barnes et al., 2014; Bouknight et al., 2006; Desiron, 2010; Desiron et al., 2013; Fantoni et al., 2010; Hoving et al., 2009; Johnsson et al., 2011; Lilliehorn et al., 2013; Moskowitz et al., 2013; Noeres et al., 2013). Despite women's interest in returning to work, Silver et al. (2013) reported that unemployment rates were higher in patients with breast, gastrointestinal, and female reproductive organ cancers compared with controls. Cancer survivors were more likely to be unemployed than healthy controls: $33.8 \%$ versus $15.2 \%$. Moreover, a number of studies described how cancer survivors are at significantly increased risk for unemployment and early retirement as well as less likely to be reemployed (Desiron et al., 2013; Noeres et al., 2013; Silver et al., 2013). 
Although the investigator's study did not directly assess the requirements of the women's jobs, many of the women described the physical and cognitive challenges of completing their work, such as moving patients, picking up small screws, lifting boxes, reading, and concentrating. Silver et al. (2013) illustrated how heavy work, chemotherapy, old age, less education, and low income were negatively associated with return to work while less invasive surgery was positively associated with employment. Within the investigator's study, all of the women who were employed returned to work even though some of the women's work was heavy. The women who returned to work had at least a high school degree and were between 41 and 60 years of age. Furthermore, the women in the investigator's study had less invasive surgery. Seventy percent had lumpectomy, and $90 \%$ had sentinel node lymph node dissection.

Along with physical impairments limiting women's ability to return to work, intrinsic factors, such as motivation, emerged from Silver et al. (2013) review of the literature. The following four categories of reasons for not returning to work did not emerge within the investigator's study, but have been described by Silver et al. (2013):

- "I'm still too fragile to return to work."

- "My workplace is a discouraging place."

- "I took an opportunity to pause."

- "I've lost the taste for work." (p. 457)

However, the participants in the investigator's study did provide similar reasons for returning to work as illustrated in the following quotes by Silver et al. (2013). "Work generates and structures my everyday life," and "I miss my workplace" (p. 457). 
Women in the investigator's study did not directly discuss the influence of health insurance as a reason for returning to work. However, three of the four married women returned to work as part-time employees, and all three of the single women returned to working greater than 40 hours per week. The findings from the investigator's study are consistent with Silver et al.'s (2013) conclusions that cancer survivors who receive health insurance as a benefit to their jobs are more likely to keep working than those who have insurance from their spouse's plan. Furthermore, this finding supports the participant's need for health insurance to pay for their and their dependents medical expenses. This observation provides a glimpse into the number of factors, outside of the cancer diagnosis and prior functional status, which are involved in returning to work for cancer survivors.

For the women in the investigator's study, at least one instrumental activity was consistently listed among the top five most important activities. These included working, shopping, managing finances, maintaining car and household, relaxing, caring for children, cooking, cleaning, going to doctor's appointments, maintaining personal health, caring for pets, and strengthening their marriages. Consistent with Ogce and Ozkan (2008) study, the women in the investigator's study experienced the lowest proportion of instrumental activity participation at the beginning of radiation therapy, which corresponds to recently ending chemotherapy.

Some women in the investigator's study reported that they were not able to complete certain instrumental activities at the same level or way as they did prior to breast cancer diagnosis. The five most common instrumental activities, which women reported that they completed either less or differently, were (a) completing yard maintenance, (b) going to the beauty shop, (c) maintaining the household, (d) fixing 
things around the house, and (e) resting. These responses were similar to those described in the studies by Hayes et al. (2005) and Lyons et al. (2013), except for going to the beauty shop and resting.

High-demand leisure. Ventura et al. (2013) found that the three most common reasons breast cancer survivors were not physically active were (a) "lack of time," (b) "lack of self-discipline," and (c) "fatigue” (or lack of energy; p. 429). Voege et al. (2014) also examined physically demanding activities but explored why breast cancer survivors did and did not participate in these activities. They organized their reasons for participating into the categories of experiencing a positive result (approach motivators) or avoiding a negative consequence (avoidance motivators). Examples of their definition of approach motivators were (a) "because it makes me feel good," (b) "to have a healthy body," and (c) "because I find exercise invigorating," and avoidance motivators were (d) “avoid ill-health," (e) “prevent health problems," and (f) "prevent breast cancer recurrence" (p. 3). Their study demonstrated that approach motivators were associated with participating in physical activities more than avoidance motivators. These findings of Ventura et al. (2013) and Voege et al. (2014) were consistent with those depicted in the investigator's study. The women in the investigator's study who were participating in high-demand leisure activities were doing so because either they enjoyed participating in the high-demand leisure activities or they wanted to adapt healthier behaviors.

Additionally the women in the investigator's study who were working less than 20 hours a week or were unemployed reported resuming a higher proportion of their high-demand leisure activities than the women who were working 30 or more hours a week. 
Low-demand leisure. Within the investigator's study, women resumed their low-demand leisure activities to a similar proportion as their instrumental activities. This same pattern was observed among survivors of stem cell transplantation (Lyons et al., 2011). In addition to this study conducted by Lyons et al. (2011), another study was conducted examining older cancer survivors whose low-demand leisure activities were reduced by $4 \%$ within 3 months post treatment (Lyons et al., 2013). Other than these studies, no other examination of low-demand leisure activities after cancer treatment was found in the literature. Furthermore, reasons for reduced low-demand leisure participation within the investigator's study included peripheral neuropathies, which reduced the ability to quilt, and visual changes, which diminished the ability to read. No other studies have provided the impact of these impairments on specific low-demand leisure activities.

Social. Within the investigator's study, three women who had the lowest proportion of social activities resumed at 6 months post radiation therapy were single and working greater than 40 hours per week. This pattern was also observed for resuming high-demand leisure activities (Charlier et al., 2013; Ventura et al., 2013). In addition to not having enough time to socialize, Downie et al. (2006) found that socializing became contingent upon energy levels. Many women discussed making tentative plans, meeting earlier in the evening, having friends over instead of going out, and "spacing out" social engagements. Other survivors avoided socializing activities, which would reveal their memory deficits to others. Within the investigator's study, only one woman described how her reduced memory affected her socializing. Furthermore, participants socialized more by talking on the telephone and using e-mail to communicate with others. 
Besides fatigue and "lack of time" decreasing participation in social activities, reduced or negative social support experienced after breast cancer diagnosis was also described. One woman in the investigator's study who dropped out after radiation therapy did not resume any of her social activities. She described how her friends stopped "calling her" and "made fun of how she looked." She also complained of intense pain and depression, which limited her ability to complete activities, including socializing. Consistent with this participant's experience, Hughes et al. (2014) demonstrated an association between breast cancer survivors who had lower or negative social support prior to treatment and experiencing higher levels of pain and depressive symptoms over time than women who were socially connected (Hughes et al., 2014).

\section{Performance}

Within the investigator's study, race and level of education did not seem to be associated with returning to physically demanding activities. In contrast to the investigator's study, Hong et al. (2007) found that African-American women and those with a low level of education reported significantly lower participation in physical activities. However, the investigator did observe in her study that women who worked greater than 40 hours a week resumed a lower proportion of high-demand leisure and social activities than women who worked less than 40 hours a week.

In addition to not having enough time, some participants in investigator's study could not complete activities or they modified them due to physical impairments. Participants with physical impairments described a reduced ability to cook, clean, complete yard work, maintain car, and physically lift at work. In contrast, Karki et al. (2005) and Swisher et al. (2010) found that breast cancer survivors were able to complete 
basic activities of daily living (ADLs) and IADLs despite physical restrictions, but had reduced their participation in leisure and social activities. Consistent with the investigator's study, Swisher et al. (2010) described that many breast cancer survivors struggled to complete specific instrumental activities, such as opening a jar, pushing open a heavy door, doing heavy housework, and carrying heavy objects.

Along with epidemiologic factors and impairments, environment or extrinsic factors also influence the breast cancer survivor's ability to participate in occupations. For example, Palmadottir (2010) described how access to information, support and care, and community and rehabilitation services helped survivors return to occupational participation. The women in investigator's study who resumed a higher proportion of their activities described a greater number of supportive extrinsic factors than women who resumed a lower proportion.

\section{Implications for Practice}

According to Christiansen and Baum (1997), there are five major strategies for improving performance. The strategies are (a) modification of physical environments, (b) application of technical aids and devices, (c) strategies for sensory and neuromotor remediation, (d) occupation as a therapeutic medium or means, and (e) teaching or learning strategies (Ludwig, 2004).

\section{Modification of Physical Environment}

For the women in the investigator's study, fear of infection was the primary reason for restricting their physical environment. As their white blood counts increased and their risk for infection decreased, some women began to broaden their number of environments; however, fatigue continued to persist for these women. Currently, 
occupational therapists provide energy conservation techniques for those experiencing fatigue (Player et al., 2014; Vockins, 2004), which are similar to those applied to individuals who have conditions, such as multiple sclerosis (Blikman et al., 2013). Although these techniques may immediately help manage daily activities, it does not address the long-term need to reduce fatigue (Mock et al., 2005).

Huang et al. (2014) illustrated how fatigue levels fluctuated for women receiving treatment for breast cancer. Severity of fatigue reached its peak at 2 months after surgery and was the lowest at 12 months after surgery. Because fatigue did not disappear at the end of each cycle of chemotherapy, fatigue would worsen with each round, and depression and distress exacerbated the symptoms (Huang et al., 2014). Matthews et al. (2012) illustrated that fatigue clustered with pain and insomnia among women receiving radiation therapy for breast cancer. These symptoms were magnified by depression and pessimism, consistent with the findings of Huang et al. (2014).

With this knowledge of the nature of fatigue among women receiving treatment for breast cancer, traditional energy techniques may not adequately teach these women how to manage their fatigue. Instead, the occupational therapist should modify traditional energy conservation techniques to include interventions to reduce depression, distress, and fatigue. Engaging women in meaningful physically active occupations has been found to reduce depression and fatigue among women undergoing and recovering from breast cancer treatment (Andrykowski et al., 2007; McNeely et al., 2006; Mock et al., 2005; Stagl et al., 2014). 


\section{Application of Technical Aids and Devices}

Occupational therapy research has not described the use of technical aids and devices for those undergoing or recovering from breast cancer treatment. However, there is a description of how these technical aids and devices are applied to those who have lung cancer (White, 2013). Similar to the interventions described by White (2013), an occupational therapist could manage refractory symptoms experienced by breast cancer survivors through the use adaptive equipment, such as textured pens for those with neuropathies. Additionally, women who are experiencing back pain from sequelae of breast cancer and continuing to work and complete household tasks would benefit from ergonomic modifications to remain active and independent in these activities (Snodgrass, 2011). Survivors in the investigator's study described using adaptations to complete daily tasks, such as magnets to pick up screws when experiencing peripheral neuropathies and a "strainer" to reach for items in a cabinet when unable to reach overhead due to shoulder restrictions.

\section{Strategies for Sensory and Neuromotor Remediation}

Occupational therapists frequently apply biomechanical approaches to remediate treatment- and diagnosis-related impairments, such as shoulder restrictions, reduced upper-body strength, pain, and lymphedema (Silver, 2007). Therapeutic exercise and activity have been found to (a) restore function, (b) improve mood, (c) reduce fatigue and lymphedema, and (d) reduce the risk for osteoporosis and cancer reoccurrence (Player et al., 2014; Schmitz et al., 2010; Silver, 2007). A structured exercise program appears to have greater benefit than unstructured exercise to elevate overall activity level (Midtgaard et al., 2006). Within the investigator's study, a woman who participated in 
the LIVESTRONG program indicated that she had resumed many of her daily activities after completing the program.

Women experience pain from the cancer and the sequelae of the treatments. Occupational therapists use a variety of interventions to reduce pain, including trigger point release, myofascial release, compression, and skin desensitization (Stubblefield \& Custodio, 2006). For one woman in the study, her pain significantly reduced her ability to participate in meaningful activities. She had sought physical and occupational therapy but due to social barriers, she did not attend regularly.

Another common impairment experienced by breast cancer survivors is lymphedema, which is associated with pain, reduced upper-body strength, and shoulder restrictions. As a result, survivors lose their ability to use the affected arm in daily activities. In order to restore function, occupational therapists, who are also lymphedema specialists, provide complete decongestive therapy to reduce arm limb volume and increase upper-body strength and flexibility by providing manual lymph drainage, teaching skin care, applying compression, and increasing activity participation and/or exercise (Hamner \& Fleming, 2007; Lasinski, 2013).

\section{Occupation as a Therapeutic Medium or Means}

Occupation as a means of restoring health and function is a fundamental concept within occupational therapy. "Abreast in a Boat," which entails breast cancer survivors racing each other with dragon boats, was one of the first demonstrations of the benefits of participating in a physically demanding leisure activity for breast cancer survivors. Not only did dragon boat racing show that physically demanding occupations improved physical functioning and reduced episodes of lymphedema, but also provided emotional 
support from other breast cancer survivors and rebuilt self-confidence (Unruh \& Elvin, 2004).

While women underwent treatment in the investigator's study and in the study by Palmadottir (2009), occupational disruption created feelings of sadness and disconnection. Women who created an occupational routine were able to focus on something other than breast cancer and maintain their personal identities, such as librarian, or optician. In addition to establishing an occupational routine, the women in the investigator's study re-evaluated self-care occupations, including diet and exercise, and social occupations, such as spending more time with family and friends. As result, many women assumed health improvement and social occupations.

Along with using occupational participation as a therapeutic modality, the experiences of engaging in occupations can be used as a means to solve daily challenges (Keesing \& Rosenwax, 2011; Lyons, 2006; Newman, 2013). Occupational therapists and survivors can use these encounters as opportunities to (a) develop alternative ways to complete desired occupations, (b) explore emotions, (c) expand skills, and (d) regain independence (Christiansen \& Baum, 1997; Christiansen \& Townsend, 2010).

\section{Teaching or Learning Strategies}

Because survivors are living longer with breast cancer and have acquired multiple impairments, these women may benefit from learning adaptive strategies to regain and/or maintain independence. As discussed earlier, in addition to the survivors who are experiencing physical impairments, women are increasingly experiencing a reduction in their cognitive skills due to whole-brain radiation (Tallet et al., 2012), stereotactic radiation (McDuff et al., 2013), and/or high-dose chemotherapy (de Ruiter et al., 2011). 
Ten years ago, $50 \%$ of survivors would have died within 5 years, but current survivors are currently living with cognitive deficits that impair their occupations. Cherrier et al. (2013) found (a) using memory aids (calendar reminders, note taking, study aids), (b) teaching memory strategies (habit formation, method of loci, chunking, learning names), and (c) practicing mindfulness meditation improved attention and quality of life among breast cancer survivors. Within the investigator's study, women described writing important information within journals and paper to help them remember.

Lyons et al. (2012) applied problem-solving techniques with women who were receiving chemotherapy for their breast cancer treatment. They discovered women wanted to adapt activities to make it either easier or more enjoyable, find new activities to solve general problems, reprioritize activities, and gather resources or options. Within the investigator's study, the problem-solving mode may have helped many of the women to either maintain or increase participation in high-demand leisure and social activities. Additionally for the participants who appeared to be struggling with depression and anxiety, they could have benefitted from this approach to resume more of their instrumental activities.

\section{Implications for Future Research}

This study provides a glimpse into the experiences of a small group of women resuming important activities during radiation therapy and 6 months post radiation therapy. The results of this study generated more questions than answers and an opportunity for further research to broaden the scope of knowledge in this area.

Breast cancer is a heterogeneous disease, requiring a variety of treatment regimens, resulting in different side effects. Further research with younger or older 
women, specific types of breast cancer, such as hormone positive and inflammatory, different sequences of treatments, neoadjuvant chemotherapy followed by surgery and radiation therapy, and single working mothers, are a few examples of how this study could be duplicated with different inclusion criteria. The investigators could compare and contrast the results of these studies to illustrate the unique and common occupational needs among various groups of breast cancer survivors. Because this study consisted of 10 participants from a similar geographic area within North Carolina, expanding the number of participants or the geographic area would provide greater support or need for refinement for factors that appear to influence resumption of activity participation found in this study.

Other areas of study to consider would be interventions to reduce the consequence of fatigue and diminished cognition. Previous studies have demonstrated the positive outcome of exercise on reducing fatigue, but no studies have explored the influence of participating in physically demanding activities (McNeely et al., 2006; Mock et al., 2005). Reduced cognition along with fatigue have been described as concerns for survivors, and neuropsychological studies have been performed to gain a greater understanding of the relationship between treatment and cognition (Ahles et al., 2012; Ahles et al., 2010; Breckenridge et al., 2010; Cherrier et al., 2013; Collins et al., 2013; de Ruiter et al., 2011; Deprez et al., 2012; Jansen et al., 2011; Jenkins et al., 2006; McDuff et al., 2013; Schilder et al., 2010; Tallet et al., 2012)). Additionally, Player et al. (2014) have described survivors "chemobrain experience," but no occupational therapy studies have explored treatment approaches to improve function for cognitively impaired survivors. 
Beyond side effects, studies are needed to understand the challenges that single working mothers are confronted when undergoing treatment and recovery. From investigator's study, these women appeared to be able to resume a higher proportion of their instrumental activities but struggled to attain similar proportions of their social and high-demand leisure activities. Larger studies are needed to determine if it is a universal struggle for working single mothers, or is it unique to this small group of women? If there is an association, occupational therapy interventions should be developed and studied to support activity resumption. In addition, further research is needed to sort through other possible reasons for why single women do not resume the same proportion of activities as other women, such as culture, financial, individual values, and perceived social support.

Many of the women in this study expressed how their diagnosis and treatment had affected their entire family and how their family was critical to their successful recovery. No occupational therapy studies have described this influence in detail. The results of these types of studies could lead to the development of interventions directed toward the woman and her family.

Furthermore, no studies have described specific occupational therapy recommendations and training in the use of adaptations and equipment to enable breast cancer survivors' participation in meaningful occupations. Understanding the benefit or lack of usefulness of various adaptations and equipment, occupational therapists can develop appropriate interventions to restore independence and premorbid activity levels for breast cancer survivors. 
Lastly, theoretical research applying PEOP and other occupational therapy approaches, frameworks, and models would provide the structure needed for occupational therapists to develop and implement effective treatment plans. Demonstrating associations between intrinsic and/or extrinsic factors and occupational performance would give support for directing interventions toward these factors. From these results, investigators could develop and evaluate interventions to improve occupational performance of breast cancer survivors.

\section{Limitations and Delimitations}

\section{Limitations}

The limitations within this study arose from recruitment, data collection, validity and reliability of the ACSm, and sample size. Recruitment was slow due to (a) dependence on radiation oncologist for identifying potential participants; (b) initiation of a new electronic medical record system, which temporarily decreased patient volumes; and (c) specific inclusion criteria. The investigator did not conduct all of the interviews face-to-face because some participants requested that the investigator conduct the interview by telephone, which may have changed the quality of the interviews. In addition, the data gathered from the interviews were susceptible to recall and social acceptance biases from the participants (Clarke, 2009; Smith et al., 2009).

While the majority of the ACSm checklists were completed in a private room at the medical center, some participants completed it at home or within the community, then faxed or mailed it back to the investigator. The varying locations may have affected how the participants completed the checklist. The reliability of the ACSm may have been threatened due to the dependence of the breast cancer survivor's ability to compare her 
current participation retention with the activities she was doing prior to her breast cancer diagnosis (Njie-Carr, 2014). Lastly, the ACSm was not standardized with breast cancer survivors, so the results cannot be compared with normative data (Baum \& Edwards, 2008; Katz et al., 2003; Sachs \& Josman, 2003).

Although the sample size may have been adequate for the qualitative method section of this study, 10 participants do not provide sufficient power to generalize the results to the population of breast cancer survivors. The study sample included women who (a) were from a small geographical area; (b) sought treatment from an academic medical center within the southeastern United States; (c) racially represent AfricanAmericans, Caucasions, and mixed race of Caucasion and American Indian; and (d) had at least a 12-year equivalent education.

\section{Delimitations}

The investigator implemented several steps to ensure the integrity of the data. First, the sample population was audited one time during the study. During this audit, one participant was excluded because she had received neoadjuvant chemotherapy, which was not identified during the selection process. The investigator rechecked the data entered into Microsoft Excel® program from the ACSm checklists and recalculated the proportion of activity resumption to ensure these were correct. Once interviews were completed and transcribed, the investigator analyzed each transcript in detail and closely followed the IPA method of analysis to reduce bias. Following the analysis, an expert in IPA reviewed all transcript analyses and theoretical ideas formulated from the data analysis. When indicated by the expert's recommendations, the investigator re-analyzed data, so the IPA method of analysis was completed correctly and consistently (Smith et 
al., 2009). Lastly, the concurrent mixed method reduced the limitations within IPA and strengthened the findings discovered within the transcripts by using the quantitative data from the ACSm to the descriptions of the women's resumption of important activities (Creswell, 2009; Morse \& Niehaus, 2009).

To encourage participants to complete all four visits, the investigator scheduled follow-up visits around physician appointments or on other days and times that were convenient to the participants. Some of the ACSm checklists were completed from home and interviews were conducted over the phone if requested by the participants. As a result, participants completed $100 \%$ of the first two visits, $90 \%$ of the first three visits, and $80 \%$ of all four visits.

\section{Summary}

In summary, this study provides a description of the activities that are important to women during and after breast cancer treatment and the experiences and associated meanings as they resumed participation. Specifically, the experiences and associated meanings illustrated which intrinsic and extrinsic factors influenced participation in important activities. For this group of women, supportive extrinsic factors seemed to positively influence performance greater than intrinsic factors. Additionally, women resumed a greater proportion of their instrumental activities, which was the most common category of activities listed.

The interpretative phenomenological analysis of the interviews provided insight into the factors shaping the women's return to their important activities, and ACSm results illustrated the proportion of activity categories resumed. When these data were analyzed concurrently, intrinsic and extrinsic factors influencing occupational 
performance were discovered, which illustrated how the PEOP model can be used by occupational therapists to organize treatment interventions for breast cancer survivors. The literature review explored many aspects of breast cancer treatment, such as (a) its side effects, (b) its influence on activity engagement, (c) various interventions to minimize side effects, and (d) different epidemiologic influences, which provided a description of factors influencing breast cancer survivor's recovery. The review illustrated that social support and exercise were associated with greater function, and fatigue, lymphedema, shoulder restrictions, and pain limited the ability to resume certain activities. Yet, the review did not provide a description of the experiences and its associated meanings that women had resuming important activities and the proportion of activity resumption by category as illustrated in this study.

To understand the experience of participating in important activities during and after breast cancer treatment and its connection with occupational performance, a concurrent mixed method was used. The investigator used the list of five most important activities generated by each woman within the ACSm to direct each of the two in-depth interviews. The analysis of these two in-depth interviews and the results of four ACSm checklists were merged to illustrate these women's experiences and associated meanings.

Results from this mixed method study illuminated the importance of extrinsic and intrinsic factors had on occupational performance for this group of 10 women. Specifically, during the last week of radiation therapy, the subsequent intrinsic factors and extrinsic factor appeared to help women participate in important activities. Intrinisic factors were (a) applying strategies to reduce stress and treatment side effects, (b) looking forward to the future, and (c) making positive personal changes, and the extrinsic factor 
was receiving support from family, friends, and health professionals. However, these intrinsic factors, which were fear of infection, fatigue, pain and other side effects, emotional reaction to personal stresses, and the cancer diagnosis and its treatments, seemed to limit participation. At 6 months post treatment, the intrinsic factors of appreciating life and making lifestyle changes and the extrinsic factors of family and friend support and work appeared to influence activity participation. In contrast, the intrinsic factors of fatigue, depression, and anxiety seemed to be detrimental to participating in important activities.

In parallel with the finding that fatigue, depression, and anxiety appear to reduce participation in important activities, other studies described the negative association of depression, anxiety, pain, and fatigue on the quality of life for breast cancer survivors. This study did not attempt to explain why women did not resume to pre-breast cancer activity levels but attempted to illustrate the women's experiences participating in their important activities. Additionally, the study seemed to show a relationship between activities that were important to them and their ability to resume this category of activity quicker.

In closing, the research questions posed "What are the breast cancer survivors' experiences and associated meanings participating in important activities before and after breast cancer treatment? and Are there connections among survivors, environments, and occupational performance?" have been answered. Additionally, the study does illustrate the influence of extrinsic and intrinsic factors on occupational participation during and after breast cancer treatment. Results of this study support the need for future occupational therapy research directed toward theory and practice. 


\section{References}

Abeydeera, K., Willis, S., \& Forsyth, K. (2006). Occupation focused assessment and intervention for clients with anorexia. International Journal of Therapy \& Rehabilitation, 13(7), 296-296. doi: 10.12968/ijtr.2006.13.7.21403

Ahles, T. A., Root, J. C., \& Ryan, E. L. (2012). Cancer- and Cancer TreatmentAssociated Cognitive Change: An Update on the State of the Science. Journal of Clinical Oncology, 30(30), 3675-3686. doi: 10.1200/JCO.2012.43.0116

Ahles, T. A., Saykin, A. J., McDonald, Y. L., Furstenberg, C. T., Hanscom, B. S., Mulrooney, T. J., . . Kaufman, P. A. (2010). Longitudinal assessment of cognitive changes associated with adjuvant treatment for breast cancer: Impact of age and cognitive reserve. Journal of Clinical Oncology, 28(29), 4434-4440. doi: 10.1200/JCO.2009.27.0827

Ahmed, R., Thomas, W., Yee, D., \& Schmitz, K. (2006). Randomized controlled trial of weight training and lymphedema in breast cancer survivors. Journal of Clinical Oncology, 24(18), 2765-2772. doi: 10.1200/JCO.2005.03.6749

Andrykowski, M., Beacham, A., \& Jacobsen, P. (2007). Prospective, longitudinal study of leisure-time exercise in women with early-stage breaset cancer. Cancer Epidemiology Biomarkers Preview, 16(3), 430-438. doi: 10.1158/1055-9965.EPI06-0735

AOTA. (2014). Occupational therapy practice framework: Domain and process (3rd edition). American Journal of Occupational Therapy, 68, S1-S48. doi: 10.5014/ajot.2014.682006

Barnes, A. J., Robert, N., \& Bradley, C. J. (2014). Job attributes, job satisfaction and the return to health after breast cancer diagnosis and treatment. Psychooncology, 23(2), 158-164. doi: 10.1002/pon.3385

Battaglinia, C., Mills, R. C., Phillips, B. L., Lee, J. T., Story, C. E., Nascimento, M. G., \& Hackney, A. C. (2014). Twenty-five years of research on the effects of xercise training in breast cancer survivors: A systematic review or the literature. World Jounral of Clinical Oncology, 5(2), 177-190. doi: 10.5306/wjco.v5.i2.177

Baum, C., \& Edwards, D. (2008). Activity Card Sort (2nd ed.). Bethesda, MD: AOTA Press. 
Bender, C. M., Sereika, S. M., Brufsky, A. M., Ryan, C. M., Vogel, V. G., Rastogi, P., . . . Berga, S. L. (2007). Memory impairments with adjuvant anastrozole versus tamoxifen in women with early-stage breast cancer. Menopause, 14(6), 995-998. doi: 10.1097/gme.0b013e318148b28b

Berterco, C. (2000). Types and sources of social support for people afflicted with cancer. Nursing and Health Sciences, 2(2), 93-101. doi: 10.1046/j.14422018.2000.00044.x

Blikman, L. J., Huisstede, B. M., Kooijmans, H., Stam, H. J., Bussmann, J. B., \& van Meeteren, J. (2013). Effectiveness of energy conservation treatment in reducing fatigue in multiple sclerosis: a systematic review and meta-analysis. Archives of Physical Medicine and Rehabilitation, 94(7), 1360-1376. doi: 10.1016/j.apmr.2013.01.025

Bloom, J. R., Stewart, S. L., Oakley-Girvan, I., Banks, P. J., \& Shema, S. (2011). Quality of life of younger breast cancer survivors: Persistence of problems and sense of well-being. Psycho-Oncology, 21(6), 655-665. doi: 10.1002/pon.1965

Bouknight, R., Bradley, C., \& Luo, Z. (2006). Correlates of return to work for breast cancer survivors. Journal of Clinical Oncology, 24(3), 345-353. doi: 10.1200/JCO.2004.00.4929

Breckenridge, L. M., Bruns, G. L., Todd, B. L., \& Feuerstein, M. (2010). Cognitive limitations associated with tamoxifen and aromatase inhibitors in employed breast cancer survivors. Psycho-Oncology, 21(1), 43-53. doi: 10.1002/pon.1860

Brocki, J., \& Wearden, A. (2006). A critical evaluation of the use of interpretative phenomenological analysis (IPA) in health psychology. Psychology and Health, 21(1), 87-108. doi: 10.1080/14768320500230185

Cantarero-Villanueva, I., Fernandez-lao, C., Fernandez-de-las-penas, C., Diaz-Rodriguez, L., Sanchez-Cantelejo, E., \& Arroyo-Morales, M. (2011). Associations among musculoskeletal impairments, depression, body image and fatigue in breast cancer survivors within the first year after treatment. European Journal of Cancer Care, 20(5). doi: 10.1111/j.1365-2354.2011.01245.x

Champion, V. L., Wagner, L. I., Monahan, P. O., Daggy, J., Smith, L., Cohee, A., . . Sledge, G. W. (2014). Comparison of younger and older breast cancer survivors and age-matched controls on specific and overall quality of life domains. Cancer, 120(13). doi: 10.1002/cncr.28737 
Charlier, C., Van Hoof, E., Pauwels, E., Lechner, L., Spittaels, H., \& De Bourdeaudhuij, I. (2013). The contribution of general and cancer-related variables in explaining physical activity in a breast cancer population 3 weeks to 6 months post treatment. Psycho-Oncology, 22(1), 203-211. doi: 10.1002/pon.2079

Cherrier, M. M., Anderson, K., David, D., Higano, C. S., Gray, H., Church, A., \& Willis, S. L. (2013). A randomized trial of cognitive rehabilitation in cancer survivors. Life Sciences, 93(17), 617-622. doi: 10.1016/j.lfs.2013.08.011

Christiansen, C., \& Baum, C. M. (1997). Person-environment-occupational performance: A conceptual model for practice. In C. Christiansen \& C. M. Baum (Eds.), Enabling function and well-being (2nd ed., pp. 46-70). Thorofare, NJ: SLACK.

Christiansen, C., Clark, F., Kielhofner, G., Rogers, I., \& Nelson, D. (1995). Position paper: Occupation. American Journal of Occupational Therapy, 49(10), 10151018.

Christiansen, C., \& Townsend, E. (Eds.). (2010). Introduction of occupation: The art and science of living. Upper Saddle River, NJ: Pearson Education, Inc.

Clarke, C. (2009). An Introduction to Interpretative Phenomenological Analysis: a Useful Approach for Occupational Therapy Research. The British Journal of Occupational Therapy, 72(1), 37-39. Retrieved from: http://www.ingentaconnect.com.ezproxylocal.library.nova.edu/

Cohen, M., \& Numa, M. (2011). Posttraumatic growth in breast cancer survivors: A comparison of volunteers and non-volunteers. Psycho-Oncology, 20(1), 69-76. doi: 10.1002/pon.1709

Coleman-Brueckheimer, K., Spitzer, J., \& Koffman, J. (2009). Involvement of rabbinic and communal authorities in decision-making by haredi Jews in teh UK with breast cancer: An interpretative phenomenological analysis. Social Science and Medicine, 68(2), 323-333. doi: 10.1016/j.socscimed.2008.10.003

Collins, B., Mackenzie, J., \& Kyeremanteng, C. (2013). Study of the cognitive effects of chemotherapy: Considerations in selection of a control group. Journal of Clinical and Experiemental Neuro-psychology, 35(4), 435-444. doi: 10.1080/13803395.2013.781995 
Cormie, P., Pumpa, K., Galvao, D., Turner, E., Spry, N., \& Saunders, C. (2013). Is it safe and efficacious for women with lymphedema secondary to breast cancer to lift heavy weights during exercise: A randomized controlled trial. Journal of Cancer Survivorship: Research and Practice, 7(3), 413-424. doi: 10.1007/s00520-0142255-7

Costanzo, E. S., Lutgendorf, S. K., \& Roeder, S. L. (2011). Common-sense beliefs about cancer and health practices among women completing treatment for breast cancer. Psycho-Oncology, 20(1), 53-61. doi: 10.1002/pon.1707

Creswell, J. W. (2009). Research design: Qualitative, quantitative, and mixed methods approaches [Kindle DX version] Retrieved from Amazon.com

Creswell, J. W., Klassen, A. C., Plano- Clark, V. I., \& Smith, K. C. (2011). Best practices for mixed methods research in the health sciences. Retrieved from http://obssr.od.nih.gov/scientific_areas/methodology/mixed_methods_research/pd f/Best_Practices_for_Mixed_Methods_Research.pdf.

Cronin-Davis, J., Butler, A., \& Mayers, C. (2009). Occupational therapy and interpretative phenomenological analysis: comparable research companions? British Journal of Occupational Therapy, 72(8), 332-338. Retrieved from: http://www.ingentaconnect.com.ezproxylocal.library.nova.edu/

Crossley, M. (2001). Sense of place and its import for life transitions: The case of HIVpositive individuals. In D. McDadams, R. Josselson, \& L. A (Eds.), Turns in the road: Narrative studies of lives in transition. Washington, DC: American Psychological Association.

de Jong, N., Candel, M. J., Schouten, H., Abu-Saad, H. H., \& Courtens, A. (2006). Course of the fatigue dimension "activity level" and the interference of fatigue with daily living activities for patients with breast cancer receiving adjuvant chemotherapy. Cancer Nursing, 29(5), E1-E13. doi: 10.1097/00002820200609000-00013

de Ruiter, M. B., Reneman, L., Boogerd, W., Veltman, D. J., van Dam, F. S. A. M., Nederveen, A. J., . . . Schagen, S. B. (2011). Cerebral hyporesponsiveness and cognitive impairment 10 years after chemotherapy for breast cancer. Human Brain Mapping, 32(8), 1206-1219. doi: 10.1002/hbm.21102

Deprez, S., Amant, F., Smeets, A., Peeters, R., Leemans, A., Van Hecke, W., . . S Sunaert, S. (2012). Longitudinal assessment of chemotherapy-induced structural changes 
in cerebral white matter and its correlation with impaired cognitive functioning. Journal of Clinical Oncology, 30(3), 274-281. doi: 10.1200/JCO.2011.36.8571

Desiron, H. (2010). Occupational therapy and return to work for breast cancer survivors. WFOT Bulletin, 61, 45-51. Retrieved from: http://search.ebscohost.com/login.aspx?direct=true\&AuthType=cookie,ip,url,uid, custuid \&custid $=$ s $1134655 \& \mathrm{db}=\mathrm{ccm} \& \mathrm{AN}=2010838160 \&$ site $=$ ehost-live

Desiron, H., Donceel, P., de Rijk, A., \& van Hoof, E. (2013). A conceptual-practice model for occupational therapy to facilitate return to work in breast cancer patients. Journal of Occupational Rehabilitation, 23(4), 516-526. doi: 10.1007/s10926-013-9427-z

Devoogdt, N., Van Kampen, M., Geraerts, I., Coremans, T., Fieuws, S., Lefevre, J., . . . Christiaens, M.-R. (2010). Physical activity levels after treatment for breast cancer: one-year follow-up. Breast Cancer Research and Treatment, 123(2), 417 425. doi: 10.1007/s 10549-010-0997-6

Downie, F., Mar Fan, H. G., Houede-tchen, N. H., Yi, Q., \& Tannock, I. F. (2006). Cognitive function, fatigue, and menopausal symptoms in breast cancer patients receiving adjuvant chemotherapy: Evaluation with patient interview after formal assessment. Psycho-Oncology, 15(10), 921-930. doi: 10.1002/pon.1035

Edelstein, K., \& Bernstein, L. J. (2014). Cognitive dysfunction after chemotherapy for breast cancer. J Int Neuropsychol Soc, 20(4), 351-356. doi:

$10.1017 / \mathrm{S} 1355617714000149$

Edwards, D. (1999). The relationship between reasons for activity and older adult wellbeing. Journal of Applied Gerontology, 18(3). doi:

10.1177/073346489901800304

Everard, K., Lach, H., Fisher, E., \& Baum, C. (2000). Relationship of activity and social support to the functional health of older adults. The Journals of Gerontology Series B, Psychological Siences and Social Sciences, 55B(4), S208-S212. doi: 10.1093/geronb/55.4.S208

Fantoni, S., Peugniez, C., Duhamel, A., Skrzypczak, J., Frimat, P., \& Leroyer, A. (2010). Factors related to return to work by women with breast cancer in northern France. Journal of Occupational Rehabilitation, 20(1), 49-58. doi: 10.1007/s10926-0099215-y 
Fitzpatrick, T., Edgar, L., \& Remmer, J. (2013). Job satisfaction among volunteers with personal cancer experience. Journal of Social Service Research, 39(3), 293-305. doi: 10.1080/01488376.2013.763890

Flick, U. (2007). Designing qualitative research. Thousand Oaks, CA: SAGE Publications, Inc.

Gadamer, H.-G. (1989). Truth and Method, 2nd rev. edn.(1st English edn, 1975), trans. by J. Weinsheimer and DG Marshall, New York: Crossroad.

Gall, T. L., \& Comblat, M. W. (2002). Breast cancer survivors give voice: A qualitative analysis of spiritual factors in long-term adjustment. Psycho-Oncology, 11(5), 524-535. doi: 10.1002/pon.613

Gibbs, G. (2007). Analysing qualitative data. Thousand Oaks, CA: Sage Publications, Inc.

Giorgi, A. (2009). The descriptive phenomenological method in psychology: A modified Husserian approach. Pittsburgh, Pennsylvania: Duquesne University Press.

Gray, J. M. (1997). Application of pheomenological method to the concept of occupation. Journal of Occupational Science, 4(1), 5-17. doi: 10.1080/14427591.1997.9686416

Hamner, J. B., \& Fleming, M. D. (2007). Lymphedema Therapy Reduces the Volume of Edema and Pain in Patients with Breast Cancer. Annals of Surgical Oncology, 14(6), 1904-1908. doi: 10.1245/s10434-006-9332-1

Hawtin, H., \& Sullivan, C. (2011). Experiences of mindfulness training in living with rheumatic disease: An interpretative phenomenological analysis. The British Journal of Occupational Therapy, 74(3), 137-142. doi: 10.4276/030802211X12996065859283

Hayes, S. C., Battistutta, D., Parker, A. W., Hirst, C., \& Newman, B. (2005). Assessing task "burden" of daily activities requiring upper body function among women following breast cancer treatment. Support Care Cancer, 13(4), 255-265. doi: 10.1007/s00520-004-0729-8 
Hayes, S. C., Rye, S., Battistutta, D., DiSipio, T., \& Newman, B. (2010). Upper-body morbidity following breast cancer treatment is common, may persist longer-term and adversely influences quality of life. Health and Quality of Life Outcomes, 8(92), 1-7. doi: 10.1186/1477-7525-8-92.

Health information privacy: Summary of the HIPAA privacy rule. (2011). U.S. Department of Health \& Human Services. Retrieved January 16, 2012, from http://www.hhs.gov/ocr/privacy/hipaa/understanding/summary/index.html

Hegel, M., Lyons, K. D., Hull, J. G., Kaufman, P., Urquhart, L., Zhongze, L., \& Ahles, T. A. (2011). Feasibility study of a randomized controlled trial of a telephonedelivered problem-solving-occupational therapy intervention to reduce participation restrictions in rural breast cancer survivors undergoing chemotherapy. Psycho-Oncology, 20(10), 1092-1101. doi: 10.1002/pon.1830

Heidegger, M. (1996). Being and time: A translation of Sein und Zeit: SUNY Press.

Hidding, J. T., Beurskens, C. H., van der Wees, P. J., van Laarhaoven, H. W., \& Nijhuisan der Sanden, M. W. (2014). Treatment related impairments in arm and shoulder in patients with breast cancer: A systematic review. PLoS ONE, 9(5), 1-17. doi: 10.1371/journal.pone.0096748.

Hogan, C. (2014). Insights from breast cancer survivors: The interplay between context, epistemology, and change. Adult Education Quarterly. doi: $10.1177 / 0741713614523666$

Hong, S., Bardwell, W., Natarajan, L., Flatt, S., Rock, C., Newman, V., . . Pierce, J. (2007). Correlates of physical activity level in breast cancer survivors participating in Women's Healthy Eating and Living (WHEL) Study. Breast Cancer Research and Treatment, 101(2), 225-232. doi: 10.1007/s10549-0069284-y

Hoving, J. L., Broekhuizen, M., \& Frings-Dresen, M. (2009). Return to work of breast cancer survivors: A systematc review of intervention studies. BMC Cancer, 9 , 117. doi: 10.1186/1471-2407-9-117

Huang, H.-P., Chen, M.-L., Liang, J., \& Miaskowski, C. (2014). Changes in and predictors of severity of fatigue in women with breast cancer: A longitudinal study. International Journal of Nursing Studies, 51(4), 582-592. doi: 10.1016/j.ijnurstu.2013.09.003 
Hughes, S., Jaremka, L., Alfano, C., Glaser, R., Povoski, S., Lipari, A., . . KiecoltGlaser, J. (2014). Social support predicts inflammation, pain, and depressive symptoms: Longitudinal relationships among breast cancer survivors. Psychoneuroendocrinology, 42, 38-44. doi: 10.1016/j.psyneuen.2013.12.016

Husserl, E. (1970). The crisis of European sciences and transcendental phenomenology: An introduction to phenomenological philosophy: Northwestern University Press.

Ikiugu, M. (2007). Measuring occupational performance: A pragmatic and dynamic systems perspective. Journal of Occupational Rehabilitation, 14(3), 123-135. doi: 10.1080/14427591.2007.9686593

Irwin, M., Crumley, D., McTiernan, A., Bernstein, L., Baumgartner, R., Gilliland, F., . . . Ballard-Barbash, R. (2003). Physical activity levels before and after diagnosis of breast carcinoma: the Health, Eating, Activity, and Lifestyle (HEAL) study. Cancer, 97(7), 1746-1757. doi: 10.1002/cncr.11227

Jansen, C. E., Cooper, B. A., Dodd, M. J., \& Miaskowski, C. A. (2011). A prospective longitudinal study of chemotherapy-induced cognitive changes in breast cancer patients. Support Care in Cancer, 19(10), 1647-1656. doi: 10.1007/s00520-0100997-4

Jenkins, V., Shilling, V., Deutsch, G., Bloomfield, D., Morris, R., Allan, S., . . . Winstanley, J. (2006). A 3-year prospective study of the effects of adjuvant treatments on cognition in women with early stage breast cancer. Br J Cancer, 94(6), 828-834. doi: 10.1038/sj.bjc.6603029

Johnson, R. B., \& Onwuegbuzie, A. (2004). Mixed methods research: A research paradigm whose time has come. Educational researcher, 33(7), 14-26. doi: 10.3102/0013189X033007014

Johnsson, A., Fornander, T., Rutqvist, L., \& Olsson, M. (2011). Work status and life changes in the first year after breast cancer diagnosis. Work, 38(4), 337-346. doi: 10.3233/WOR-2011-1137.

Kahana, E. (1982). A congruence model of person-environment interaction. In M. P. Lawton, P. G. Windley, \& T. D. Byers (Eds.), Aging and the environment: Theorectical approaches (pp. 97-121). New York: Springer. 
Kaplan, R., Yadav, R., Talavera, F., \& Foye, P. (2011). Breast cancer and rehabilitation. Cancer and rehabilitation. Retrieved September 24, 2011, from http://emedicine.medscape.com/article/320261-overview\#aw2aab6b3

Kaplan, S. (1983). A model of person-enviornment compatibility. Environment and Behaviour, 15(3), 311-332. doi: 10.1177/0013916583153003

Karki, A., Simonen, R., Malkia, E., \& Selfe, J. (2005). Impairments, activity limitations and participation restrictions 6 and 12 months after breast cancer operation. Journal of Rehabilitation Medicine, 37(3), 180-188. doi: 10.1080/16501970410024181

Katz, N., Karpin, H., Lak, A., Furman, T., \& Hartman-Maeir, A. (2003). Participation in occupational performance: Reliability and validity of the activity card sort. OTJR: Occupation, Participation \& Health, 23(1), 10-17. Retrieved from: http://web.ebscohost.com.ezproxylocal.library.nova.edu/ehost

Kaya, T., Karatepe, A., Gunaydin, R., Yetis, H., \& Uslu, A. (2010). Disability and healthrelated quality of life after breast cancer surgery: Relation to impairments. Southern Medical Journal, 103(1), 37-41. doi: 10.1097/SMJ.0b013e3181c38c41

Keegan, T., Shariff-Marco, S., Sangaramoorthy, M., Koo, J., Hertz, A., Schupp, C., . . . Gomez, S. (2014). Neighborhood influences on recreational physical activity and survival after breast cancer. Cancer Causes Control, 25(10), 1295-1308. doi: 10.1007/s10552-014-0431-1

Keesing, S., \& Rosenwax, L. (2011). Is occupation missing from occupational therpay in palliative care. Australian Journal of Occupational Therapy, 58(5), 329-336. doi: 10.1111/j.1440-1630.2011.00958.x

Kenyon, M., Mayer, D. K., \& Owens, A. K. (2014). Late and Long-Term Effects of Breast Cancer Treatment and Surveillance Management for the General Practitioner. Journal of Obstetric, Gynecologic, and Neonatal Nursing, 43(3), 382-398. doi: 10.1111/1552-6909.12300

Kheir, W. J., Sniegowski, M. C., El-Sawy, T., Li, A., \& Esmaeli, B. (2014). Ophthalmic complications of targeted cancer therapy and recently recognized ophthalmic complications of traditional chemotherapy. Survey of Ophthalmology, 59(5), 493502. doi: http://dx.doi.org/10.1016/j.survophthal.2014.02.004 
Kim, D. S., Sim, Y.-J., Jeong, J., \& Kim, G. C. (2010). Effect of active resistive exercise on breast cancer-related lymphedema: A randomized controlled trial. Archives of Physical Medicine and Rehabilitation, 91(12), 1844-1848. doi: 10.1016/j.apmr.2010.09.008

Knapper, C., Lerner, S., \& Bunting, T. (1986). Special groups and the environment: An introduction. Environments, 18(3), 1-5.

Knobf, M. T., \& Sun, Y. (2005). A longitudinal study of symptoms and self-care activities in women treated with primary radiotherapy for breast cancer. Cancer Nursing, 28(3), 210-218. doi: 10.1097/00002820-200505000-00010

Kopec, J. A., Colangelo, L. H., Land, S. R., Julian, T. B., Brown, A. M., Anderson, S. J., ... Ganz, P. (2013). Relationship between arm morbidity and patient-reported outcomes following surgery in women with node-negative breast cancer: NSABP protocol B-32. Journal of Supportive Oncology, 11(1), 22-30. Retrieved from: http://www.oncologypractice.com/fileadmin/content_images/jso/PDF/Arm_Morbi dity.pdf

Kroenke, C. H., Kwan, M. L., Neugut, A. I., Ergas, I. J., Wright, J. D., Caan, B. J., . . . Kushi, L. H. (2013). Social networks, social support mechanisms, and quality of life after breast cancer diagnosis. Breast Cancer Research and Treatment, 139, 515+. doi: 10.1007/s10549-013-2477-2

Kuroi, K., Shimozuma, K., Ohashi, Y., Hisamatsu, K., Masuda, N., Takeuchi, A., . . . Hausheer, F. (2009). Prospective assessment of chemotherapy-induced peripheral neuropathy due to weekly paclitaxel in patients with advanced or metastatic breast cancer (CSP-HOR 02 study). Support Care Cancer, 17(8), 1071-1080. doi: $10.1007 / \mathrm{s} 00520-008-0550-\mathrm{x}$

Kvale, S. (2009). Doing interviews. Thousand Oaks, CA: Sage Publications Inc.

Kwan, M. L., Sternfeld, B., Isaac, J., Timperi, A. W., Roh, J. M., Hong, C., . . Kushi, L. H. (2011). Change in physical activity during active treatment in a prospective study of breast cancer survivors. Breast Cancer Research and Treatment, 131(2), 679-690. doi: 10.1007/s10549-011-1788-4

la Cour, K., Johannessen, H., \& Josephsson, S. (2009). Activity and meaning making in the everyday lives of people with advanced cancer. Palliative Support Care, 7(4), 469-479. doi: 10.1017/S1478951509990472 
la Cour, K., Nordell, K., \& Josephsson, S. (2008). Everyday lives of people with advanced cancer: Activity, time, location, and experience. OTJR: Occupation, Participation \& Health, 29(4), 154-162. doi: 10.3928/15394492-20090914-03

Lasinski, B. B. (2013). Complete Decongestive Therapy for Treatment of Lymphedema. Seminars in Oncology Nursing, 29(1), 20-27. doi: 10.1016/j.soncn.2012.11.004

Law, M., Baum, C., \& Baptiste, S. (2002). Occupation-based practice: Fostering performance and participation therapy. Thorofare, NJ: SLACK, Inc.

Law, M., Cooper, B., Strong, S., Stewart, D., Rigby, P., \& Letts, L. (1996). The personenvironment-occupation model: A transactive approach to occupational performance. Canadian Journal of Occupational Therapy, 63(1), 10-23. Retrieved from: http://go.galegroup.com.ezproxylocal.library.nova.edu/

Lawton, M. P. (1977). The impact of the environment on aging and behaviour. In J. E. Birren \& K. W. Schale (Eds.), New dimensions in environmental design (pp. 276301). New York: Van Nostrand Reinhold.

Lee, J., Dibble, S., Pickett, M., \& Judith, L. (2005). Chemotherapy-induced nauseavomiting and functional status in women treated for breast cancer. Cancer Nursing, 28(4), 249-255. doi: 10.1097/00002820-200507000-00002

Lee, T., Kilbreath, S., Refshauge, K., Herbert, R., \& Beith, J. (2008). Prognosis of the upper limb following surgery and radiation for breast cancer. Breast Cancer Research and Treatment, 110(1), 19-37. doi: 10.1007/s10549-007-9710-9

Lee, T., Kilbreath, S. L., Sullivan, G., Refshauge, K. M., Belth, J. M., \& Harris, L. M. (2009). Factors that affect intention to avoid strenuous arm activity after breast cancer surgery. Oncology Nursing Forum, 36(4), 454-462. doi: 10.1188/09.ONF.454-462

Levy, E. W., Pfulzer, L. A., Danoff, J., Springer, B. A., McGarvey, C., Shieh, C., . . . Stout, N. L. (2012). Predictors of functional shoulder recovery at 1 and 12 months. Breast Cancer Research and Treatment, 134(1), 315-324. doi: 10.1007/s10549-012-2061-1

Lichtman, M. (2010). Qualitative research in education: A user's guide. Thousand Oaks, CA: Sage. 
Lilliehorn, S., Hamberg, K., Kero, A., \& Salander, P. (2013). Meaning of work and the returning process after breast cancer: A longitudinal study of 56 women.

Scandinavian Journal of Caring Sciences, 27(2), 267-274. doi: 10.1111/j.14716712.2012.01026.x

Lindbohm, M. L., Kuosma, E., Taskila, T., Hietanen, P., Carlsen, K., Gudbergsson, S., \& Gennarsdottir, H. (2014). Early retirement and non-employment after breast cancer. Psycho-Oncology, 23(6), 634-641. doi: 10.1002/pon.3459

Litchman, R. R., Taylor, S. E., \& Wood, J. V. (1987). Social support and marital adjustment after breast cancer. Journal of Psychosocial Oncology, 5(3), 47-74. doi: 10.1300/J077v05n03_03

Littman, A., Tang, M., \& Rossing, M. (2010). Longitudinal study of recreational physical activity in breast cancer survivors. Journal of Cancer Survivor, 4(2). doi: 10.1007/s11764-009-0113-2

Loh, S. Y., Chew, S.-L., \& Lee, S.-Y. (2011). Physical activity and women with breast cancer: Insights from expert patients. Asian Pacific Journal of Cancer Prevention, 12(1), 87-94. Retrieved from: http://www.apocp.org/journal_of_cancer_prevention_volume_12.php

Ludwig, F. M. (2004). Occupation-based Occupation-centered perspectives. In K. F. Walker \& F. M. Ludwig (Eds.), Perspectives on Theory for the Practice of Occupational Therapy, 3rd Ed. (pp. 373--442). Austin, TX: Pro-ed.

Lyons, K. D. (2006). Occupation as a vehicle to surmount the psychosocial challenges of cancer. Occupational Therapy in Health Care, 20(2), 1-16. doi: 10.1300/J003v20n02_01

Lyons, K. D., Erickson, K. S., \& Hegel, M. T. (2012). Problem-solving strategies of women undergoing chemotherapy for breast cancer. Canadian Journal of Occupational Therapy, 79(1), 33-40. doi: 10.2182/cjot.2012.79.1.5

Lyons, K. D., Hull, J. G., Root, L. D., Kimtis, E., Schaal, A. D., Stearns, D. M., . . Ahles, T. A. (2011). A pilot study of activity engagement in the first six months after stem cell transplantation. Oncology Nursing Forum, 38(1), 75-83. doi: 10.1188/11.ONF.75-83 
Lyons, K. D., Lambert, L. A., Stefan, B., Hegel, M. T., \& B., S. (2013). Changes in activity levels of older adult cancer survivors. OTJR: Occupation, Participation \& Health, 33(1), 31-39. doi: 10.3928/15394492-20120607-02

Lyons, K. D., Li, Z., Tosteson, T. D., Meehan, K. R., \& Ahles, T. A. (2010). Consistency and construct validity of the activity card sort (modified) in measuring activity resumption after stem cell transportation. American Journal of Occupational Therapy, 64(4), 562-569. doi: 10.5014/ajot.2010.09033

Mandelblatt, J., Gheorghe, L., Kwan, M., Makgoeng, S., Ergas, I., Roh, J., . . Kushi, L. (2011). Associations of physical activity with quality of life and functional ability in breast cancer patients during active adjuvant treatment: The pathways study. Breast Cancer Research and Treatment, 129(2). doi: 10.1007/s10549-011-1483-5

Matthews, E., Schmiege, S., Cook, P., \& Sousa, K. (2012). Breast Cancer and Symptom Clusters During Radiotherapy. Cancer Nursing, 35(2), E1-E11 doi: 10.1097/NCC.0b013e3182277222

McDuff, S., Taich, Z., Lawson, J., Sanghvi, P., Wong, E., Barker, F., . . Chen, C. (2013). Neurocognitive assessment following whole brain radiation therapy and radiosurgery for patients with cerebral metastases. Journal of Neurology, Neurosuergery, \& Psychiatry, 84(12), 1385-1391. doi: 10.1136/jnnp-2013305166

McNeely, M. L., Campbell, K. L., Rowe, B. H., Klassen, T. P., Mackey, J. R., \& Courneya, K. S. (2006). Effects of exercise on breast cancer patients and survivors: A systematic review and meta-analysis. Canadian Medical Association Journal, 175(1), 34-41. doi: 10.1503/cmaj.051073

Merleau-Ponty, M. (1996). Phenomenology of perception: Motilal Banarsidass Publishe.

Midtgaard, J., Tveteras, A., Rørth, M., Stelter, R., \& Adamsen, L. (2006). The impact of supervised exercise intervention on short-term postprogram leisure time physical activity level in cancer patients undergoing chemotherapy: 1- and 3-month follow-up on the body \& cancer project. Palliative \& Supportive Care, 4(01), 2535. doi: $10.1017 / \mathrm{S} 1478951506060044$

Miedema, B., Hamilton, R., Tatemichi, S., Thomas-MacLean, R., Hack, T., Quinlan, E., . .. Kwan, W. (2011). Do breast cancer survivors' post-surgery difficulties with recreational activities persist over time? Journal of Cancer Survivor, 5(4), 405412. doi: $10.1007 / \mathrm{s} 11764-011-0190-\mathrm{x}$ 
Mock, V., Frangakis, C., Davidson, N. E., Ropka, M. E., Pickett, M., Poniatowski, B., . . McCorkle, R. (2005). Exercise manages fatigue during breast cancer treatment: A randomized controlled trial. Psycho-Oncology, 14(6), 464-477. doi: 10.1002/pon.863

Mols, F., Beijers, T., Vreugdenhil, G., \& Poll-Franse, v. d. (2014). Chemotherapyinduced peripheral neuropathy and its association with quality of life: A systematic review. Support Care in Cancer. doi: 10.1007/s00520-014-2255-7

Moore, K., VanHaitsma, K., Curyto, K., \& Saperstein, A. (2003). A pragmatic environmental psychology: A meta theoretical inquiry into the work of M. Powell Lawton. Journal of Environmental Psychology, 23(4), 471-482. doi: 10.1016/S0272-4944(02)00116-0

Moos, R. H. (1980). Specialized living environments for older people: A conceptual framework for evaluation. Journal of Social Issues, 36(2), 75-94. doi: 10.1111/j.1540-4560.1980.tb02023.x

Morse, J. M., \& Niehaus, L. (2009). Mixed method design: Principles and procedures. Walnut Creek, CA: Left Coast Press, Inc.

Moskowitz, M. C., Feuerstein, M., \& Todd, B. L. (2013). Job stress and physical activity related to elevated symptom clusters in breast cancer survivors at work. Journal of Occupational \& Environmental Medicine, 55(1), 93-98. doi: 10.1097/JOM.0b013e31826eef97

Moustakas, C. (1994). Phenomenolgical research methods. Thousand Oaks, CA: SAGE Publications.

Munhall, P. (2007). A phenomenological method. In P. Munhall (Ed.), Nursing research: A qualitative perspective. Sudbury, MA: Jones and Barlett Publishers.

Nesbit, S. (2006). Using creativity to experience flow on my jouney with breast cancer. Occupational Therapy in Mental Health, 22(2), 61-77. doi: 10.1300/J004v22n02_03

Nesvold, I.-L., Reinertsen, K., Fossa, S. D., \& Dahl, A. A. (2011). The relation between $\mathrm{arm} /$ shoulder problems and quality of life in breast cancer survivors: A crosssectional and longitudinal study. Journal of Cancer Survivor, 5(1), 62-72. doi: 10.1007/s11764-010-0156-4 
Newman, R. M. (2013). Re-defining one's occupational self 2 years after breast cancer: A case study. Work: A Journal of Prevention, Assessment and Rehabilitation, 46(4), 439-444. doi: 10.3233/WOR-131679.

Nilsson, M. I., Olsson, M., Wennman-Larsen, A., Petersson, L. M., \& Alexanderson, K. (2013). Women's reflections and actions regarding working after breast cancer surgery - a focus group study. Psycho-Oncology, 22(7), 1639-1644. doi: 10.1002/pon.3192

Njie-Carr, V. (2014). Violence experiences among HIV-infected women and perceptions of male perpetrators' roles: A concurrent mixed method study. Journal of the association of nurses in aids care, 25(5). doi: 10.1016/j.jana.2013.11.002

Noeres, D., Park-Simon, T., Grabow, J., Sperlich, S., Koch-Giesselmann, H., Jaunzeme, J., \& Geyer, S. (2013). Return to work after treatment for primary breast cancer over a 6-year period: Results from a prospective study comparing patients with the general population. Support Care Cancer, 21(7), 1901-1909. doi: 10.1007/s00520-013-1739-1

O'Brien, J. C., Bergeron, A., Duprey, H., Olver, C., \& St. Onge, H. (2009). Children with disabilities and their parents' views of occupational participation needs. Occupational Therapy in Mental Health, 25(2), 164-180. doi: 10.1080/01642120902859196

Ogce, F., \& Ozkan, S. (2008). Changes in functional status and physical and psychological symptoms in women receiving chemotherapy for breast cancer. Asian Pacific Journal of Cancer Prevention, 9(3), 449-452. Retrieved from: http://www.apocp.org/journal_of_cancer_prevention_volume_9.php

Onwuegbuzie, A., \& Leech, N. (2006). Linking research questions to mixed methods data analysis procedures. The Qualitative Report, 11(3), 474-498. Retrieved from: http://www.nova.edu/ssss/QR/QR11-3/onwuegbuzie.pdf

Onwuegbuzie, A., \& Teddlie, C. (2003). A framework for analyzing data in mixed methods research. In A. Tashakkori \& C. Teddlie (Eds.), Handbook of mixed methods in social and behavioral research (pp. 351-383). Thousand Oaks, CA: Sage.

Padilla, R. (2003). Clara: A phenomenology of disability. American Journal of Occupational Therapy, 57(4), 413-423. doi: 10.5014/ajot.57.4.413 
Paganini-Hill, A., \& Clark, L. J. (2000). Preliminary assessment of cognitive function in breast cancer patients treated with tamoxifen. Breast Cancer Research and Treatment, 64(2), 165-117. doi: 10.1023/A:1006426132338

Palmadottir, G. (2009). The road to recover: Experiences and occupational lives of Icelandic women with breast cancer. Occupational Therapy in Health Care, 23(4), 3190335. doi: 10.3109/07380570903242433

Palmadottir, G. (2010). The role of occupational participation and environment among Icelandic women with breast cancer: A qualitative study. Scandinavian Journal of Occupational Therapy, 17(4), 299-307. doi: 10.3109/11038120903302874

Parry, D. (2008). The contribution of dragon boat racing to women's health and breast cancer survivorship. Qualitative health research, 18(2), 222-233. doi: $10.1177 / 1049732307312304$

Penttinen, H. M., Saarto, T., Kellokumpu-Lehtinen, P., Blomqvist, C., Huovinen, R., Kautiainen, H., . . Hakamies-Blomqvist, L. (2011). Quality of life and physical performance and activity of breast cancer patients after adjvant treatments. Psycho-Oncology, 20(11), 1211-1220. doi: 10.1002/pon.1837

Pettican, A., \& Prior, S. (2011). 'It's a new way of life': An exploration of the occupational transition of retirement. The British Journal of Occupational Therapy, 74(1), 12-19. doi: 10.4276/030802211X12947686093521

Phillips, S. M., \& McAuley, E. (2013). Social cognitive influences on physical activity participation in long-term breast cancer survivors. Psycho-Oncology, 22(4), 783791. doi: 10.1002/pon.3074

Pinto, B., Trunzo, J., Reiss, P., \& Shiu, S. (2002). Exercise participation after diagnosis of breast cancer: Trends and effects on mood and quality of life. PsychoOncology, 11(5), 389-400. doi: 10.1002/pon.594

Player, L., MacKenzie, L., Willis, K., \& Loh, S. Y. (2014). Women's experiences of cognitive changes or 'chemobrain' following treatment for breast cancer: A role for occupational therapy? Australian Journal of Occupational Therapy. doi: $10.1111 / 1440-1630.12113$

Poirier, P. (2011). The impact of fatigue on role functioning during radiation therapy. Oncology Nursing Forum, 38(4), 457-465. doi: 10.1188/11.ONF.457-465 
Portney, L. G., \& Watkins, M. (2009). Foundations of clinical research: Applications to practice (3rd ed.). Upper Saddle River, New Jersey: Pearson Education, Inc.

Prigozin, A., Uziely, B., \& Musgrave, C. F. (2010). The relationship between symptom severity and symptom interference, education, age, marital status, and type of chemotherapy treatment in Israeli women with early-stage breast cancer. Oncology Nursing Forum, 37(6), E411-E418. doi: 10.1188/10.ONF.E411-E418 .

Reed, K. L., Hocking, C., \& Smyth, L. (2010). The interconnected meanings of occupation: The call, being-with, possibilities. Journal of Occupational Science, 17(3), 140-149. doi: 10.1080/14427591.2010.9686688

Reuter-Lorenz, P. A., \& Cimprich, B. (2012). Cognitive fumction and breast cancer: Promise and potential insights from functional brain imaging. Breast Cancer Research and Treatment, 137(1), 33-43. doi: 10.1007/s10549-012-2266-3

Reynolds, F., \& Prior, S. (2003). 'A lifestyle coat-hanger': A phenomenological study of the meaning of artwork for women coping with chronic illness. Disability and Rehabilitation, 25(14), 785-794. doi: 10.1080/0963828031000093486

Rietman, J., Dijkstra, P., Debreczeni, R., Geertzen, J., Robinson, D., \& de Vries, J. (2004). Impairments, disabilities and health related quality of life after treatment for breast cancer: a follow-up study 2.7 years after surgery. Disability and Rehabilitation, 26(2), 78-84. doi: 10.1080/09638280310001629642

Rietman, J., Dijkstra, P., Hoekstra, H., Eisma, W., Szabo, B., Groothoff, J., \& Geertzen, J. (2003). Late morbidity after treatment of breast cancer in relation to daily activities and quality of life: A systematic review. European Journal of Surgical Oncology, 29(3), 229-238. doi: 10.1053/ejso.2002.1403

Rosenblum, S., Yurman, G., Gotfrid, Z., Wolpart, M., \& Binyamin, N. (2005). Changes in leisure activity participation of women after undergoing surgical intervention for breast cancer. The Israel Journal of Occupational Therapy, 14(3), E112-E113.

Roulston, K. (2010). Reflective interviewing: A guide to theory and practice. Thousand Oaks, CA: Sage publications, Inc.

Rowland, J., Hewitt, M., \& Ganz, P. (2006). Cancer survivorship: A new challenge in delivering quality cancer care. Journal of Clinical Oncology, 24(32), 5101-5104. doi: 10.1200/JCO.2006.09.2700 
Ruini, C., \& Vescovelli, F. (2013). The Role of Gratitude in Breast Cancer: Its Relationships with Post-traumatic Growth, Psychological Well-Being and Distress. Journal of Happiness Studies, 14(1), 263-274. doi: 10.1007/s10902-0129330-x

Sabiston, C. M., \& Brunet, J. (2012). Reviewing the benefits of physical activity during cancer survivorship. American Journal of Lifestyle Medicine, 6(2), 167-177. doi: $10.1177 / 1559827611407023$

Sachs, D., \& Josman, N. (2003). The activity card sort: A factor analysis. OTJR: Occupation, Participation \& Health, 23(4), 165-174. Retrieved from: http://web.ebscohost.com.ezproxylocal.library.nova.edu/ehost

Sagen, A., Karesen, R., Sandvik, L., \& Risberg, M. A. (2009). Changes in arm morbidities and health-related quality of life after breast cancer surgery - a fiveyear follow-up study. Acta Oncologica, 48(8), 1111-1118. doi: $10.3109 / 02841860903061691$

Sartre, J.-P. (1956). Being and Nothingness, Hazel E. Barnes, trans.(New York: Washington Square,[1943] 1966), 101-103.

Savin-Baden, M., \& Fisher, A. (2002). Negotiating 'honesties' in the research process. The British Journal of Occupational Therapy, 65(4), 191-193. Retrieved from: http://docserver.ingentaconnect.com.ezproxylocal.library.nova.edu/

Schilder, C. M., Seynaeve, S., Beex, L. v., Boogerd, W., Linn, S. C., Gundy, C. M., . . . Schagen, S. B. (2010). Effects of tamoxifen and exemestane on cognitive functioning of postmenopausal patients with breast cancer: Results of neuropsychological side study of the tamoxifen and exemestane adjuvant multinational trial. Journal of Clinical Oncology, 28(8), 1294-1300. doi: $10.1200 / \mathrm{JCO} .2008 .21 .3553$

Schleiermacher, F., \& Bowie, A. (1998). Schleiermacher: hermeneutics and criticism: and other writings: Cambridge University Press.

Schmidt, M. E., Chang-Claude, J., Siebold, P., Vrieling, A., Heinz, J., Flesch-Janys, D., \& Steindorf, K. (2014). Determinants of long-term fatigue in breast cancer survivors: Results of a prospective cohort study. Psycho-Oncology. doi: $10.1002 /$ pon.3581 
Schmitz, K. H., Ahmed, R. L., Troxel, A., Cheville, A., Lewis-Grant, L., Smith, R., . . . Chittams, J. (2010). Weight lifting for women at risk for breast cancer-related lymphedema: a randomized trial. Journal of the American Medical Association, 304(24), 2699-2705. doi: 10.1001/jama.2010.1837

Schmitz, K. H., Ahmed, R. L., Troxel, A., Cheville, A., Smith, R., Lewis-Grant, L., . . . Greene, Q. P. (2009). Weight lifting in women with breast-cancer-related lymphedema. The New England Journal of Medicine, 361(7), 664-673. doi: 10.1056/NEJMoa0810118

Seifert, M. L. (2010). Fatigue, pain, and functional status during outpatient chemotherapy. Oncology Nursing Forum, 37(2), E114-E123. doi: 10.1188/10.ONF.114-123

Shalinsky, W. (1986). Disabled persons and their environments. Environments, 17(1), 18.

Shannon, C. (2005). Breast cancer treatment: The effect on and therapeutic role of leisure. American Journal of Recreation Therapy, 4(3), 25-31.

Shannon, C., \& Bourque, D. (2005). Overlooked and underutilized: The critical role of leisure interventions in facilitating social support throughout breast cancer treatment and recovery. Social Work in Health Care, 42(1), 73-92. doi: 10.1300/J010v42n01_05

Siegel, R., DeSantis, C., Virgo, K., Stein, K., Mariotto, A., Smith, T., .. . Ward, E. (2012). Cancer treatment and survivorship statistics, 2012. CA: A Cancer Journal for Clinicians, 62(4), 220-241. doi: 10.3322/caac.21149

Siegel, R., Miller, K., \& Jemal, A. (2015). Cancer statistics, 2015. CA: A Cancer Journal for Clinicians, 65(1), 5-29. doi: 10.3322/caac.21254

Silver, J. K. (2007). Rehabilitation in Women with Breast Cancer. Physical Medicine and Rehabilitation Clinics of North America, 18(3), 521-537. doi: http://dx.doi.org/10.1016/j.pmr.2007.05.003

Silver, J. K., Baima, J., Newman, R., Galantino, M. L., \& Shockney, L. D. (2013). Cancer rehabilitation may improve function in survivors and decrease the economic burden of cancer to individuals and society. Work, 46(4), 455-472. doi: 10.3233/WOR-131755 
Smith, J. A. (1996). Beyond the divide between cognition and discourse: Using the interpretative phenomenological analysis in health psychology. Psychology and Health, 11(2), 261-271. doi: 10.1080/08870449608400256

Smith, J. A., Flowers, P., \& Larkin, M. (2009). Interpretative phenomenological analysis: Theory, method, and research. London: Sage.

Smoot, B., Wong, J., Cooper, B., Wanek, L., Topp, K., Byl, N., \& Dodd, M. (2010). Upper extremity impairments in women with or without lymphdema following breast cancer treatment. Journal of Cancer Survivor, 4(2), 167-178. doi: 10.1007/s11764-010-0118-x

Smyth, G., Harries, P., \& Dorer, G. (2011). Exploring mental health service users' experiences of social inclusion in their community occupations. The British Journal of Occupational Therapy, 74(7), 323-331. doi: 10.4276/030802211X13099513661072

Snodgrass, J. (2011). Effective occupational therapy interventions in the rehabilitation of individuals with work-related low back injuries and illnesses: A systematic review. American Journal of Occupational Therapy, 65(1), 37-43. doi: 10.5014/ajot.2011.09187

Stagl, J. M., Antoni, M. H., Lechner, S. C., Carver, C. S., \& Lewis, J. E. (2014). Postsurgical physical activity and fatigue-related daily interference in women with non-metastatic breast cancer. Psychology \& Health, 29(2), 177-198. doi: $10.1080 / 08870446.2013 .843682$

Stubblefield, M. D., \& Custodio, C. M. (2006). Upper-Extremity Pain Disorders in Breast Cancer. Archives of Physical Medicine and Rehabilitation, 87(3), 96-99. doi: 10.1016/j.apmr.2005.12.017

Swisher, A. K., Davison, C., Aranda, R., Eye, D., \& Erickson, M. (2010). Frequency and severity of self-reported upper extremity impairments, activity limitations, and participation restrictions following breast cancer treatment. Rehabilitation Oncology, 28(1), 3-9. Retrieved from: http://proquest.umi.com.ezproxylocal.library.nova.edu/

Tallet, A. V., Azria, D., Barlesi, F., Spano, J.-P., Carpentier, A. F., Gonçalves, A., \& Metellus, P. (2012). Neurocognitive function impairment after whole brain radiotherapy for brain metastases: actual assessment. Radiat Oncol, 7, 77. Retrieved from: http://www.biomedcentral.com/content/pdf/1748-717X-7-77.pdf 
Tashakkori, A., \& Teddlie, C. (2003). Handbook of mixed methods in the social \& behavioral research. Thousand Oaks, CA: Sage Publications.

Townsend, E. (1997). Occupation: Potential for personal and social transformation. Journal of Occupational Science, 4(1), 18-16. doi: $10.1080 / 14427591.1997 .9686417$

Triple negative breast cancer. (2014). from http://ww5.komen.org/BreastCancer/TripleNegativeBreastCancer.html

Tzanidaki, D., \& Reynolds, F. (2011). Exploring the meanings of making traditional arts and crafts among older women in Crete, using interpretative phenomenological analysis. The British Journal of Occupational Therapy, 74(8), 375-382. doi: 10.4276/030802211X13125646370852

Unruh, A. M., \& Elvin, N. (2004). In the eye of the dragon: Women's experience of breast cancer and the occupation of dragon boat racing. Canadian Journal of Occupational Therapy, 71(3), 138-149. Retrieved from: http://find.galegroup.com.ezproxylocal.library.nova.edu

Unruh, A. M., Scammell, C., \& Smith, N. (2000). The occupation of gardening in lifethreatening illness: A qualitative pilot project. Canadian Journal of Occupational Therapy, 67(1), 70-77. Retrieved from: http://find.galegroup.com.ezproxylocal.library.nova.edu

van der Spek, N., Vos, J., van Uden-Kraan, C. F., Breitbart, W. T., R., Cuijpers, P., \& Verdonck-de Leeuw, I. M. (2013). Meaning making in cancer survivors: A focus group study. PLoS ONE, 8(9). doi: 10.1371/journal.pone.0076089

Ventura, E., Ganz, P., Bower, J., Abascal, L., Petersen, L., Stanton, A., \& Crespi, C. (2013). Barriers to physical activity and healthy eating in young breast cancer survivors: Modifiable risk factors and associations with body mass index. Breast Cancer Research and Treatment, 142(2), 423-433. doi: 10.1007/s10549-0132749-x

Verbelen, H., Gebruers, N., Eeckhout, F., Verlinden, K., \& Tjalma, W. (2014). Shoulder and arm morbidity in sentinel node-negative breast cancer patients: A systematic review. Breast Cancer Research and Treatment, 144(1), 21-31. doi: $10.1007 / \mathrm{s} 10549-014-2846-5$ 
Vockins, H. (2004). Occupational therapy intervention with patients with breast cancer: a survey. European Journal of Cancer Care, 13(1), 45-52. doi: 10.1111/j.13652354.2004.00443.x

Voege, P., Bower, J. E., Stanton, A. L., \& Ganz, P. A. (2014). Motivations associated with physical activity in young breast cancer survivors. Psychology, Health \& Medicine, 1-7. doi: 10.1080/13548506.2014.955033

Vrkljan, B., \& Miller-Polgar, J. (2001). Meaning of occupational engagement in lifethreatening illness: A qualitative pilot project. Canadian Journal of Occupational Therapy, 68(4), 237-246. Retrieved from: http://find.galegroup.com.ezproxylocal.library.nova.edu

Ward, K., Mitchell, J., \& Price, P. (2007). Occupation-based practice and its relationship to social and occupational participation in adults with spinal cord injury. OTJR: Occupation, Participation \& Health, 27(4), 149-156. Retrieved from: http://web.ebscohost.com.ezproxylocal.library.nova.edu/

Watters, J., Yau, J., O'Rourke, K., Tomiak, E., \& Getrler, S. (2003). Functional status is well maintained in older women during adjuvant chemotherapy for breast cancer. Annals of Oncology, 14(12), 1744-1750. doi: 10.1093/annonc/mdg497

Waxler-Morrison, N., Hislop, G., Mears, B., \& Kan, L. (1991). Effects of social relationships on survival of women with breast cancer: A prospective study. Social Sciences and Medicine, 33(2), 177-183. doi: 10.1016/02779536(91)90178-F

Wefel, J. S., Vardy, J., Ahles, T., \& Schlagen, C. B. (2011). International cognition and cancer task force recommendations to harmonize studies of cognitive function in patients with cancer. The Lancet Oncology, 12(7), 703-708. doi: 10.1016/S14702045(10)70294-1

Weisman, G. (1981). Modelling environment-behaviour systems: A brief note. Journal of Man-Environment Relations, 1, 32-41.

White, K. M. (2013). Occupational therapy interventions for people living with advanced lung cancer. Lung Cancer Management, 2, 121-127. doi: 10.2217/lmt.13.3 
Wickham, R. (2007). Chemotherapy-induced peripheral neuropathy: A review and implications for oncology nursing practice. Clinical Journal of Oncology Nursing, 11(3), 361-376. doi: 10.1188/07.CJON.361-376

Wilcock, A. (1998). Reflections on doing, being and becoming. Canadian Journal of Occupational Therapy, 65(5), 248-256. Retrieved from: http://go.galegroup.com.ezproxylocal.library.nova.edu/

Wright-St. Claire, V., Kerse, N., \& Smyth, E. (2011). Doing everyday occupations both conceals and reveals the phenomenon of being aged. Australian Occupational Therapy Journal, 58(2), 88-94. doi: 10.1111/j.1440-1630.2010.00885.x

Yardley, L. (2000). Dilemmas in qualitative health research. Psychology and Health, 15(2), 215-228. doi: 10.1080/08870440008400302 
Appendix A

Activity Card Sort-Modified Scoring System

ID\#:

Used with permission from Carolyn Baum, PhD, OTR/L, FAOTA

\begin{tabular}{|c|c|c|c|c|c|}
\hline $1^{\text {st }}$ visit: & visit: & $3^{\text {rd }} \mathbf{v}$ & & $4^{\text {th }}$ visit: & \\
\hline Activity & $\begin{array}{l}\text { Never } \\
\text { done prior } \\
\text { to breast } \\
\text { surgery }\end{array}$ & $\begin{array}{l}\text { Do now } \\
\text { (as often as } \\
\text { before } \\
\text { breast } \\
\text { surgery) }\end{array}$ & $\begin{array}{l}\text { Do less or } \\
\text { differently } \\
\text { than before } \\
\text { breast } \\
\text { surgery }\end{array}$ & $\begin{array}{l}\text { Not done } \\
\text { since } \\
\text { breast } \\
\text { surgery }\end{array}$ & $\begin{array}{l}\text { New } \\
\text { activity } \\
\text { since } \\
\text { breast } \\
\text { surgery }\end{array}$ \\
\hline Shopping in a store & & & & & \\
\hline Shopping for groceries & & & & & \\
\hline Dishes & & & & & \\
\hline Laundry & & & & & \\
\hline Yard maintenance & & & & & \\
\hline Taking out the trash & & & & & \\
\hline Cooking dinner & & & & & \\
\hline Mending & & & & & \\
\hline Preserving food & & & & & \\
\hline Household maintenance & & & & & \\
\hline $\begin{array}{l}\text { Fixing things around the } \\
\text { house }\end{array}$ & & & & & \\
\hline Driving & & & & & \\
\hline Getting gas & & & & & \\
\hline Car maintenance & & & & & \\
\hline Taking care of a pet & & & & & \\
\hline Paying bills & & & & & \\
\hline Managing investments & & & & & \\
\hline Resting & & & & & \\
\hline Beauty/barber shop & & & & & \\
\hline Child care & & & & & \\
\hline Spectator sports & & & & & \\
\hline Recreational shopping & & & & & \\
\hline Cooking as a hobby & & & & & \\
\hline Sewing & & & & & \\
\hline Quilting & & & & & \\
\hline Hand crafts & & & & & \\
\hline $\begin{array}{l}\text { Table games (e. g., } \\
\text { checkers, cards, etc. ) }\end{array}$ & & & & & \\
\hline Flower arranging & & & & & \\
\hline Computer & & & & & \\
\hline Collecting & & & & & \\
\hline
\end{tabular}


ID\#:

\begin{tabular}{|c|c|c|c|c|c|}
\hline Activity & 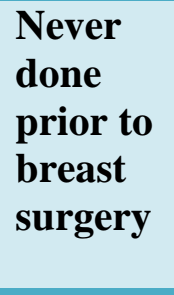 & $\begin{array}{l}\text { Do now } \\
\text { (as often } \\
\text { as before } \\
\text { breast } \\
\text { surgery) }\end{array}$ & $\begin{array}{l}\text { Do less or } \\
\text { differently } \\
\text { than } \\
\text { before } \\
\text { breast } \\
\text { surgery }\end{array}$ & $\begin{array}{l}\text { Not done } \\
\text { since } \\
\text { breast } \\
\text { surgery }\end{array}$ & $\begin{array}{l}\text { New } \\
\text { activity } \\
\text { since } \\
\text { breast } \\
\text { surgery }\end{array}$ \\
\hline \multicolumn{6}{|c|}{$\begin{array}{l}\text { Puzzles (e. g., jigsaw, } \\
\text { wood, crossword) }\end{array}$} \\
\hline \multicolumn{6}{|l|}{ Drawing/painting } \\
\hline \multicolumn{6}{|l|}{ Interior decorating } \\
\hline \multicolumn{6}{|l|}{$\begin{array}{l}\text { Playing a musical } \\
\text { instrument }\end{array}$} \\
\hline \multicolumn{6}{|l|}{$\begin{array}{l}\text { Reading } \\
\text { magazines/books }\end{array}$} \\
\hline \multicolumn{6}{|c|}{ Reading newspaper } \\
\hline \multicolumn{6}{|c|}{$\begin{array}{l}\text { Reading the } \\
\text { bible/religious or } \\
\text { spiritual activities }\end{array}$} \\
\hline \multicolumn{6}{|c|}{ Creative writing/journal } \\
\hline \multicolumn{6}{|l|}{ Letter writing } \\
\hline \multicolumn{6}{|l|}{ Bird watching } \\
\hline \multicolumn{6}{|c|}{ Going to the museum } \\
\hline \multicolumn{6}{|l|}{ Attending concerts } \\
\hline \multicolumn{6}{|c|}{ Going to the theater } \\
\hline \multicolumn{6}{|l|}{$\begin{array}{l}\text { Watching movies } \\
\text { (theater or home) }\end{array}$} \\
\hline \multicolumn{6}{|c|}{ Watching television } \\
\hline \multicolumn{6}{|c|}{ Listening to music } \\
\hline \multicolumn{6}{|l|}{ Sitting/thinking } \\
\hline \multirow{2}{*}{\multicolumn{6}{|c|}{$\begin{array}{l}\text { Swimming } \\
\text { Woodworking }\end{array}$}} \\
\hline \multirow{2}{*}{\multicolumn{6}{|c|}{$\begin{array}{l}\text { Woodworking } \\
\text { Bowling }\end{array}$}} \\
\hline \multirow{2}{*}{\multicolumn{2}{|c|}{$\begin{array}{l}\text { Bowling } \\
\text { Golfing }\end{array}$}} & & & & \\
\hline & & & & & \\
\hline \multicolumn{6}{|l|}{ Walking } \\
\hline \multicolumn{6}{|l|}{ Running } \\
\hline \multicolumn{6}{|l|}{ Exercising } \\
\hline \multicolumn{6}{|l|}{$\begin{array}{l}\text { Playing tennis or } \\
\text { similar sports }\end{array}$} \\
\hline \multicolumn{6}{|l|}{ Hiking } \\
\hline \multicolumn{6}{|l|}{ Biking } \\
\hline Horseback riding & & & & & \\
\hline
\end{tabular}


ID\#:

\begin{tabular}{|l|l|l|l|l|l|}
\hline Activity & $\begin{array}{l}\text { Never } \\
\text { done } \\
\text { prior to } \\
\text { breast } \\
\text { surgery }\end{array}$ & $\begin{array}{l}\text { Do now } \\
\text { (as often as } \\
\text { before } \\
\text { breast } \\
\text { surgery) }\end{array}$ & $\begin{array}{l}\text { Do less or } \\
\text { differently } \\
\text { than } \\
\text { before } \\
\text { breast } \\
\text { surgery }\end{array}$ & $\begin{array}{l}\text { Not } \\
\text { done } \\
\text { since } \\
\text { breast } \\
\text { surgery }\end{array}$ & $\begin{array}{l}\text { New } \\
\text { activity } \\
\text { since } \\
\text { breast } \\
\text { surgery }\end{array}$ \\
\hline $\begin{array}{l}\text { Yard games (e. g., } \\
\text { Frisbee, croquet, } \\
\text { horseshoes) }\end{array}$ & & & & & \\
\hline Camping & & & & \\
\hline $\begin{array}{l}\text { Canoeing/Boating/ } \\
\text { Sailing }\end{array}$ & & & & \\
\hline Hunting & & & & \\
\hline Fishing & & & & \\
\hline $\begin{array}{l}\text { Gardening/growing } \\
\text { flowers }\end{array}$ & & & & \\
\hline $\begin{array}{l}\text { Studying for personal } \\
\text { advancement }\end{array}$ & & & & \\
\hline Traveling & & & & \\
\hline Parties/picnics & & & & \\
\hline Family gathering & & & & \\
\hline $\begin{array}{l}\text { Talking on the } \\
\text { telephone }\end{array}$ & & & & \\
\hline $\begin{array}{l}\text { Visiting family/friends } \\
\text { who are ill }\end{array}$ & & & & & \\
\hline $\begin{array}{l}\text { Visiting with } \\
\text { family/friends }\end{array}$ & & & & & \\
\hline Eating at a restaurant & & & & \\
\hline Dancing & & & & \\
\hline $\begin{array}{l}\text { Going to place of } \\
\text { worship }\end{array}$ & & & & \\
\hline Volunteer work & & & & \\
\hline $\begin{array}{l}\text { Going to children's or } \\
\text { grandchildren's } \\
\text { activities }\end{array}$ & & & & \\
\hline $\begin{array}{l}\text { Storytelling with } \\
\text { children }\end{array}$ & & & & \\
\hline Marriage/relationship & & & & \\
\hline $\begin{array}{l}\text { Entertaining at home or } \\
\text { club }\end{array}$ & & & & \\
\hline & & & & \\
\hline
\end{tabular}




\section{ID\#:}

Identify the five most important activities for you

1.

2.

3.

4.

5. 
Appendix B

Participant Profile

ID\#:

Birth date:

Race:

Marital status:

Number of individuals in the household:

Co-morbidities:

Past surgeries:

Medications:

Dominant hand:

Breast cancer type, stage, and tumor size:

Surgery (type and number of lymph nodes removed):

Complications (infections, increased wound healing, number of aspirations, hospitalizations):

Hormonal therapy:

Chemotherapy:

Radiation therapy: 
ID\#:

Are you a caregiver? If yes, to whom?

Educational level: 12 years or GED associate degree some college bachelor's degree master's degree professional degree (law, medical school) $\mathrm{PhD}$

Employment status before breast cancer diagnosis: employed on medical leave unemployed disabled retired

Occupation:

Average hours per week:

Current employment status: employed on medical leave unemployed disabled retired

Occupation:

Average hours per week: 
Appendix C

Study Flyer

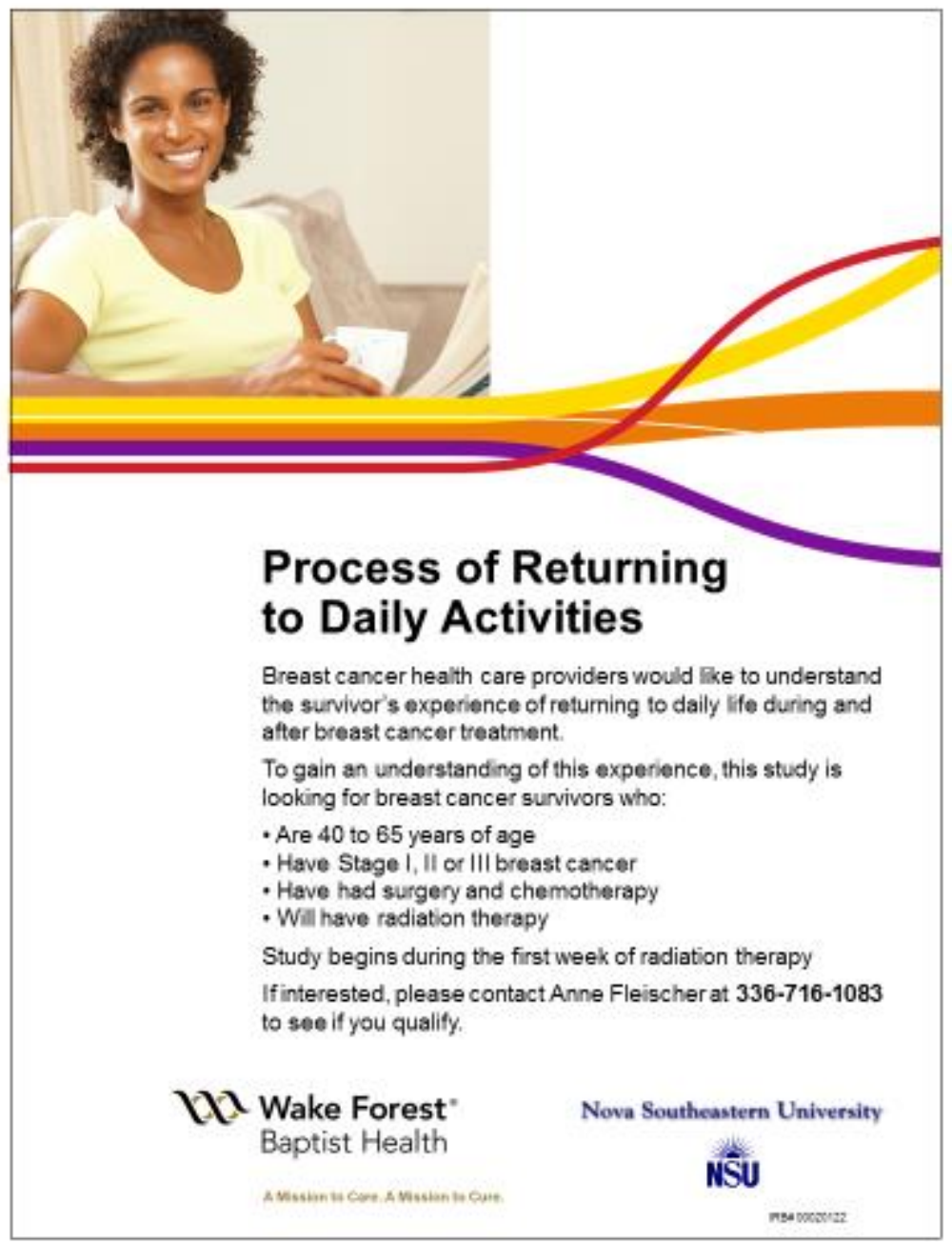




\section{Appendix D}

\section{Nova Southeastern University IRB Approval Letter}

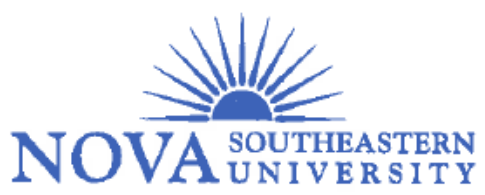

\section{MEMORANDUM}

To: $\quad$ Anne Fleischer, MPH, OT/L

HPD - College of Health Care Sciences

From: $\quad$ David Thomas, MD, JD CEFordoT

Vice-Chair, Institutional Review Board

Date: $\quad$ July 13,2012

Re: $\quad$ Exploring Breast Cancer Survivors' Experiences Participating in Activities During and After Treatment - Research Protocol No. 06111207Exp.

I have reviewed the revisions to the above-referenced research protocol by an expedited procedure. On behalf of the Institutional Review Board of Nova Southeastern University, Exploring Breast Cancer Survivors' Experiences Participating in Activities During and After Treatment is approved in keeping with expedited review categories \#6 and \#7. Your study is approved on July 13, 2012 and is approved until July 12, 2013. You are required to submit for continuing review by June 12, 2013. As principal investigator, you must adhere to the following requirements:

1) CONSENT: You must use the stamped (dated consent forms) attached when consenting subjects. The consent forms must indicate the approval and its date. The forms must be administered in such a manner that they are clearly understood by the subjects. The subjects must be given a copy of the signed consent document, and a copy must be placed with the subjects' confidential chart/file.

2) ADVERSE EVENTS/UNANTICIPATED PROBLEMS: The principal investigator is required to notify the IRB chair of any adverse reactions that may develop as a result of this study. Approval may be withdrawn if the problem is serious.

3) AMENDMENTS: Any changes in the study (e.g., procedures, consent forms, investigators, etc.) must be approved by the $\mathbb{R B}$ prior to implementation.

4) CONTINUING REVIEWS: A continuing review (progress report) must be submitted by the continuing review date noted above. Please see the IRB web site for continuing review information.

5) FINAL REPORT: You are required to notify the IRB Office within 30 days of the conclusion of the research that the study has ended via the IRB Closing Report form.

The NSU IRB is in compliance with the requirements for the protection of human subjects prescribed in Part 46 of Title 45 of the Code of Federal Regulations (45 CFR 46) revised June 18, 1991.

Cc: Dr. M. Samuel Cheng

Dr. Max Ito
Dr. Patrick Hardigan

Ms. Jennifer Dillon 
Appendix: E

Nova Southeastern University and Wake Forest Baptist Health Informed Consent Form

\section{N Wake Forest" School of Medicine}

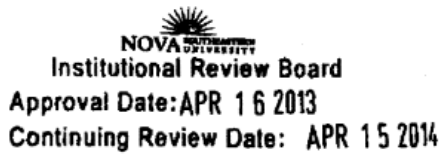

Continuing Review Date: APR 152014

\author{
EXPLORING BREAST CANCER SURVIVORS' EXPERIENCES PARTICIPATING \\ IN ACTIVITIES DURING AND AFTER TREATMENT \\ Informed Consent Form to Participate in Research \\ Anne Fleischer, MPH, OT/L, Principal Investigator \\ Max Ito, Ph.D, OTR/L, Co-investigator \\ Adrienne Lauer, Ed.D, OTR/L, Co-investigator \\ Robin Cooper, Ph.D., Co-investigator
}

\title{
INTRODUCTION
}

You are invited to be in a research study. Research studies are designed to gain scientific knowledge that may help other people in the future. You are being asked to take part in this study because you have stage I, II, or III breast cancer, will have or have had mastectomy or breast conserving surgery, chemotherapy, and are planning to have radiation therapy for the treatment of your breast cancer. Your participation is voluntary. Please take your time in making your decision to participate or not participate. Ask the investigator to explain any words or information contained in this informed consent document that you do not understand. You may also discuss the study with your friends and family.

\section{WHY IS THIS STUDY BEING DONE?}

This research project is part of the Ph.D. degree education for the researcher, Anne Fleischer, $\mathrm{MPH}, \mathrm{OT} / \mathrm{L}$. The results of this study will provide a better understanding of the experience of participating in activities during and after breast cancer treatment.

\section{HOW MANY PEOPLE WILL TAKE PART IN THE STUDY?}

Ten people at Wake Forest Baptist Health will participate in this study.

\section{WHAT IS INVOLVED IN THE STUDY?}

If you choose to participate in this study, the following will occur:

Your first visit will be scheduled to occur during the first week of your radiation treatment. At your first visit, you will participate in a face-to-face confidential interview with the researcher, during which you will be asked questions about the following: (a) previous and current medical history, (b) hand dominance, (c) household, (d) level of education, and (e) work history. During this initial visit, you will also complete a brief, 20-minute survey that is designed to assess your activity participation during your breast cancer treatment.

Intials: Date: Page 1 of 6

Version: 1

IRB Template Version 6-30-12 2012

\section{Adult Consent Form}




\section{Novic \\ Institutional Review Board \\ Approval Date: APR 162013 \\ Continuing Review Date: APR 152014}

Your second visit will occur during your final week of radiation therapy. At this time, you will complete the same 20-minute activity survey during your first visit, and participate in a 60-90 minute face-to-face interview with the researcher. This interview is designed to gain an understanding of your experiences while participating in important daily activities during and after your treatment for breast cancer. The interview will begin with the following question: "Tell me about your experience participating in [your most important activity]."

Your third visit will occur approximately three months after you complete your radiation therapy. During this visit, you will be asked to once again complete the 20-minute activity survey that you also completed during visits one and two.

Your fourth and final visit will occur approximately six months after you complete your radiation therapy. At this visit, you will complete the 20 -minute activity survey and will also participate in another 60-90 minute face-to-face interview with the researcher.

\section{AUDIO TAPING DURING THIS STUDY}

As part of this research study, your interview will be audiotaped with a digital recorder. The digital recording will be used to record your interview so your words can be used as part of the data for this study. If you do not feel comfortable being audiotaped, you may not want to participate in this study because it is necessary for this study. You should also understand that you will not be able to inspect, review, or approve the audiotapes before they are used in this study. You can withdraw from the study at any time.

The audio recordings will be erased from the digital recorder after each interview has been transcribed. The digital recordings will be transcribed. Both the recording and the transcription will be assigned another name than yours for confidentiality and stored on a password protected encrypted computer for 36 months after the study has been completed in a location only available to the researcher.

Please choose one of the following regarding the use and disclosure of the transcripts used in this research study:

I would like the digital recordings and transcripts to be destroyed once their use for this study has been finished.

The digital recordings and transcripts of my interviews can be kept for use in future studies if they are kept in a secure location and any future studies will be reviewed by the IRB. I understand that I will not be able to inspect, review, or approve their future use.

HOW LONG WILL I BE IN THE STUDY?

You will be in the study for approximately 8-9 months. You can stop participating in this study at any time.

WHAT ARE THE RISKS OF THE STUDY?

The procedures or activities in this study may have unknown or unforeseeable risks. We expect the

Intials: Date: Page 2 of 6

Version: 1

Adult Consent Form

IRB Template Version 6-30-12 2012 


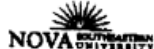 \\ Institutional Review Board \\ Approval Date: APR 162013 \\ Continuing Review Date: APR 152014}

risk of emotional discomfort that may happen due to your participation in this research study is not expected to be more than you would have experienced talking to someone about your experiences participating in activities during and after breast cancer treatment.

Taking part in this research study may involve providing information that you consider confidential or private. Efforts, such as coding research records, using another name other than yours, keeping research records secure and allowing only authorized people to have access to research records, will be provided. Although all efforts will be made to avoid that others will hear the audio recording, there will continue to be a small risk that this may occur.

\section{ARE THERE BENEFITS TO TAKING PART IN THE STUDY?}

If you agree to take part in this study, there will not be a direct benefit to you. We hope the information learned from this study will benefit other survivors in the future. We hope to learn how to provide appropriate support to survivors so breast cancer survivors can resume participation in their important activities.

\section{WHAT OTHER CHOICES ARE THERE?}

This is not a treatment study. Your alternative is not to participate in this study.

\section{WHAT ABOUT MY HEALTH INFORMATION?}

In this research study, any new information we collect from you and information we get from your medical records about your health or behaviors is considered Protected Health Information. The information we will collect for this research study includes: birth date, ethnicity, medical history, medications, hand dominance, marital status, number of individuals in the household, if and whom you provide care, educational level, previous and current employment status, type of work, and the average number of hours worked per week. Additionally, the surveys and interviews that you will complete will provide the type of activities that you have or continue to participate, and your descriptions of your experiences participating in these activities

We will make every effort to keep your Protected Health Information private. We will store records of your Protected Health Information in a password protected encrypted computer within the principal investigator's home office.Only the following people or organizations will be granted access to your Protected Health Information:

1) The principal investigator, Anne Fleischer, MPH, OT/L

2) Principal investigator's dissertation committee at Nova Southeastern University: Max Ito, Ph.D., OTR/L, Adrienne Lauer, Ed.D., OTR/L, and Robin Cooper, Ph.D.

3) Wake Forest Baptist Health and Nova Southeastern University's Institutional Review Boards and regulatory agencies.

All information obtained in this study is strictly confidential unless disclosure is required by law

Intials: Date: Page 3of 6

Adult Consent Form 


\section{Novate \\ Institutional Review Board Approval Date: APR 162013 \\ Continuing Review Date: APR 152014}

or court order. In this case, we might also have to share your Protected Health Information with a judge, law enforcement officer, government agencies, or others. If your Protected Health Information is shared with any of these groups, it might no longer be protected by federal or state privacy rules.

Any Protected Health Information collected from you in this study that is maintained in the research records will be kept for at least 36 months after the study is finished.

You can tell, Anne Fleischer, MPH, OT/L, or any of the co-investigators that you want to take awray your permission to use and share your Protected Health Information at any time by sending a ietter to any of these addresses

Anne Fleischer, MPH, OT/L

Comp Rehab

131 Miller Street

Winston-Salem, NC 27103Max Ito, Ph.D, OTR/L

Nova Southeastern University 3200 S. University Drive

Ft. Lauderdale, FL 33328

\author{
Adrienne Lauer, Ed.D, OTR/L \\ Nova Southeastern University \\ 3200 S. University Drive \\ Ft. Lauderdale, FL 33328 \\ Robin Cooper, Ph.D \\ Nova Southeastern University \\ 3301 College Avenue, \\ Ft Lauderdale, FL 33314
}

However, if you take away permission to use your Protected Health Information, you will not be able to be in the study any longer. We will stop collecting any more information about you, but any information we have already collected can still be used for the purposes of the research study. By signing this form, you give me permission to use your Protected Health Information for this study.

WHAT ARE THE COSTS?

There are no costs to you for taking part in this study.

WHERE WILL I PARTICIPATE IN THIS STUDY?

You will participate in this study at Wake Forest Baptist Health Comprehensive Cancer Center, Medical Center Blvd, Winston-Salem, NC 27157.

\section{WILL YOU BE PAID FOR PARTICIPATING?}

A \$20 Target gift card will be provided to you after each visit for a total of 4 visits. If you complete all four visits, you will receive a total of $\$ 80$ in Target gift cards. When compensation is greater than $\$ 50$, you must provide your social security number, name and address so that we can comply with Internal Revenue Service (IRS) reporting requirements. When payments are reported to the IRS, we do not let them know what the payment is for, only that you have been

Intials: Date: Page 4 of 6

Ve:sion: 1

IRB Template Version 6-30-12 2012

Adult Consent Form 


\section{NovA \\ Institutional Review Board \\ Approval Date: APR 162013 \\ Continuing Review Date: APR 152014}

paid. If you do not wish to provide this information, you can still take part in this study but you will not be paid.

\section{WHO IS SPONSORING THIS STUDY?}

Nova Southeastern University will be providing funding for the Target gift cards, transcription of the interviews and small stipend to the principal investigator to present the results of this study. This study is part of the educational experience for a doctoral level occupational therapy student at Nova Southeastern University.

\section{WHAT ARE MY RIGHTS AS A RESEARCH STUDY PARTICIPANT?}

Taking part in this study is voluntary. You may choose not to participate or you may leave the study at any time. Refusing to participate or leaving the study will not result in any penalty or loss of benefits to which you are entitled. If you decide to stop participating in the study, we encourage you to talk to the investigator. The investigator has the right to stop your participation in the study at any time, if your medical treatment changes from those outlined in the requirements for this study. You will be informed of any changes in this study.

If you choose to stop participating in this study, any information collected about you before the date you leave the study will be kept in the research records, including the digital recordings of the interview and the transcripts of these interviews for at least 36 months after the study has been completed and may be used as a part of the research.

\section{SCHEDULING APPOINTMENTS FOR THE STUDY}

May the researcher access your electronic medical record to determine when you have completed the radiation simulation visit so we can contact you to schedule a time to complete the activity participation survey?

$$
\text { Yes }
$$
No

\section{WHOM DO I CALL IF I HAVE QUESTIONS OR PROBLEMS?}

If you have any questions about the research, your research rights, or have a research-related injury, please contact, Anne Fleischer, MPH, OT/L, at (336) 716-1083, Max Ito, Ph.D, OTR/L at (954) 262-1227, Adrienne Lauer, Ed.D, OTR/L at (954) 262-1280, or Robin Cooper, Ph.D. at (954) 262-1593. You may also contact the IRB at the numbers indicated below with questions about your research rights

The Institutional Review Board (IRB) is a group of people who review the research to protect your rights. If you have a question about the research, your rights as a research participant or have a research-related injury, please contact the Wake Forest Baptist Health Chairman of the IRB at (336) 716-4542 and/or the Nova Southeastern Human Oversight Board at (954) 2625369/Toll Free: 866-499-0790

Intials: Date:

Adult Consent Form \\ _Page 5of 6}

WFU Health Sclences Institutional Review Board IRB Number: IRB00020124 Meeting Date Approved 3/28/2013
Version Valid Untll: $3 / 27 / 2014$ 
May the researcher contact you in the future regarding other research studies?

Yes No

\section{SIGNATURES}

I agree to take part in this study. I authorize the use and disclosure of my health information as described in this consent and authorization form. If I have not already received a copy of the Privacy Notice, I may request one or one will be made available to me. The study has been explained to me and I have read the consent document. I have been told that I may ask the IRB personnel questions about my study rights. I have had a chance to ask questions about being in this study and have had those questions answered. By signing this consent and authorization form, I am not releasing or agreeing to release the investigator, the sponsor, the institution, or its agents from liability for negligence.

Subject Name (Printed):

Subject Signature:

Date:

Time: $\mathrm{am} / \mathrm{pm}$

Person Obtaining Consent: Date: Time: $\mathrm{am} / \mathrm{pm}$

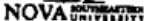

Institutional Review Board

Approval Oate: APR 162013

Continuing Review Date: APR 152014

Intials: Date: Page 6 of 6

Ve:sion: 1

IRB Template Version 6-30-12 2012

Adult Consent Form 


\title{
Appendix F
}

Wake Forest University IRB Approval E-mail

\section{IRB: Notification of IRB Approval}

\author{
eIRB - Institutional Review Board
}

To:

Anne Fleischer

You forwarded this message on 5/8/2012 1:08 PM.

$x$ Wake Forest University

\author{
IRB APPLICATION APPROVED \\ To: \\ Anne Fleischer \\ Study Title: $\quad$ Exploring Breast Cancer Survivors' Experiences \\ IRB \#: \\ IRB00020124 \\ PI: \\ Anne Fleischer
}

Link to Workspace: IRB00020124

PLEASE DO NOT RESPOND TO THIS EMAIL- Call (336) 716-4542 if you have questions.

The Insitutional Review Board has reviewed and approved the above referenced research study. Please use the "Link to Workspace" above to access the approval memo, consent forms, assent forms, and other items associated with this study.

Please do not respond to this email by using the "reply" address. This account is configured exclusively for outgoing messages from eIRB.

If you have received this notification while outside of the WFUBMC or WFU network, the link(s) in the above notification will not access their intended target. eIRB is an internal application and can be accessed only while on the Wake forest network.

WFUBMC users may access eIRB remotely via WFUBMC Citrix Portal. If you have Citrix portal access, click here, If you need access, contact the WFUHS HELP Desk at 716-HELP (716-4357)

WFU-Reynolda may access eIRB remotely via a Citrix VPN connection. If you need help with VPN connection, contact the WFU IS Service Desk at 758-HELP (758-4357). 